Representativeness of Wind Measurements in a Complex Terrain Region in Southern Virginia

\author{
Stephanie Phelps \\ Marietta, Georgia
}

BS Physical Geography, University of Georgia

A Thesis presented to the Graduate Faculty of the University of Virginia in Candidacy for the Degree of Master of Science

Department of Environmental Science

University of Virginia

December, 2014 


\section{Representativeness of Wind Measurements in a Complex Terrain Region in Southern Virginia}

Representative meteorological measurements are important in many applications, including air quality and dispersion modeling. The site selection for representative wind measurements in complex terrain is not always straightforward, and requires detailed investigations of the flows in the region around potential measurement sites. Topography has the potential to alter wind measurements over small spatial scales $(<1.5 \mathrm{~km})$, especially during stable conditions when topographically induced flows are pronounced. A proposed mining and milling operation in Southern Virginia has motivated a study to investigate the representativeness of wind measurements at a single baseline site in this region that is characteristic of elevations differences of a few tens of meters over a horizontal scale of a few kilometers. The objective of this study is to determine the representativeness of wind measurements at this site. To address the objective, four $10-\mathrm{m}$ meteorological towers were set up surrounding a $10-\mathrm{m}$ meteorological tower at the baseline site. A variety of methods were used to determine the representativeness of the wind measurements from the baseline tower, including statistical and wind rose analyses, intensive field campaigns, and mesoscale model simulations using the Weather Research and Forecasting (WRF) model. The statistical and wind rose analyses showed that the representativeness of the baseline tower is significantly reduced during stable and synoptically quiescent conditions in the presence of topographically induced flows. Results from the field campaigns and WRF model simulations during these conditions show that topographically induced flows in the region can occur from different directions in the lowest few tens of meters above the ground. Based on our investigations, we recommend that for maximizing the representativeness of wind measurements at the baseline site, the measurements should be made at heights at or above $30 \mathrm{~m}$. This study contributes to the development of better guidelines for collecting representative wind measurements at the study site in Chatham, Virginia and in other areas of moderately complex terrain. 
Chapter 1: Introduction......................................................

Chapter 2: Data and Methods....................................................

2.1 Site Details........................................................ 8

2.2 Meteorological measurements at baseline tower.........................11

2.3 Meteorological measurements at four towers surrounding the................11

central baseline tower

2.4 Additional meteorological data .....................................17

2.5 Statistical methods.................................................. 18

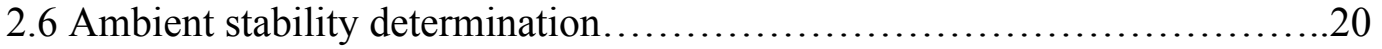

2.7 Intensive Field Campaigns............................................26

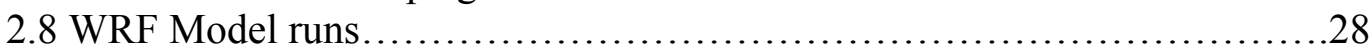

Chapter 3: Results.......................................................... 30

3.1 Statistical comparisons between each site and the baseline site..............30

3.1.1 Description of wind climatology at baseline tower................30

3.1.2 Comparison between baseline tower and four additional towers...32

3.1 .3 Winds..................................................

3.1.4 Wind differences as a function of synoptic winds and stability....34

3.1.5 Summary of method and assessment of baseline representativeness........................................48

3.2 Field campaigns and WRF model runs................................. 51

3.2.1 Field Campaign \#1: August 14-15, 2013 ......................54

3.2.1.1 Synoptic and surface weather patterns........................54

3.2.1.2 Field measurements during field campaign \#1...........57

3.2.1.3 WRF model simulation of field campaign $\# 1 \ldots \ldots \ldots \ldots . .62$

3.2.2 Field Campaign \#2: April 9-10, 2014........................66

3.2.2.1 Synoptic and surface weather patterns..................65

3.2.2.2 Field measurements during field campaign $\# 2 \ldots \ldots \ldots \ldots . .68$

3.2.2.3 WRF model simulation of field campaign $\# 2 \ldots \ldots \ldots \ldots .72$

3.2.3 Field Campaign \#3: May 19-20, 2014............................76

3.2.3.1 Synoptic and surface weather patterns..................76

3.2.3.2 Field measurements during field campaign \#3............88

3.2.3.3 WRF model simulation of field campaign \#3 ...........82

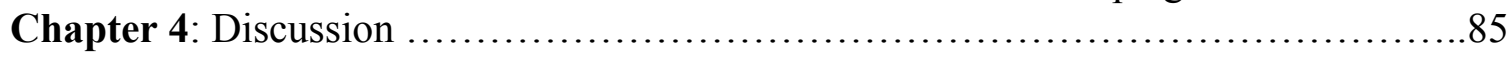

Chapter 5: Conclusion..................................................87

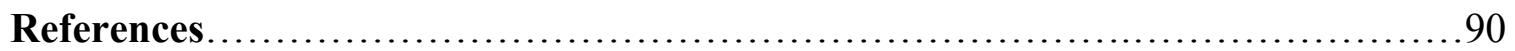

Appendix A: Data Details.............................................92

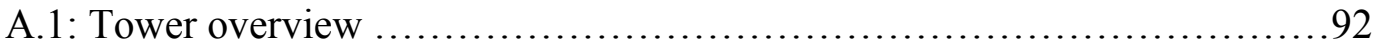

A.2: Data management and quality control............................... 100

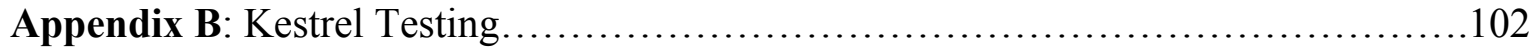

Appendix C: WRF Validation.............................................. 107 


\section{List of Figures}

1. Map of Virginia and relative location of the study site in Chatham, Virginia......8

2. Topographic map of Coles Hill Farm, Chatham, Virginia..................... 10

3. Wind roses for the baseline, and the Danville and Lynchburg Regional Airports (July 2012-Dec 2013) .................................................... 10

4. Close up topography maps of each site................................... 14

5. Diurnal distribution of stability classes at baseline site ......................23

6. Comparison between gradient Richardson number and Pasquill Stability

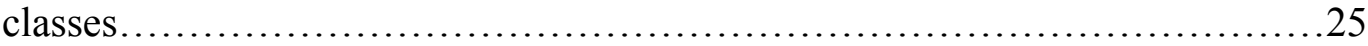

7. Schematic of Kestrel attachment apparatus..............................27

8. Geographical location of three nested WRF model domains....................29

9. Wind rose for all data between July 2012 and December 2013 for baseline site...31

10. Wind roses for each site overlaid on topographic map for all data between July 2012 and

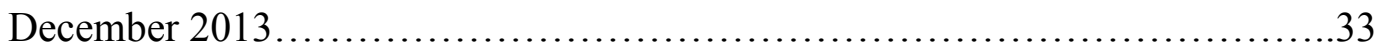

11. Wind roses corresponding to conditions when synoptic flow is $0-270^{\circ}$ and $0-10$ $\mathrm{m} / \mathrm{s}$

12. Wind roses corresponding to conditions when synoptic flow is $0-270^{\circ}$ and $10+$ $\mathrm{m} / \mathrm{s}$

13. Wind roses corresponding to conditions when synoptic flow is $270-360^{\circ}$ and $0-10$ $\mathrm{m} / \mathrm{s}$

14. Wind roses corresponding to conditions when synoptic flow is $270-360^{\circ}$ and $10+$ $\mathrm{m} / \mathrm{s}$ .42

15. Wind roses corresponding to varying wind speed thresholds

16. Climatology of winds during the night for clear nights between September 2012 and August 2013 for the central and south sites. .54

17. Synoptic weather map that is valid at 07:00 LST on August 15, 2014. .55

18. Tower measurements for the day before, the night of, and the day after the field campaign

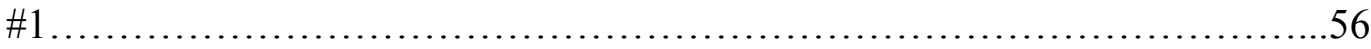

19. Potential temperature profiles from field campaign $\# 1 \ldots \ldots \ldots \ldots \ldots \ldots \ldots \ldots . \ldots . \ldots . \ldots$ 


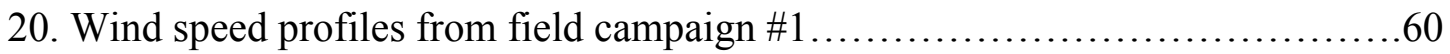

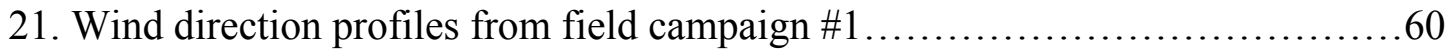

22. Wind speed and direction profile for the $11^{\text {th }}$ profile of field campaign $\# 1 \ldots \ldots . .61$

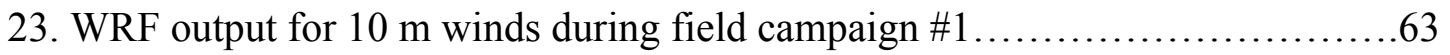

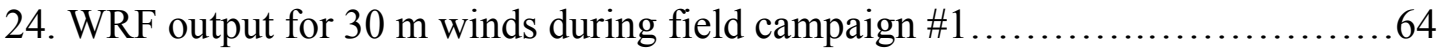

25. A synoptic weather map that is valid at 07:00 LST on April 10, 2014_..........66

26. Tower measurements for the day before, the night of, and the day after the field campaign

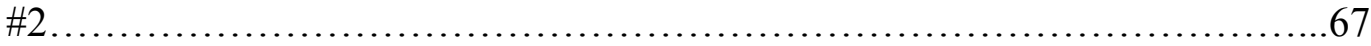

27. Potential temperature profiles from field campaign $\# 2 \ldots \ldots \ldots \ldots \ldots \ldots \ldots \ldots \ldots . . . . . . . . . .69$

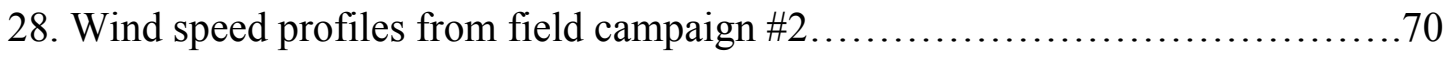

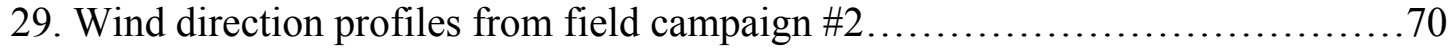

30. Wind speed and direction profile for the $10^{\text {th }}$ profile of field campaign $\# 2 \ldots \ldots . . .71$

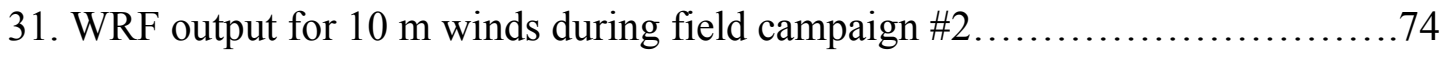

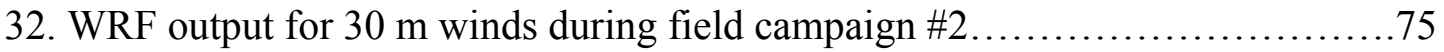

33. A synoptic weather map that is valid at 07:00 LST on May 20, 2014_............77

34. Tower measurements for the day before, the night of, and the day after the field campaign

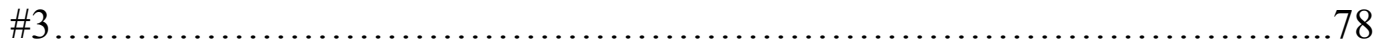

35. Potential temperature profiles from field campaign $\# 3 \ldots \ldots \ldots \ldots \ldots \ldots \ldots \ldots \ldots . \ldots . \ldots \ldots$

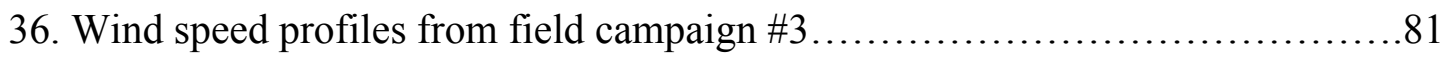

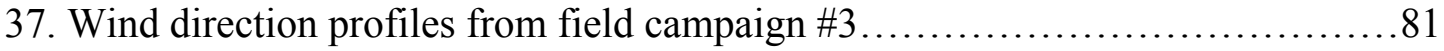

38. WRF output for $10 \mathrm{~m}$ winds during field campaign $\# 3 \ldots \ldots \ldots \ldots \ldots \ldots \ldots \ldots \ldots \ldots \ldots$

39. WRF output for $30 \mathrm{~m}$ winds during field campaign $\# 3 \ldots \ldots \ldots \ldots \ldots \ldots \ldots \ldots \ldots . . . . . . \ldots 4$

A.1: Photos of baseline site........................................................ 95

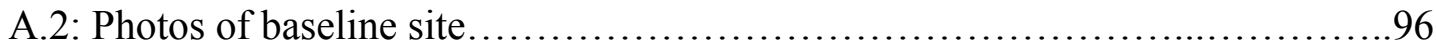

A.3: Photos of baseline site ..................................................... 97

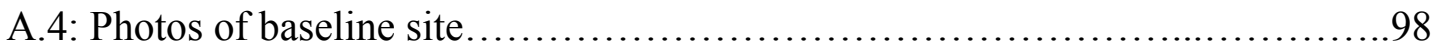

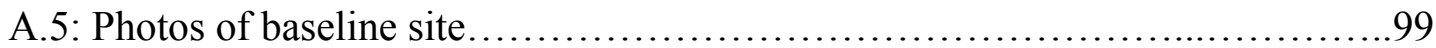

A.6: Data QAQC flow chart................................................... 101

B.1: Locations of Kestrel testing................................................ 104

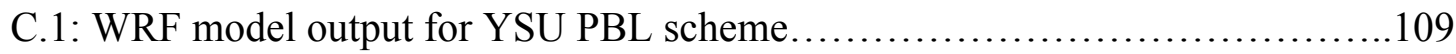

C.2: WRF model output for MYNN PBL scheme...............................110 
C.3: WRF model output for MYJ TKE PBL scheme.

C.4: Tower vs. WRF $10 \mathrm{~m}$ winds for field campaign \#1

C.5: Tower vs. WRF $10 \mathrm{~m}$ winds for MYNN PBL scheme.

C.6: Tower vs. WRF $10 \mathrm{~m}$ winds for MYJ TKE PBL scheme....

\section{List of Tables}

1. Sensors and accuracies of instruments on baseline tower that are used in study..11

2. Details about the location of the five towers.............................. 12

3. Maximum, minimum, and average elevation of $0.5 \mathrm{~km}$ radius around each site.. 12

4. Completeness of data from each site.................................... 16

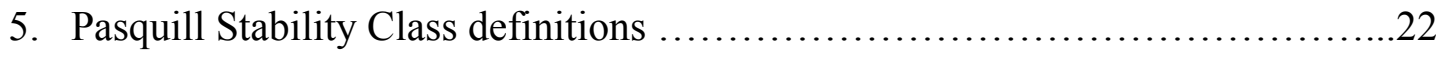

6. Synoptic wind categories used to subset tower wind data...................... 35

7. Results of the statistical comparisons...................................... 36

8. Example differences in wind speed for a statistically significant comparison.....44

9. Times of tethered balloon soundings for field campaign $\# 1 \ldots \ldots \ldots \ldots \ldots \ldots . \ldots 59$

10. Times of tethered balloon soundings for field campaign $\# 2 \ldots \ldots \ldots \ldots \ldots \ldots \ldots . \ldots 6$

11. Times of tethered balloon soundings for field campaign $\# 3 \ldots \ldots \ldots \ldots \ldots \ldots \ldots . \ldots . \ldots . \ldots$

A.1: The instrument name, manufacturer, model, and accuracy of all instruments that are installed on the baseline tower............................................93

A.2: Instruments that are installed at each of the additional towers................94

A.3: Thresholds data are passed through for quality control......................101

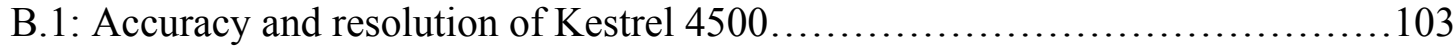

B.2: MAE results for Kestrel vs. Kestrel tests................................. 104

B.3: MAE results for Kestrel vs. RM Young tests............................. 105

B.4: MAE results for Kestrel vs. Tower tests................................ 106 


\section{Acknowledgements}

First I would like to thank my adviser, Dr. Stephan De Wekker for allowing me the opportunity to earn my masters degree at the University of Virginia. His guidance, support, and encouragement led to the development of a unique and extensive skillset that I will appreciate for the rest of my life. I also want to thank my committee, Dr. Robert Davis and Dr. Paolo D'Odorico, for their insight and dedication. I would like to thank my lab group from past and present: Temple Lee, Zeljko Vecenaj, Mark Sghiatti, Sandip Pal, Nevio Babic, Sandip Pal, Mohamadou Diallo, Michael Van Den Bossche, and Yuefei He. In particular, I would like to especially thank those who helped me in the field. The help was instrumental to my research and my project would have been impossible without it.

A large thanks goes to Virginia Uranium Incorporated (VUI) who funded this research. I am grateful for the opportunity to conduct this meaningful and applicable research project. I would like to especially thank Stewart East from VUI for his countless hours of field work and data downloading. His help was vital to the success of this project.

This thesis would not have been possible without the help of a number of people from the University of Virginia Department of Environmental Science. Many thanks to the fellow graduate students who helped me along the way with field work and data analysis tasks, especially including Kyle Davis who helped me figure out innumerable tasks from GIS to statistics, and Jessica Gephart, who also helped me navigate the complicated world of statistics. Thank you to Will Tomanek for the large amount of computer support and thank you to the Environmental Science office administrative staff for all of the logistical help this project required.

Finally, thank you to my loving family and boyfriend. Their unending love, encouragement, and patience were vital to the successful completion of my degree. 
Chapter 1: Introduction

Representativeness has been defined as "the extent to which a set of measurements taken in a space-time domain reflects the actual conditions in the same or different space-time domain taken on a scale appropriate for a specific application" (Nappo et al. 1981). Representative meteorological data are required by a variety of model types including air quality and dispersion models and numerical weather prediction models for data assimilation purposes. Air quality and dispersion models are operated on a variety of scales for every day and accidental circumstances. The dispersion within the planetary boundary layer has to be simulated +1 in these models and, therefore, much focus is given to how underlying topography will manipulate dispersion. When these models are run in regions of complex terrain, the representativeness of the meteorological input data must be closely investigated to ensure proper dispersion prediction. Issues can arise when wind measurements are influenced by underlying topography and are unrepresentative of the surrounding area. If such wind measurements are used as model input, dispersion models may incorrectly predict the transport and diffusion of pollutants. For this reason, per the passage of the Clean Air Act in 1977, regulatory agencies require the collection of representative baseline meteorological measurements at any operation that has the potential to introduce new pollution to the atmosphere. The site selection for the collection of representative meteorological measurements, especially in complex terrain, is not always straightforward. The identification of a representative location for meteorological measurements in complex terrain requires further investigation because such terrain can alter meteorological variables over small spatial scales. In particular, wind measurements are highly influenced by underlying topography, which could cause large differences in wind characteristics over small spatial scales. The goal of this study is 
to investigate the representativeness of wind measurements made at a baseline $10 \mathrm{~m}$ meteorological tower located in a region of semi-complex terrain.

The Environmental Protection Agency's (EPA) Meteorological Monitoring Guidance for Regulatory Modeling Application (EPA 2000) addresses the topic of site selection for the collection of data at a single location for air quality and dispersion modeling applications. The report indicates that "meteorological data should be representative of conditions affecting the transport and dispersion of pollutants in the area of interest" (EPA 2000). In order to identify a representative site within an area of interest, special consideration is required about the complexity of the topography surrounding the source and the meteorological monitoring site, the proximity of the meteorological monitoring site to the source, and the instrumentation and exposure of the meteorological monitoring site (EPA 2000). If the terrain of an area of interest is characterized as complex, the EPA provides specific instructions for instrument siting, while noting, "each complex terrain situation has unique features to consider [and] no specific recommendations can be given to cover all cases" (EPA 2000). Effectively, the EPA recommends that for regions of complex topography, in addition to the recommendations for flat terrain, a detailed investigation of a topographic map should occur and the application of each meteorological variable should be carefully considered. In complex terrain regions, topographic influence on meteorological variables is not always predictable based on an analysis of the topography only and actual data collection throughout the region and modeling is necessary. Therefore, the recommendations made by the EPA may fall short for many complex terrain regions.

Topographically induced flows, such as aerodynamic wakes, channeling flows, and thermally driven slope and valley flows can cause unrepresentative wind measurements (e.g. 
Whiteman 2000). Upper-level flow and ambient stability are two major factors affecting the nature and intensity of topographically induced flows (Whiteman 2000). In complex terrain, the daytime convective boundary layer is characteristic of upslope, or up valley, flows caused by the heating of a slope or valley sides, which causes a favorable pressure gradient for a flow to develop. These flows can persist for an entire day, but are weakened by strong synoptic forcing. For example, Banta and Cotton (1981) identified that when a deep convective boundary layer existed in a broad mountain basin, the synoptic winds would mix down to the surface and directly influence the direction of flow at the surface. During times of strong synoptic forcing and instability, the vertical transport of horizontal momentum from the upper levels of the atmosphere to the surface will cause surface winds to flow in a similar direction compared to the geostrophic flow. Turbulent mixing is most characteristic of unstable or neutral ambient stability and, in combination with strong synoptic flow, is a favorable condition for forced channeling by local topography (Whiteman 1993). The direction of channeling is specific to each topographic feature and depends on the direction of the flow aloft. The aforementioned phenomena would mostly correspond with widespread representativeness of the wind.

At times when less or no turbulent mixing is observed (i.e. stable conditions) one expects reduced representativeness of wind measurements due to the increased presence of local flows such as down slope or down valley flows or flow deflections. Weak upper-level forcing and stable ambient stability conditions lead to an enhancement of thermal forcing at the surface, especially for regions that experience large diurnal cycles in sensible heat flux. During clear and synoptically quiescent nights, thermally driven downslope, or drainage, flows can occur and become pronounced over any surface that is slightly tilted (Mahrt 1990). Downslope flow is forced by the temperature difference between a slope and the air at the same height away from 
the slope. Therefore, the flow strength will decrease when the atmosphere becomes increasingly horizontally stratified and the temperature differences between the slope and the same elevation away from the slope are relatively uniform (Zardi and Whiteman, 2012). The typical height of a downslope flow wind speed maximum is $1-15 \mathrm{~m}$ above the ground, where frictional forces are significantly reduced, at a speed of 1-4 m/s. (Zardi and Whiteman, 2012). Drainage flows can occur simultaneously at different scales and at varying heights for a given location depending on the local (a few hundred meters to a few kilometers) and regional (tens of kilometers) slope characteristics (Mahrt et al. 2001). When determining a location for the collection of representative baseline meteorological measurements, one must investigate and understand the characteristics of topographically induced flows that could cause unrepresentative wind measurements at the location.

Different methods exist to evaluate the representativeness of wind measurements for a variety of spatial scales and terrain types. Some statistical approaches in these evaluations include the calculation of variances, empirical regression formulas (Lockhard and Irwin 1980, Hanna 1982, Hanna 1992), correlation coefficients (Ha, et al. 2009), kernel distributions of wind vectors, similarity curves (Deligiorgi 2013), joint frequency distributions (Ashton 2012 and Deligiorgi 2013), and wind roses (Ha, et al. 2009 and Ashton 2012). A common conclusion of these studies is that the representativeness of wind measurements is significantly reduced in areas of complex terrain (Ha, et al. 2009 and Deligiorgi 2013). To our knowledge, no studies exist that assess the representativeness of wind measurements made at a particular location in a small area $(3 \times 3 \mathrm{~km})$ of semi-complex terrain region using a network of meteorological towers. Studies such as this one are important for improving guidelines for the placement of representative meteorological towers. In the first part of this thesis, an original method for 
assessing representativeness is presented. The second part of this study investigates the physical processes that influence the degree of representativeness of the baseline site.

This work was motivated by a requirement to collect baseline meteorological measurements for regulatory purposes at a proposed uranium mining and milling site in southern Virginia. The collection of representative baseline meteorology and air quality data is a necessary component in the process to support the permitting and licensing of any proposed mine or mill that has the potential to introduce new pollutants to the atmosphere. Given the complexity of the underlying topography, topographically induced flows likely occur over the region simultaneously at varying scales. We hypothesize that the baseline site is least representative under stable and synoptically quiescent conditions and the representativeness increases with decreasing stability and increasing synoptic forcing. We do not expect a regional scale flow occurring over a few tens of kilometers to reduce the representativeness of the baseline site since it would equally affect all sites. Alternatively, local topographically induced flows at a horizontal scale of a few hundred meters to a few kilometers oriented in varying directions depending on the local topography are expected to influence the five sites to varying extents. We therefore further hypothesize that local topographically induced flows in our investigation area reduce the representativeness of the baseline site. In the first part of this thesis, a careful investigation is made to determine which combinations of synoptic flow and ambient stability conditions lead to representative or unrepresentative wind measurements at the baseline site. This investigation aims to answer the following questions:

- How can we quantify the representativeness of the baseline site?

- What combination of stability and synoptic flow conditions lead to representative and unrepresentative conditions at the baseline site? 
To answer these questions, an original and thorough method for assessing wind representativeness is presented.

The second part of this thesis seeks to explain the physical processes that affect the representativeness of the baseline site through intensive field campaigns and Weather Research and Forecasting (WRF) model runs. In this section, the following questions are addressed:

- How do the wind characteristics vary vertically during stable and synoptically quiescent conditions at the baseline site and one additional site?

- Are there different terrain induced flows that influence the baseline and south towers simultaneously during stable and synoptically quiescent conditions and how do they change vertically at the two sites?

To investigate these hypotheses and questions, a temporary baseline meteorological monitoring site was installed near the proposed location of uranium mining and milling at Coles Hill in Chatham, VA, in the spring of 2012. The location of this baseline site was determined by several factors such as the proximity of the site to the anticipated location of the mining/milling operations, the accessibility and ownership of the site, and the complexity of the surrounding topography. Given the complexity of the landscape in the surroundings of the baseline tower and the potential for local terrain effects on the wind characteristics, the representativeness of the meteorological measurements was questioned. Careful thought and consideration was given to ideas for assessing wind representativeness in complex terrain and, after much consideration, four additional meteorological towers were established in the area at an average distance of about $1.5 \mathrm{~km}$ from the baseline tower. The sites of each tower were determined based on their proximity to local terrain features, the baseline site, and the mining and milling locations. The distance of $\sim 1.5 \mathrm{~km}$ was chosen based on the estimated spatial scale of the proposed uranium 
mining and milling operations, which is on the order of $10 \mathrm{~km}^{2}$. The data collected at the four additional towers were meant for detailed comparisons between each tower and the baseline tower.

In the following chapter, the data and methods are explained for this study. Next, chapters 3 and 4 include the results and discussion of the study, respectively, followed by the conclusion.

\section{Chapter 2: Data and Methods}

This chapter provides a description of the methods and data used in this thesis. First, a brief explanation of the experimental method used in this study is necessary. For this research, a thorough investigation of the topography and wind characteristics of the study region was conducted (Section 2.1). Next, the location of the baseline tower (section 2.2) was determined and four additional towers (section 2.3) were set up surrounding the baseline tower for comparison purposes. Data from the North American Regional Reanalysis model are also used in this study to determine the synoptic flow characteristics and to initialize the Weather Research and Forecasting (WRF) model and are outlined in section 2.4. To compare the additional towers to the baseline tower, statistical methods are employed (section 2.5). The statistical comparisons are used to individually compare the additional towers to the baseline tower in terms of wind speed and wind direction. The comparisons are carried out based on different combinations of synoptic wind condition and ambient stability class (section 2.6) to determine the impact of those factors on the wind representativeness of the baseline tower.

A major component of this thesis included multiple intensive field campaigns to seek details about how the representativeness of the baseline site increases with height when compared to one additional site (section 2.7). These field campaigns are also meant to identify 
whether different flows occur simultaneously over the investigation area during clear and synoptically quiescent nights. Following these field campaigns, the Weather Research and Forecasting (WRF) model was run for each field campaign night (section 2.8) to gain a broader understanding of the flow characteristics during each night.

\subsection{Site Details}

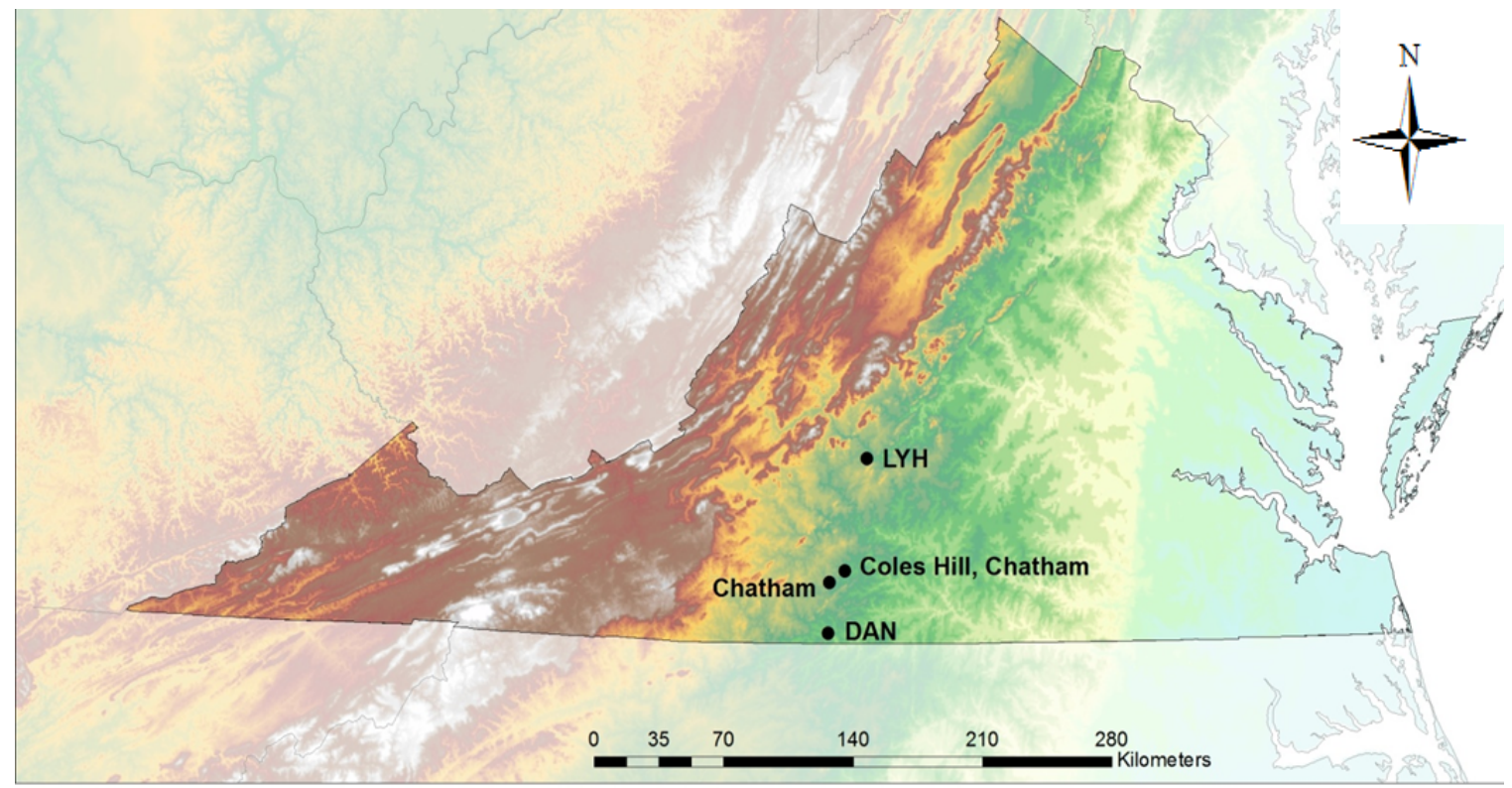

Figure. 1: Geographical representation of where the study region (Coles Hill, Chatham) is located relative to the Appalachian Mountains and the Atlantic Ocean in the state of Virginia. In this map, LYH stands for Lynchburg Regional Airport and DAN stands for Danville Regional Airport.

The data used in this thesis are collected from five $10 \mathrm{~m}$ meteorological towers near the proposed mining and milling site at Coles Hill located about $10 \mathrm{~km}$ northeast of Chatham, VA (Figure 1). The terrain is characterized by rolling hills and the site is located in the piedmont between the Appalachian Mountains and the Atlantic Ocean. The Appalachian Mountains are approximately 70 kilometers to the northwest and the Atlantic Ocean is approximately 250 
kilometers to the east (Figure 1). The average elevation of the proposed mining and milling site is approximately $180 \mathrm{~m}$ above sea level and the elevation differences within the investigation area are less than $80 \mathrm{~m}$ (Figure 2). The study region is made up of a mixture of cow pastures and forest land. There are no immediate obstructions to the meteorological towers and all towers are cited at least a distance of $20 \mathrm{~m}$ from any nearby obstruction. The prevailing wind direction in southern Virginia is southwesterly (Brode 1980). An analysis of the wind data from the Lynchburg and Danville Regional Airports between July 2007 and July 2012 confirms this finding (Figure 3). Based on the same airport wind direction analysis, northeasterly winds are also frequent at both stations. In contrast, the baseline site shows less frequent northeasterly flow and more frequent northwest flow compared to the two airports (Figure 3). 

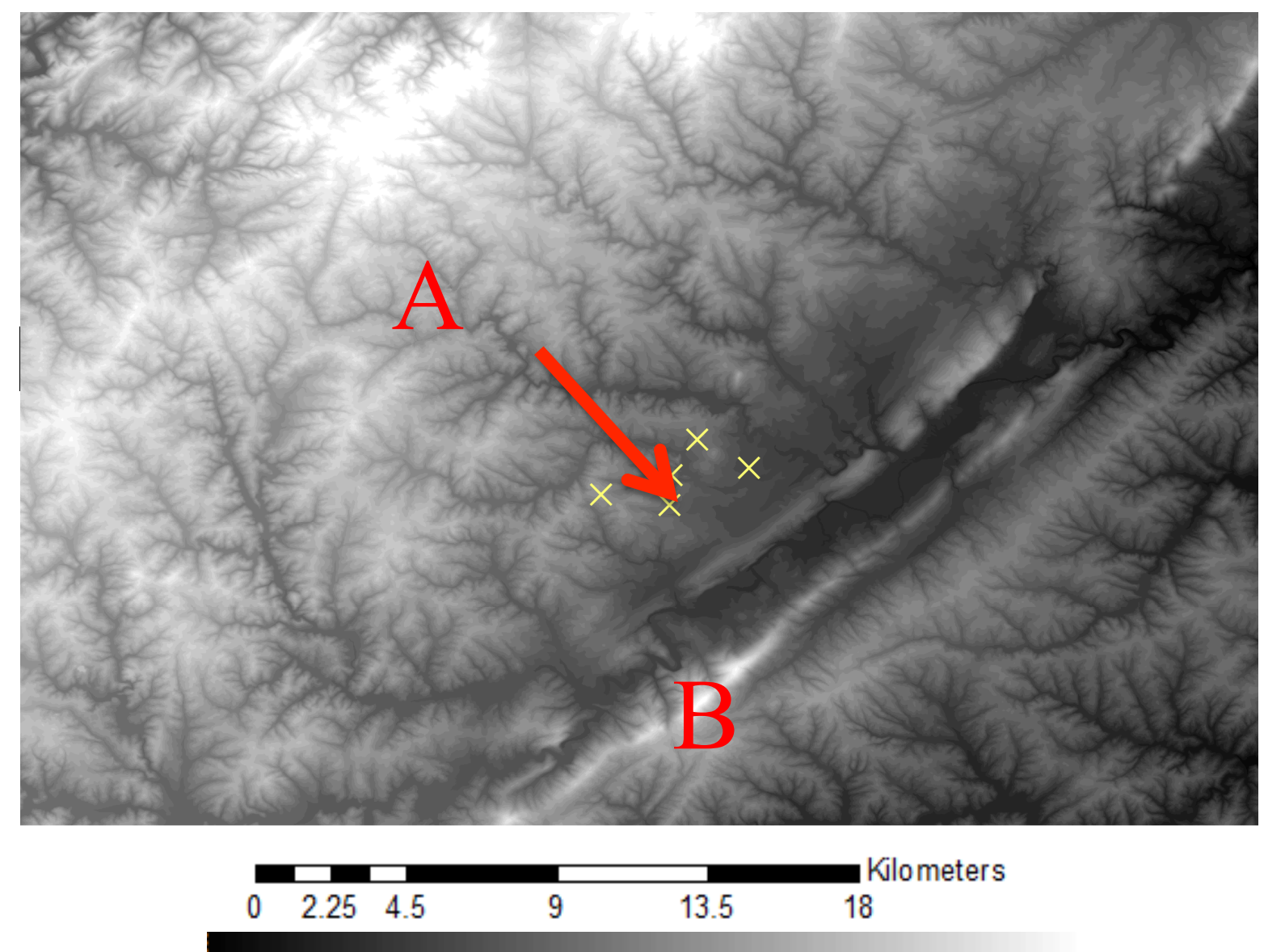

$115 \mathrm{~m}$

$300 \mathrm{~m}$

Figure 2: Topographic map of the Coles Hill Farm, Chatham, Virginia. The five towers are represented with yellow X's. The red A indicates a large slope to the west of the towers and the red B indicates White Oak Mountain. The red arrow indicates the direction of the slope.
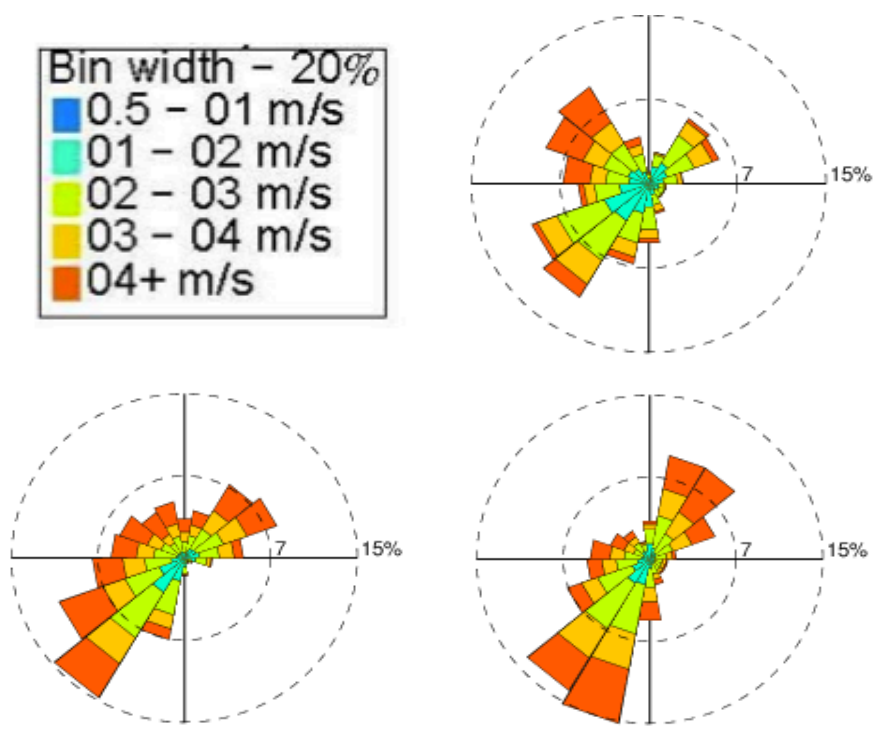

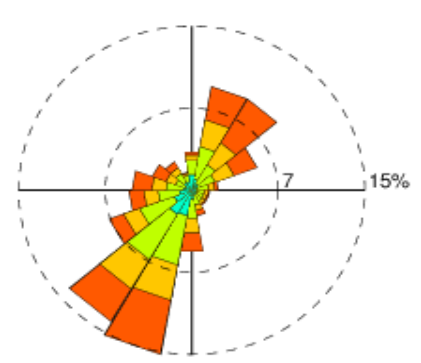

Figure 3: Wind roses for the Baseline site (top) Danville Regional Airport (left) and the Lynchburg Regional Airport (right). All valid data between July 2012 and December 2013 are used in these figures and a calm threshold of 1.34 is used. 


\subsection{Meteorological measurements at baseline tower}

The required meteorological measurements collected at the baseline site were determined according to guidelines contained in regulatory documents provided by the Nuclear Regulatory Commission (NRC) (1980, 1988) and the Environmental Protection Agency (EPA) (2000). Wind speed (horizontal and vertical) at $10 \mathrm{~m}$, wind direction at $10 \mathrm{~m}$, ambient temperature and relative humidity (aspirated) at 2 and $10 \mathrm{~m}$, vertical temperature difference between 2 and $10 \mathrm{~m}$, precipitation, barometric pressure, solar radiation measurements, and evaporation measurements are recorded at the baseline tower. All sensors located at the baseline tower either meet or exceed the EPA recommended system accuracies and resolutions, as provided in table $\mathbf{1}$ and Appendix A.

Table 1: The sensors, and their accuracies, that are installed on the baseline tower. Only the instruments utilized in this study are included in this table. Other instruments are installed on the tower but are not listed here. A complete list of the instruments and their accuracies is included in Appendix A.

\begin{tabular}{|c|c|}
\hline Instrument & Instrument Accuracy \\
\hline Anemometer/ Wind Direction Sensor & $\pm 0.07 \mathrm{~m} / \mathrm{s}$ or $\pm 1 \%$, whichever is greater $/$ \\
\pm 2 degrees
\end{tabular}

\subsection{Meteorological measurements at four towers surrounding the central baseline} tower

To investigate the representativeness of the baseline site, we installed four additional $10 \mathrm{~m}$ towers at an average distance from the baseline tower of approximately $1.5 \mathrm{~km}$ (Figure 2). Details of the location of each of the towers are provided in table $\mathbf{2}$ and details about the 
minimum, maximum, and average elevation of a $0.5 \mathrm{~km}$ circle surrounding each site are included in table 3.

Table 2: Details about the distance from the baseline tower, elevation, latitude and longitude for each site (topographic data: Dollison 2010).

\begin{tabular}{|c|c|c|c|c|}
\hline Tower & $\begin{array}{c}\text { Distance to } \\
\text { Baseline } \\
\text { Tower }(\mathbf{k m})\end{array}$ & $\begin{array}{c}\text { Tower Elevation (m } \\
\text { above MSL) }\end{array}$ & Latitude (N) & Longitude (W) \\
\hline Baseline & N/A & 195 & $36^{0} 52^{\prime} 11.7^{\prime \prime}$ & $079^{0} 18^{\prime} 45.2^{\prime \prime}$ \\
\hline North & 1.32 & 195 & $36^{0} 52^{\prime} 49.5^{\prime \prime}$ & $079^{0} 18^{\prime} 18.4^{\prime \prime}$ \\
\hline South & 0.96 & 191 & $36^{0} 51^{\prime} 41.1^{\prime \prime}$ & $079^{0} 18^{\prime} 47.3^{\prime \prime}$ \\
\hline East & 2.00 & 170 & $36^{0} 52^{\prime} 19.6^{\prime \prime}$ & $079^{0} 17^{\prime} 24.4^{\prime \prime}$ \\
\hline West & 1.78 & 215 & $36^{0} 51^{\prime} 58.1^{\prime \prime}$ & $079^{0} 19^{\prime} 54.9^{\prime \prime}$ \\
\hline
\end{tabular}

Table 3: For each site, a circle with a $0.5 \mathrm{~km}$ radius was drawn with the each tower in the center. For each circle, the minimum, maximum and average topographic height above sea level was determined (topographic data: Dollison 2010).

\begin{tabular}{|c|c|c|c|}
\hline Tower & Minimum (m) & Maximum (m) & Average (m) \\
\hline Baseline & 175 & 203 & 187 \\
\hline North & 177 & 202 & 192 \\
\hline South & 177 & 203 & 190 \\
\hline East & 163 & 177 & 169 \\
\hline West & 193 & 226 & 212 \\
\hline
\end{tabular}

The south tower is closest to the baseline site and the east tower is furthest from the baseline site at distances of $0.96 \mathrm{~km}$ and $2.0 \mathrm{~km}$, respectively. The maximum, minimum, and average topographic height was analyzed within a $0.5 \mathrm{~km}$ radius of each site. All sites, except 
the east site, have local relief on the order of 25-30 $\mathrm{m}$ and an average height between $187 \mathrm{~m}$ and $212 \mathrm{~m}$. The eastern site has a local relief of $15 \mathrm{~m}$ and an average height of $169 \mathrm{~m}$. The additional towers all have wind speed and direction measurements at $10 \mathrm{~m}$ and temperature/relative humidity measurements at 2 and $10 \mathrm{~m}$ (i.e., at the same height levels as the baseline tower). Topographic maps of the immediate surroundings of each of the towers are in

\section{figure 4.}




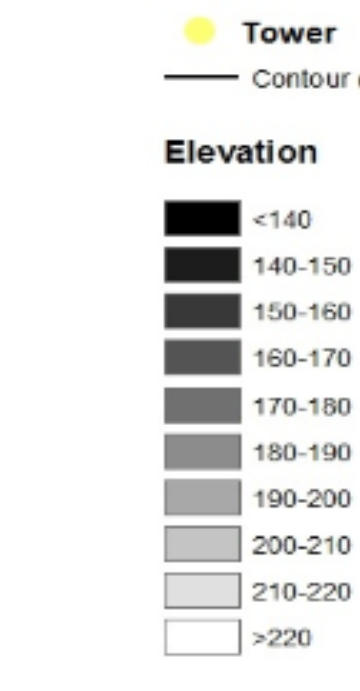

North

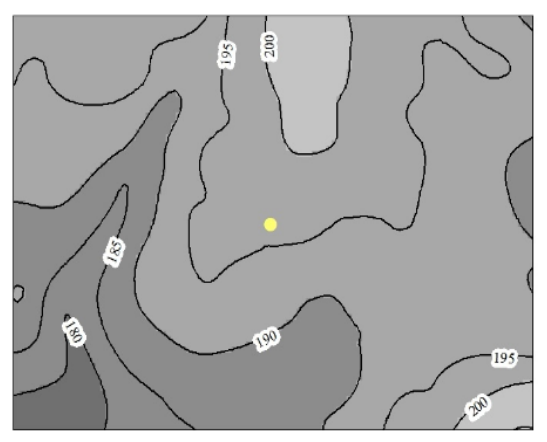

East

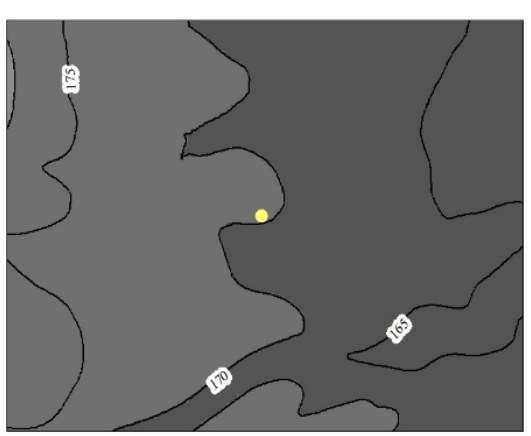

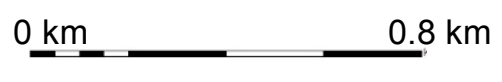

Baseline

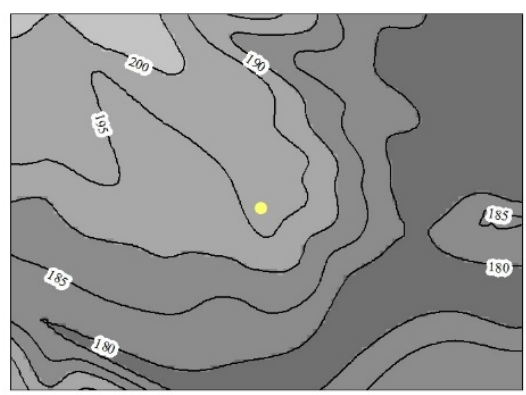

South

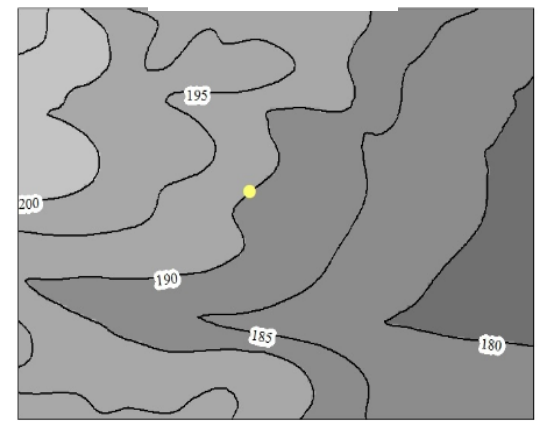

West

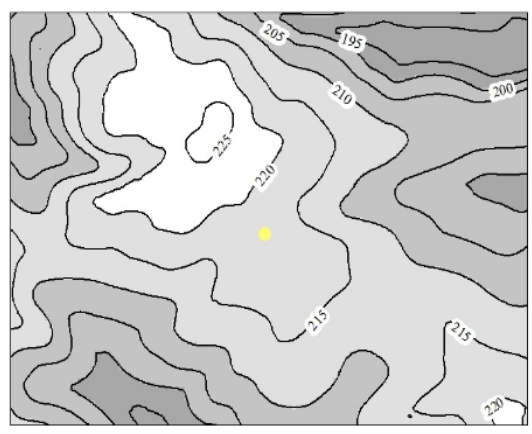

Figure 4: Each map shows, in detail, the immediate topographic surroundings around each site. The distance scale is the same for each map and the topography is represented with the gray scale shading. The dots on each map indicate the location of the tower and the maps are labeled on the top with which tower is shown. The contours on the maps are every $5 \mathrm{~m}$. 
Mark Abrams from Technical Environmental Services performed an independent audit on all instruments on the baseline tower in March 2013 and September 2013 and on all anemometers on the additional towers in September 2013. The audit report confirmed that all instruments were operating under stated accuracy and did not require replacement of parts or factory recalibration.

One-minute data are collected at all five tower sites and hourly data are created from the one-minute data during post processing steps. Each hourly time stamp indicates the data for the following hour (i.e. hour 1:00 includes data from 1:00 to 1:59). A rigorous quality control method is completed following each data download where each data point is checked for possible errors and assessed for accuracy. To accurately compare the wind characteristics between the baseline tower and the four surrounding towers, we only used those hourly data in which all five towers report a valid wind direction data point simultaneously. The completeness of wind speed and wind direction for all five towers and the total overlap between the baseline tower and each tower and the total overlap of all towers was calculated (Table 4). The overlap of valid wind speed and wind direction data points between each site and the baseline site is $94 \%$ or greater individually, and $88 \%$ of all valid data points overlap between all towers simultaneously. 


\begin{tabular}{|c|c|c|}
\hline Central & $\begin{array}{c}\text { Data } \\
\text { Completeness } \\
(\%)\end{array}$ & $\begin{array}{c}\text { Overlap with Baseline } \\
(\%)\end{array}$ \\
\hline Wind Speed & 95.6882 & \\
\hline $\begin{array}{c}\text { Wind } \\
\text { Direction }\end{array}$ & 95.6882 & \\
\hline \multicolumn{3}{|l|}{ South } \\
\hline Wind Speed & 97.32121 & 94.07127343 \\
\hline $\begin{array}{c}\text { Wind } \\
\text { Direction }\end{array}$ & 97.32121 & 94.07127343 \\
\hline \multicolumn{3}{|l|}{ East } \\
\hline Wind Speed & 98.11761 & 93.99887378 \\
\hline $\begin{array}{c}\text { Wind } \\
\text { Direction }\end{array}$ & 98.11761 & 93.99887378 \\
\hline \multicolumn{3}{|l|}{ West } \\
\hline Wind Speed & 99.09903 & 94.78722548 \\
\hline $\begin{array}{c}\text { Wind } \\
\text { Direction }\end{array}$ & 98.94618 & 94.78722548 \\
\hline \multicolumn{3}{|l|}{ North } \\
\hline Wind Speed & 96.34784 & 92.06017215 \\
\hline $\begin{array}{c}\text { Wind } \\
\text { Direction }\end{array}$ & 96.34784 & 92.06017215 \\
\hline \multicolumn{3}{|l|}{ ALL } \\
\hline Wind Speed & 88.09428 & \\
\hline $\begin{array}{c}\text { Wind } \\
\text { Direction }\end{array}$ & 88.09428 & \\
\hline
\end{tabular}

Table 4: The completeness of wind speed and wind direction data for each site and the percent overlap of valid data points between each site and the baseline site. Gaps in the data exist because of a variety of reasons, such as battery failure and instrument malfunction. These issues lead non- $100 \%$ completeness. 


\subsection{Additional meteorological data}

To put the local climatology of the investigation area in context with the regional climate surrounding the area, data are used from the nearest National Climatic Data Center (NCDC) sites: the Lynchburg and Danville Regional Airports. These sites are the nearest NCDC land based data collection sites to Chatham, VA (figure 1). The historical meteorological data recorded at these sites is at the NCDC Climate Data Online website (www7.ncdc.noaa.gov/CDO/cdo). Wind, temperature, precipitation, relative humidity, and sky condition data are collected at each of these sites. It is important to note that the calm threshold for the wind data is $1.34 \mathrm{~m} / \mathrm{s}$ (NOAA Satellite and Information Service 2014). This calm threshold is significantly higher than the calm threshold used at the five towers, which is $0.5 \mathrm{~m} / \mathrm{s}$. The Danville Regional airport is located approximately 35 kilometers south southwest of the baseline tower and the Lynchburg Regional airport is located approximately 50 kilometers north northeast of the baseline tower.

Some analyses in this thesis employ upper level, or synoptic, wind speed and direction data. These data are obtained from the North American Regional Reanalysis (NARR) model. The NARR model is run 8 times daily and has a spatial resolution of $32 \mathrm{~km}$ for 29 pressure levels. For the purpose of this investigation, the $700 \mathrm{mb}$ level is considered representative of the synoptic conditions. A sensitivity test was conducted for differences between the NARR grid point located directly over the baseline site and the 8 surrounding grid points, and between the $700 \mathrm{mb}$ and $850 \mathrm{mb}$ heights. Significant differences were not present between the grid points and heights and, therefore, the single grid box located above the study area and the $700 \mathrm{mb}$ height is used for this analysis. $U$ and $V$ wind component data are obtained from the NARR 
model output to calculate synoptic wind speed and direction. NARR data are also used to initialize WRF model runs for the region (section 2.9).

\subsection{Statistical methods}

There are a variety of statistical methods available to compare the winds between the baseline tower and the additional towers. For this study, we attempt to quantify the representativeness of the baseline site using simple and straightforward statistical tests. In general, the tower wind data are divided into subset groups based on 1) synoptic wind speed

class, 2) synoptic wind direction class, and 3) ambient stability class at the baseline site. All valid wind data points (table 4) corresponded to valid temperature and incoming solar radiation data points, which are necessary for the ambient stability class determination. Details about the different stability classes are outlined in section 2.6. Once the wind data are subset into the different groups, statistical tests are carried out to determine if there are statistically significant differences between the baseline site and each additional site.

Two different statistical tests are used to compare the wind data between each site and the baseline site. Originally, a simple t-test to compare the wind speeds and directions between the baseline site and the additional sites was desired, although non-normal distributions (wind speed) and circular variables (wind direction) caused the need to find equivalent alternative tests. Nonparametric tests, such as the Mann-Whitney U Test, are similar to a t-test, but make no assumption that the distributions of groups are normal, like the t-test. Sometimes a deterministic function is applied to every point in a data set to attempt to create a new, but equivalent, dataset that meets the assumptions of a particular statistical test, such as the t-test. This is referred to as a data transformation. Since the wind speed data from the towers were non-normal, despite 
attempts of data transformations, and because a normal data set is a required assumption of a ttest, the Mann-Whitney U test was selected to compare the wind speed data between each tower and the baseline tower. The Mann Whitney- $U$ test is a ranked non-parametric version of a two sample t-test, which compares the means of two groups to determine if there are significant differences between the groups. The term 'ranked' refers to how the test assigns a relative rank to each data point in a sample after the data are put into ascending order. The null hypothesis of the Mann-Whitney U test is that two groups are the same. The test statistic, or the p-value, of this test is determined based on the $U$ parameter, which is calculated from the summation of ranks within each sample. If the resultant $p$-value is $>0.01$ we fail to reject the null hypothesis and confirm that the two groups are not statistically different. If the resultant $p$-value is $<0.01$ we reject the null hypothesis and confirm that the two means are statistically different.

Statistics can be difficult to compute when working with circular variables, such as wind direction, because, for example, wind directions of $360^{\circ}$ and $0^{\circ}$ are numerically very different but fundamentally the same. In order to compute statistics of circular variables, an entire realm of statistics, called circular statistics, was developed. There are a variety of books (i.e. Topics in Circular Statistics, Jammalamadaka and Sengupta 2001; 100 Statistical Tests, Kanji 1993; Statistical Methods in the Atmospheric Sciences, Wilkes 2011) and publications (i.e. Mardia 1975, Jammalamadaka and Lund 2006, and Tasdan and Yeniay 2013) available that explain the methods and advantages of using circular statistics. The circular analysis of variance (ANOVA) is an equivalent to the linear ANOVA, but for circular data, and is a way to compare the means of samples to test for significant differences. ANOVA's can be applied to two or more groups, although when only two groups are considered, the test is essentially the same as a t-test that computes a simple 1:1 comparison. The assumptions of the circular ANOVA test are that 1) all 
samples are random and come from a von Mises, or normal, distribution and 2) the groups of samples have a common concentration parameter, or a similar distribution. The null hypothesis of the circular ANOVA test is that all of the means are equal and the alternative hypothesis is that the means are different. The circular ANOVA test determines whether to accept the null hypothesis or not comparing the means of the samples after computing an equation that breaks down the data into the resultant vectors and compares the means (Agostinelli and Lund 2013).

Using the 'circular' package in the R statistical package, circular ANOVA tests are used to compare wind direction measurements between each site and the baseline site. The assumptions of circular ANOVA, which relate to the distribution and concentration of the groups, were checked and verified for the tower wind direction data. Similar to the wind speed statistical tests, if the resultant $p$-value is $<0.01$ we reject the null hypothesis and confirm that the two groups are statistically different.

\subsection{Ambient stability determination}

Ambient stability data are required for the statistical analyses in this study. There are a number of different methods for characterizing ambient stability, including: Obukhov Length, Richardson Number, vertical temperature difference, and Pasquill stability classes. The issue of required data availability was a limiting factor for some methods (Obukhov Length and Richardson Number) while overall reliability of method was an issue for other methods (vertical temperature difference). Ultimately, as explained below, it was decided that Pasquill Stability classes are the most appropriate method for assessing ambient stability at the baseline site.

Pasquill stability classes, which are a commonly used method for characterizing ambient stability for regulatory air quality purposes, are used using data from the baseline site. The 
Pasquill stability classes are: A (extremely unstable), B (moderately unstable), C (slightly unstable), D (neutral), E (slightly stable), and F (moderately stable) and G (extremely stable).

Pasquill stability classes can be determined using a number of methods. Pasquill's (1961) original method characterized turbulence intensity based on vertical and horizontal wind direction fluctuations. At this point, the A-F stability categories did not exist. Gifford (1961) later created the A-F categories and improved on Pasquill's method, which required specialized anemometers, through the development of a turbulence characterization scheme that utilized vertical temperature gradients and wind direction standard deviations to characterize stability. Turner (1964) modified Gifford's method through the application of additional variables such as time of day, wind speed, cloudiness, and ceiling height to determine stability. This method for assigning P-G stability classes is not feasible in locations where an actual cloud observer is not present on a daily basis. To eliminate the need for a manned weather station to diagnose cloud variables, Bowen et al. (1983) later proposed a more objective method for deriving Pasquill stability, which the EPA (1993) later adapted, called the solar radiation delta-T (SRDT) method for deriving Pasquill stability classes.

The SRDT method is desirable because it retains the rationale of Turner's method while implementing a more objective estimation of meteorological parameters that contribute to the stability estimation. The SRDT method uses incoming solar radiation and wind speed during the day and delta-T (between $10 \mathrm{~m}$ and $2 \mathrm{~m}$ ) and wind speed during the night to predict stability, and has no requirement for cloud cover data (Table 5) (EPA 1993). 
Table 5: Pasquill Stability classes defined by the solar radiation delta-T method (EPA 2000). The SRDT method is an adaptation to Turner's method of the Pasquill stability classes. The top table (A) describes daytime stability and the bottom table (B) describes nighttime stability.

A) Daytime

\begin{tabular}{|c|c|c|c|c|}
\hline \multirow{2}{*}{$\begin{array}{c}\text { Wind } \\
\text { Speed } \\
(\mathbf{m} / \mathbf{s})\end{array}$} & \multicolumn{4}{|c|}{ Solar Radiation (w/m2) } \\
\cline { 2 - 5 } & $>=925$ & $925-675$ & $675-175$ & $<175$ \\
\hline$<2$ & $\mathrm{~A}$ & $\mathrm{~A}$ & $\mathrm{~B}$ & $\mathrm{D}$ \\
\hline $2-3$ & $\mathrm{~A}$ & $\mathrm{~B}$ & $\mathrm{C}$ & $\mathrm{D}$ \\
\hline $3-5$ & $\mathrm{~B}$ & $\mathrm{~B}$ & $\mathrm{C}$ & $\mathrm{D}$ \\
\hline $5-6$ & $\mathrm{C}$ & $\mathrm{C}$ & $\mathrm{D}$ & $\mathrm{D}$ \\
\hline$>=6$ & $\mathrm{C}$ & $\mathrm{D}$ & $\mathrm{D}$ & $\mathrm{D}$ \\
\hline
\end{tabular}

B) Nighttime

\begin{tabular}{|c|c|c|}
\hline \multirow{2}{*}{ Wind Speed (m/s) } & \multicolumn{2}{|c|}{ Vertical Temperature Gradient $\left({ }^{\circ} \mathbf{c} / \mathbf{k m}\right)$} \\
\cline { 2 - 3 } & $<0$ & $>=0$ \\
\hline$<2$ & $\mathrm{E}$ & $\mathrm{F}$ \\
\hline $2.0-2.5$ & $\mathrm{D}$ & $\mathrm{E}$ \\
\hline$>=2.5$ & $\mathrm{D}$ & $\mathrm{D}$ \\
\hline
\end{tabular}

For this study, we group ' $F$ ' and ' $G$ ' as well as 'A' and ' $B$ ' due to the infrequent nature $(<2 \%$ of the time) of the extremely stable ('G') and unstable ('A') categories. The distribution of the stability classes at the baseline site is displayed in figure $\mathbf{5 .}$ 
- A+B: Extremely and Moderately Unstable

- C:Slightly Unstable

- D: Neutral

- E: Slightly Stable

F+G: Extremely and Moderately Stable

\section{Stability Frequency: Central}

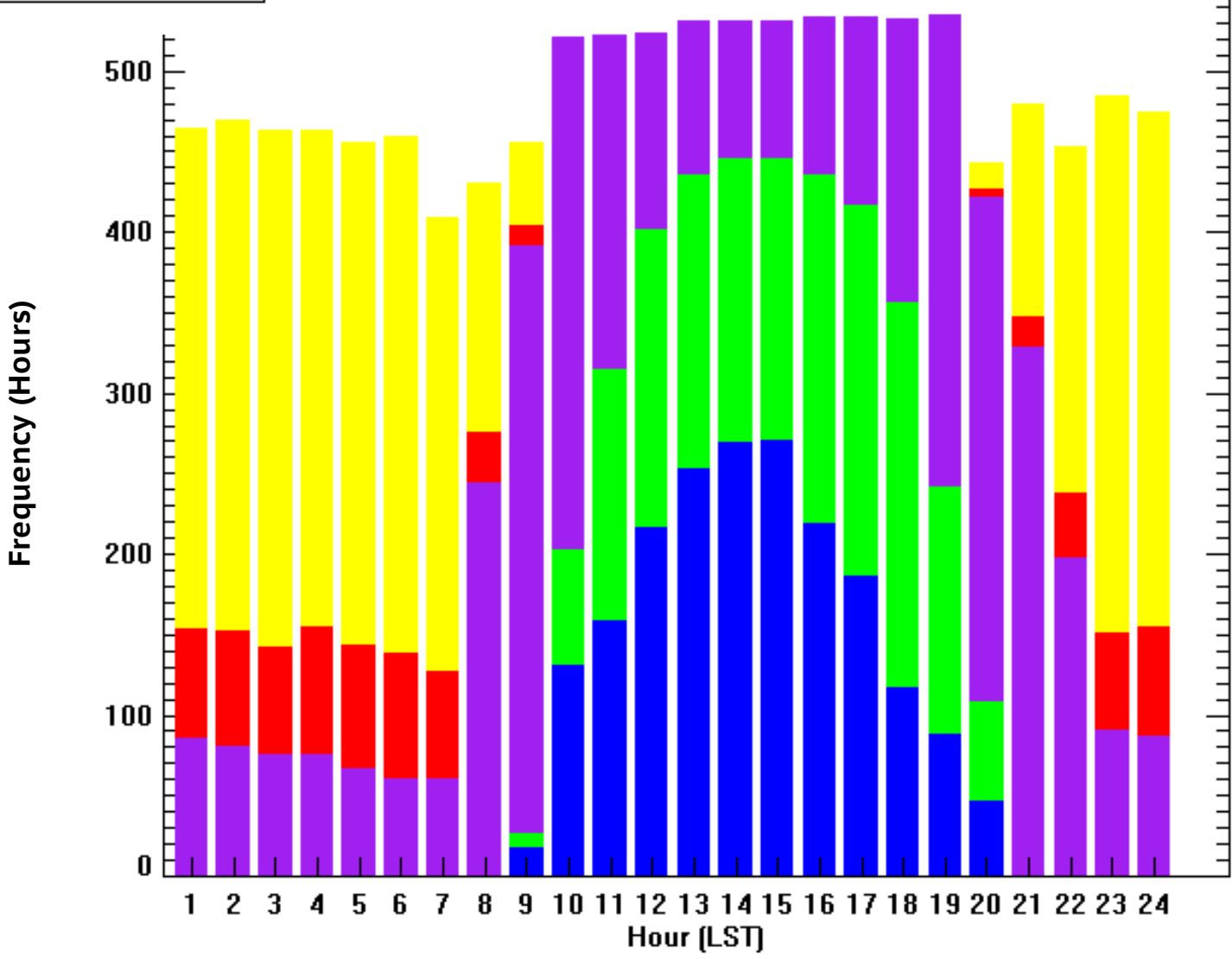

Figure 5: Diurnal distribution of stability categories derived from SRDT Pasquill Stability classification method, diurnally averaged over the 18-month period between July 2012 and December 2013. For this calculation, the extremely and moderately stable and the extremely and moderately unstable cases are grouped together because of the infrequency of both extreme stability categories.

For this study, the SRDT method was selected given the available meteorological variables and its accuracy shown here and in previous studies (Bowen et al. 1983, EPA 1993, DOE 2007). The DeltaT method was also considered for this study since there are temperature measurements at two heights. Typically, the DeltaT method is employed over a much larger vertical distance (i.e. $2 \mathrm{~m}-100 \mathrm{~m}$ ) compared to the $8 \mathrm{~m}$ temperature gradient available on the 
towers. Because of the small height difference, the deltaT calculation at the baseline site does not sufficiently capture the stability. The SRDT Pasquill Stability class method also uses incoming solar radiation and wind speed in addition to DeltaT measurements, and is therefore assumed more accurate.

The Richardson Number is yet another method for quantifying stability but was not an option for this study because the necessary variables were only available for a subset of the entire measurement period. We provide here a comparison between the Richardson number method and PG method for a selected period.. There are a variety of ways to calculate the Richardson Number, but the most common type is the Bulk Richardson Number (eq. 1). The graident Richardson Number is based on the change of wind and potential temperature with height and, therefore, requires a minimum of wind and temperature measurements at two heights:

$$
R_{i}=\frac{g \Delta \theta_{v} / \theta_{v}}{\left.[(U)]^{2}+(V)^{2}\right] / \Delta z}
$$

where $\mathrm{g}$ refers to gravity, $\theta_{v}$ is the virtual potential temperature, $\mathrm{U} / \mathrm{V}$ is the east-west/north-south component of the wind, and $\mathrm{z}$ is the height AGL. Sufficient data to calculate the Bulk Richardson number were available for roughly a three-month period at the baseline site from a 3 m tripod (see Appendix A). Using this data, a detailed comparison was conducted between the average Bulk Richardson numbers for each Pasquill stability class. Good agreement was found between the Bulk Richardson number and the Pasquill stability classes, as the Bulk Richardson number increased with increasing stability (Figure 6). 


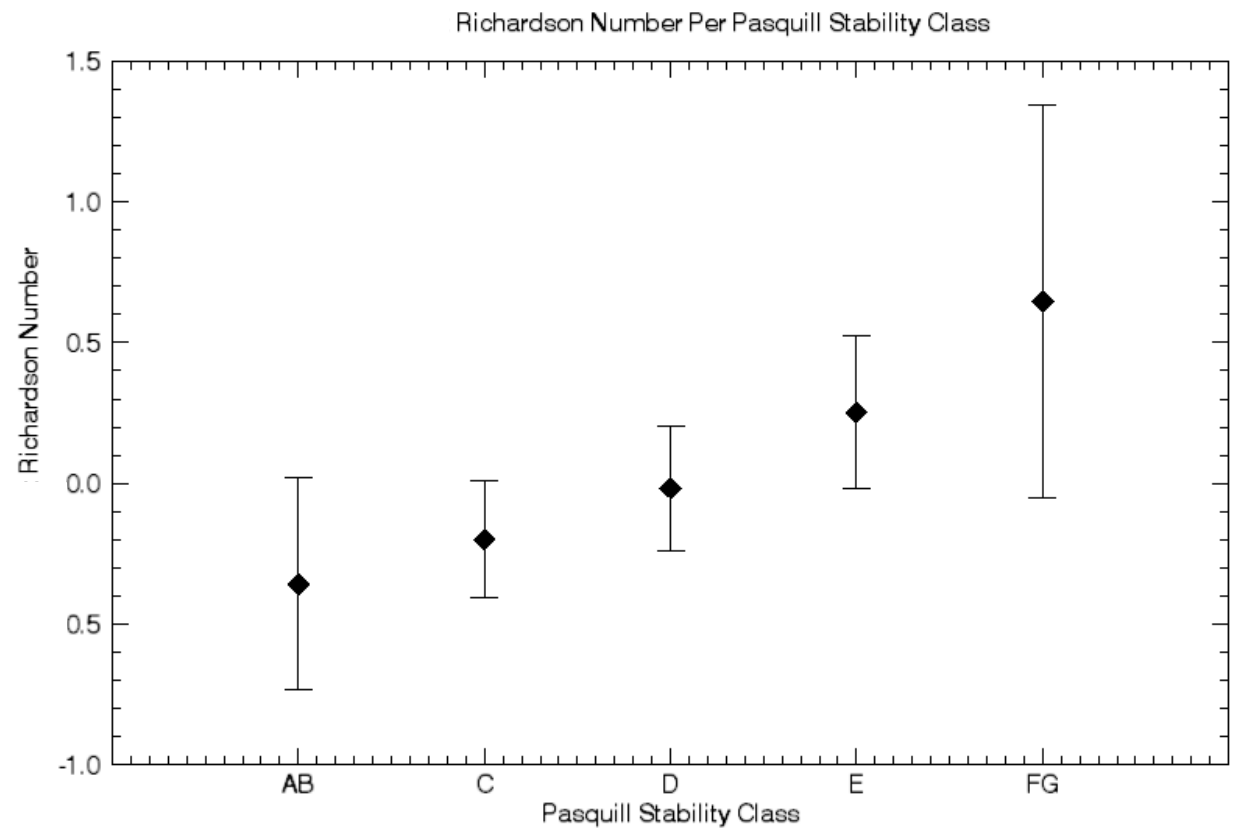

Fig. 6: Comparison of Bulk Richardson number and Pasquill stability class. Data between August and November 2012 are used in this comparison and the average Bulk Richardson number is plotted with error bars showing one standard deviation.

Previous studies have analyzed the accuracy of the aforementioned stability estimation methods. Bowen et al. (1983) compared a Pasquill stability estimation method similar to Turner's method to three different stability classification methods: 1) vertical temperature difference, 2) Bulk Richardson number, and 3) horizontal and vertical standard deviation of wind. It was found that, for irregular terrain, the Pasquill stability class method is a good method for estimating stability when compared to the alternative methods and showed the greatest agreement with the Bulk Richardson number. Subsequently, EPA (1993) and DOE (2007) provided sufficient evidence of good agreement between Turner's method and the SRDT method. Therefore, we employ the SRDT method with confidence in this study. 


\subsection{Intensive Field Campaigns}

Three intensive field campaigns were held with the objectives to determine the vertical extent of topographically induced flows from 0 to $100 \mathrm{~m}$ AGL at the two sites and to investigate the representativeness of the baseline site during conditions when the greatest spatial variability in winds is expected. During the field campaigns, 12-14 tether balloon profiles were made throughout the duration of each night at each site.

The field campaign nights were selected based on specific criteria: synoptically weak winds, synoptic flow not from the northwest, and clear, stable conditions. These conditions are conducive to the presence of local drainage flows, which could reduce the representativeness of the baseline site. To forecast for these nights, a variety of forecast tools were used. First, the National Weather Service's forecast discussion and synoptic weather maps were analyzed. If a particular night seemed ideal, the 700 and $850 \mathrm{mb}$ wind, and cloud forecasts produced by the GRS, NAM, and RUC models were consulted. If each forecasting resource portrayed ideal conditions for a field experiment, we would select that night as a 'go'. One problem that arose during this process was that clear, calm nights are highly difficult to predict. Therefore, not every field campaign night fit the aforementioned criteria perfectly.

Kestrel 4500 handheld weather meters were used to measure wind speed, wind direction and temperature using an originally designed attachment apparatus (figure 7) for tethersonde profiles. 


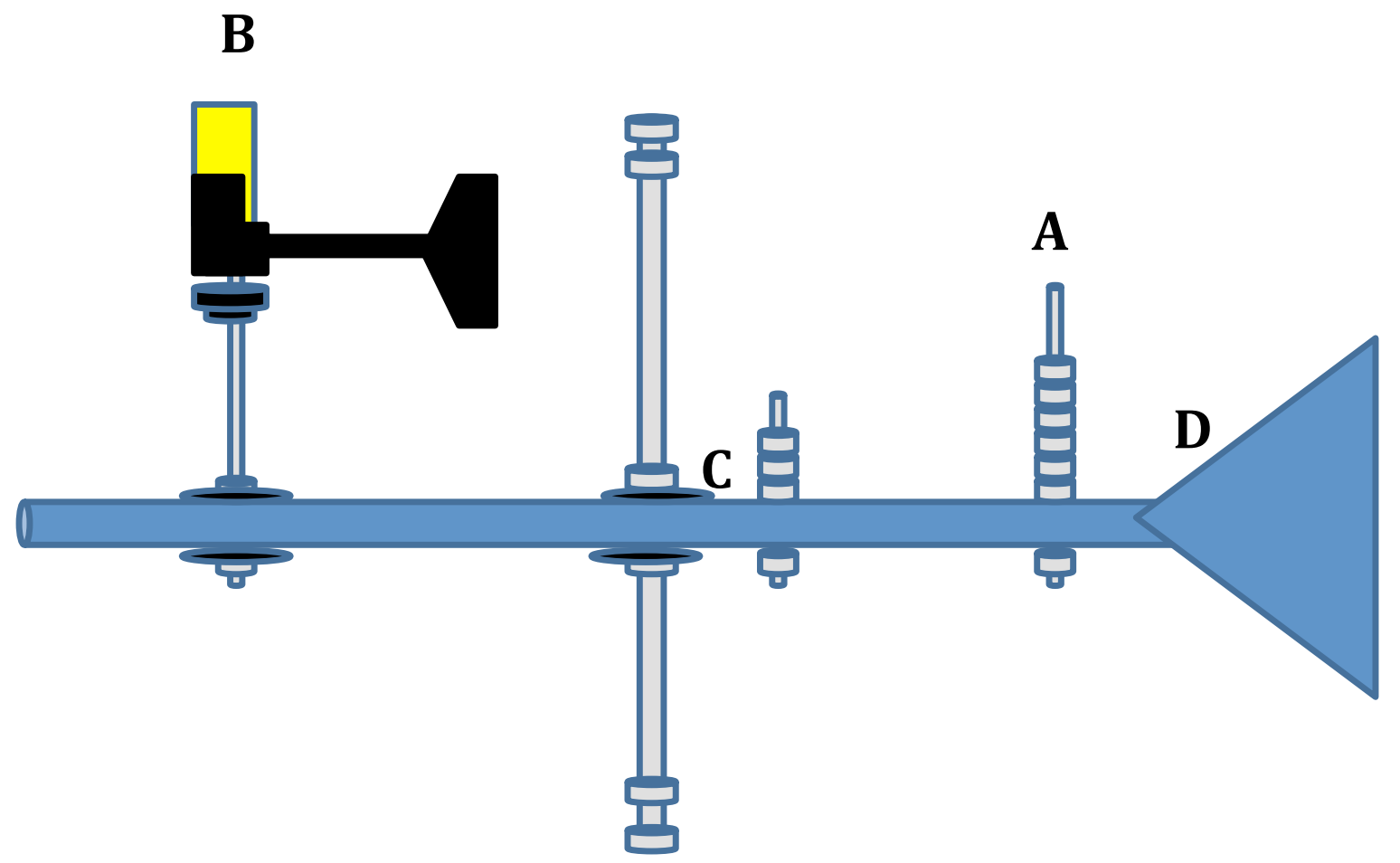

Figure 7: Cartoon of the kestrel attachment apparatus constructed by the de Wekker lab group. The apparatus consists of materials such as PVC pipe (blue tube), metal rod (gray rod), plastic tail (blue triangle), and a number of bearings and bolts. The Kestrel 4500 and the corresponding wind vane are attached to the right side of the apparatus. A) Washers are screwed on to a long screw to counter balance the kestrel side of the apparatus to ensure level flying. B) The Kestrel 4500 measures and records the data. C) Bearings, originally made for skateboards, are used to allow the entire PVC rod to rotate freely. D) A plastic fin is added to the end of the PVC rod to allow the entire apparatus to point into the wind more freely.

The Kestrel 4500's and attachment apparatus were designed to replicate commercially available tethersonde systems in a low cost manner. The tethersonde attachment apparatus is comprised of low weight materials such as PVC pipe, narrow metal rods and nuts and bolts. The apparatus is cross-shaped with a metal rod in the vertical and a PVC pipe in the horizontal direction. The PVC pipe is rigged to bearings, which allow it to freely rotate around the metal rod. On one side of the PVC pipe the Kestrel 4500 wind vane is attached. This wind vane is free to move on its 
own as dictated by the wind. On the opposite end of the PVC pipe is a large tail made of clear plastic. Although the Kestrel 4500 wind vane attachment points into the wind on its own, the large clear plastic tail is attached to the opposite side of the PVC pipe to allow the entire apparatus to point into the wind, and increase wind measurement accuracy. Different sized pieces of hardware are attached on the opposite side of the PVC pipe as the Kestrel 4500 and wind vane to counter balance the weight. Levels were used to ensure the levelness of the PVC pipe and the Kestrel 4500 wind vane attachment.

The kestrel attachment is hooked onto a strong line that is connected to a 13 -foot helium blimp on one end and a spool on the other. The line has a break in it $20 \mathrm{~m}$ below the blimp where the kestrel is attached to the top and bottom of the break. The apparatus is attached this way so that the string does not become wound around the metal rod as it rotates. To ensure the safety of the compete setup, the spool is staked securely into the ground. Exhaustive tests were done to determine the reliability of the Kestrel 4500 and the attachment apparatus and it was found that the set-up provided reliable wind and temperature data. Details about the testing can be found in appendix B. The calm threshold of the Kestrel 4500's is $0.5 \mathrm{~m} / \mathrm{s}$.

\subsection{WRF Model runs}

The Weather Research and Forecasting (WRF) model was used in this project to simulate the meteorological conditions of nights that are characteristic of unrepresentative wind conditions for the baseline site. The WRF model is a numerical weather prediction model that can conduct idealized and real-data simulations. For this project, simulations based on real initial and boundary conditions are done. The purpose of these simulations is to simulate the winds at different levels in the atmosphere and qualitatively interpret the physical processes that alter the winds in the region and the vertical extent of topographic influence over the winds. The 
results of the WRF model runs are all 30-hour model runs from 12 UTC (08 LST) on day 1 to 18 UTC (14 LST) on day 2. The runs are set up in this manner to allow appropriate time for the model to initialize the boundary conditions of each domain. Each run is done with a nested 3domain set up with grid spacing of 9,3 , and $1 \mathrm{~km}$ grid spacing (figure 8).

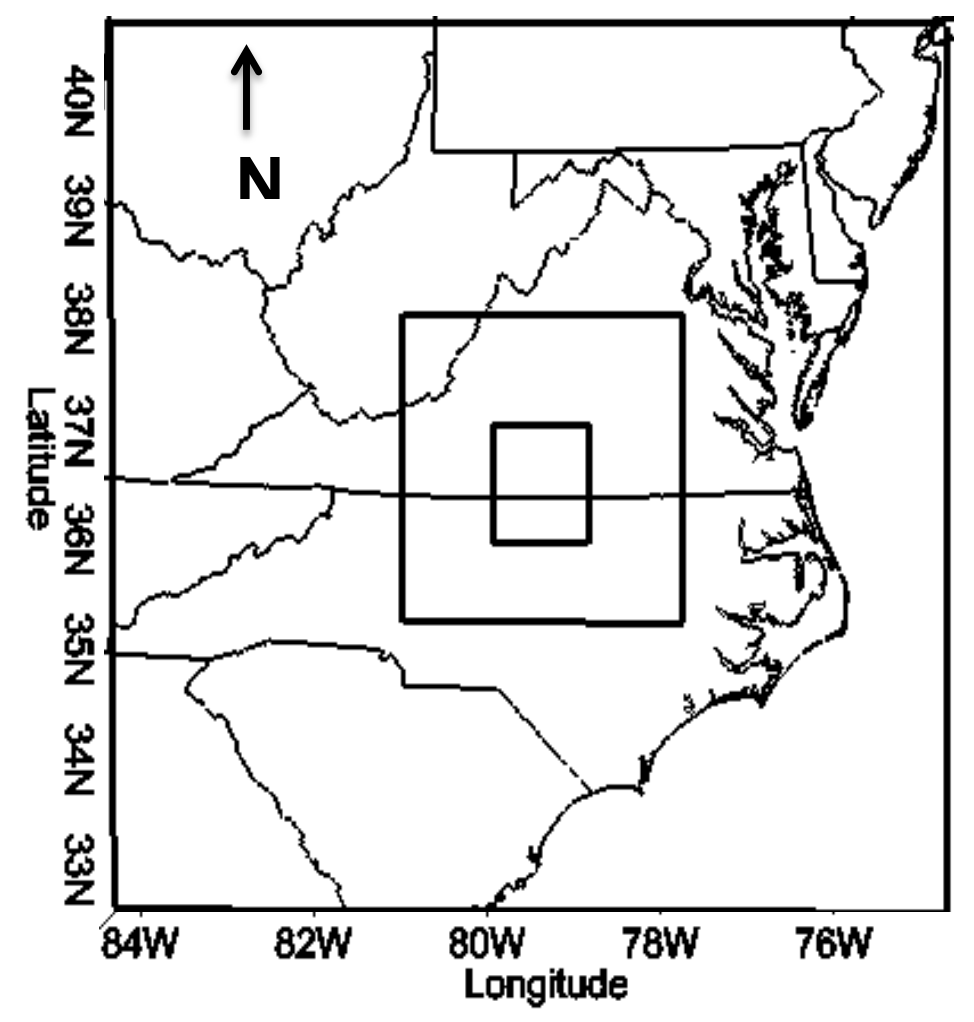

Figure 8: The geographical location of the three nested domains for the WRF model runs included in this thesis.

The NARR model output is used as initial and boundary conditions for these runs and WRF outputs an hourly data set. A sensitivity test was conducted to determine the differences in local and regional wind patterns caused by varying PBL schemes and negligible differences were found (Appendix C). The Mellor-Yamada-Janjic TKE scheme was used as the PBL scheme for all model runs and is justified in Appendix C (Janjic 1994). This PBL scheme is only compatible 
with the Monin-Obukhov (Janjic) surface layer option (Janjic 2002) and the Unified Noah landsurface model was used for the land surface physics scheme (Tewari 2004). Forty-two eta (sigma) levels are used to define the vertical levels for each model run with a model top at 100 $\mathrm{mb}$. The lowest 10 sigma levels are: 1.0000, 0.9960, 0.9930, 0.9890, 0.9860, 0.9820, 0.9790, $0.9750,0.9720$, and 0.9680 , which approximately correspond to the $0,11,19,31,40,52,60,72$, 80, and $92 \mathrm{~m}$ heights.

\section{Chapter 3: Results}

In this chapter the results from the statistical and wind roses analyses and the field campaigns and WRF model runs are provided. The statistical and wind rose results (section 3.1) are described first. This section includes a brief description of the winds at the baseline and additional sites followed by the results from the wind rose and statistical analyses. Next the intensive field campaigns and WRF model run results are described (section 3.2).

\subsection{Statistical and wind rose comparisons between each site and the baseline site}

\subsubsection{Description of wind climatology at baseline tower}

Wind climatology can be described succinctly using wind roses, which summarize horizontal wind characteristics for a particular location over a specified time period. Wind roses are used throughout this study to compare and contrast wind characteristics. The wind rose for the baseline site from July 2012 to December 2013 is shown in figure 9. 


\begin{tabular}{|l|}
\hline Bin width $-20 \%$ \\
$0.5-01 \mathrm{~m} / \mathrm{s}$ \\
$01-02 \mathrm{~m} / \mathrm{s}$ \\
$02-03 \mathrm{~m} / \mathrm{s}$ \\
$03-04 \mathrm{~m} / \mathrm{s}$ \\
$04+\mathrm{m} / \mathrm{s}$ \\
\hline
\end{tabular}

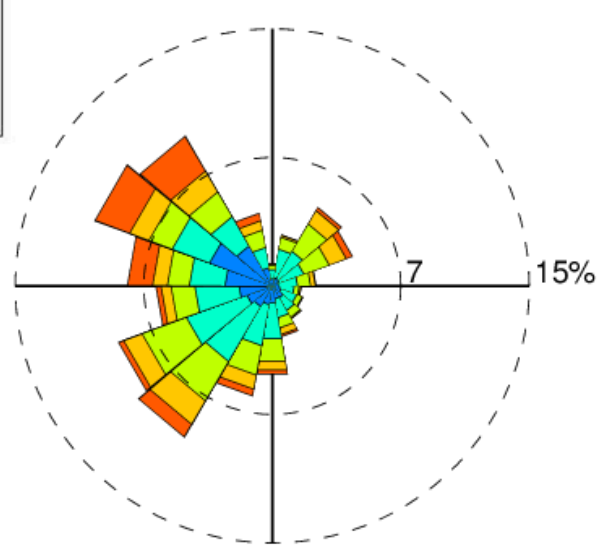

Figure 9: Wind rose for the baseline site for the 18 month period between July 2012 and December 2013. All valid data points ( $\sim 95 \%$ of data) are included in this wind rose. $5.1 \%$ of wind data are below the $0.5 \mathrm{~m} / \mathrm{s}$ calm threshold and are not included in this figure.

The predominant wind directions for this 18-month period are from the northwest and from the southwest. Winds are also frequent from the northeast, although to a lesser extent. Calms, defined as wind speeds smaller than $0.5 \mathrm{~m} / \mathrm{s}$, occur $5.1 \%$ of the time. The weakest winds $(0.5-1$ $\mathrm{m} / \mathrm{s})$ and the strongest winds $(4+\mathrm{m} / \mathrm{s})$ are from the northwesterly direction. Southeasterly flows are rare at the site. It is difficult to make any comparison between the baseline site and the Danville and Lynchburg Regional airport wind data because of the relatively high calm threshold used at those sites. The calm threshold at the airports $(1.34 \mathrm{~m} / \mathrm{s})$ is much higher than the calm threshold used at the baseline site $(0.5 \mathrm{~m} / \mathrm{s})$. Roughly $30 \%$ of the wind data fall between $0.5 \mathrm{~m} / \mathrm{s}$ and $1.34 \mathrm{~m} / \mathrm{s}$ at the baseline site, and therefore, a comparison would be inconclusive, although a partial comparison can be made by also setting the calm threshold at $1.34 \mathrm{~m} / \mathrm{s}$ for the baseline site. A comparison of the three stations, using the calm threshold of $1.34 \mathrm{~m} / \mathrm{s}$, shows that the baseline site experiences more winds form the northwest compared to the two airports and is most similar to the Danville Regional Airport, which shows more northwesterly flow compared to the Lynchburg Regional Airport (figure 3). In general, both airport sites show more flows from the northeast and southwest and fewer flows from the northwest compared to the baseline site. The northeast and southwest flows are consistent with typical flow patterns east of the Blue Ridge. All three sites almost never experience flow from the southeast. Simply based on this 
comparison, the airport data do not sufficiently represent the winds at the baseline site and, therefore, could not be used as an alternative to wind measurements made at the Chatham site. Also, since weak winds conditions coincide with less representative wind measurements and are excluded from this comparison, the airport data would especially misrepresent the winds over the Chatham region.

\subsubsection{Comparison between baseline tower and four additional towers}

We now assess the representativeness of measurements at the baseline tower as a function of ambient stability and upper-level winds. First, 18-month wind roses are presented for all five

towers. Next, the tower wind data are subset based on Pasquill stability class, prevailing synoptic wind direction, and synoptic wind speed to determine which combinations of conditions cause the baseline site to be most and least representative of the study region. This was carried out by first dividing the tower wind data into subsets for all possible combinations of Pasquill stability class, synoptic wind direction, and synoptic wind speed. Then, for each subset, wind roses were created for each tower and statistical tests were carried out to compare the wind speed and wind direction between each site and the baseline site for each subset.

\subsubsection{Winds}

The baseline site shows different wind characteristics compared to the Danville and Lynchburg regional airports, as explained in section 3.1.1 (figure 3). The wind measurements from the nearby NCDC sites are less influenced by local topography and, therefore, show more northeast and southwest wind direction components compared to the baseline site. Since the calm threshold is required to be $1.34 \mathrm{~m} / \mathrm{s}$ due to restrictions of the NCDC instruments, it would 
be expected that the differences between the baseline site and the two NCDC sites would increase if winds below the calm threshold of $1.34 \mathrm{~m} / \mathrm{s}$ were included.

Wind roses for all five towers representing the 18 -month time period are presented in figure 10. Again, a calm threshold of $0.5 \mathrm{~m} / \mathrm{s}$ is used in these wind roses. Most obvious are the more frequent weak northwesterly winds and less frequent southwesterly winds at the baseline site compared to the other sites.

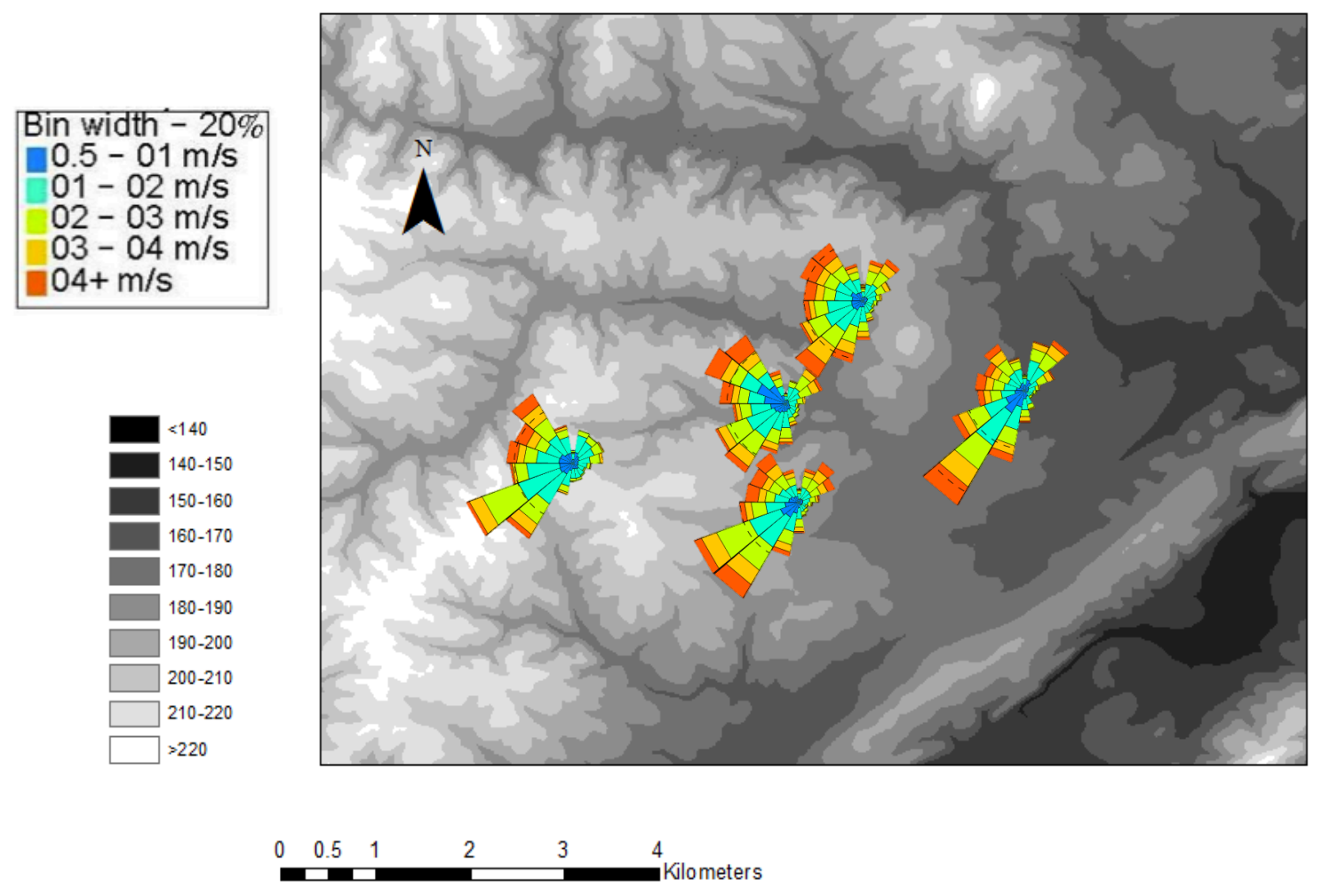

Fig. 10: Wind roses for each tower overlaid on the topographic map of the region. Each wind rose contains data collected between July 2012 and December 2013.

The southern and eastern towers appear most similar to each other. At these two sites, northwesterly winds are least frequent and northeasterly winds are most frequent, compared to the other sites. Winds at the western and eastern sites show northeasterly flow least and most frequently, respectively. 
After a careful analysis of the topographic map of the region and the wind roses, differences between each tower and the baseline tower were identified. As described in the introduction, thermally induced drainage flows can exist at a variety of scales simultaneously. Based on the local and regional topography, both regional and local thermally induced drainage flows from the northwest were suspected. The regional drainage flows exists to some extent at each site and influence the baseline site the greatest. The baseline site is situated on a steeper topographic gradient, oriented from northwest to southeast, similar to the west and north sites compared to the east and south sites. In addition, it is situated near two gullies or drainages. The ridge to the south of the region also plays a larger role in the wind climatology of the east and south sites compared to the other three sites. Flow deflection effects are evident at these sites because of the relatively large frequency of winds from the southwest at these two sites compared to the other three sites.

\subsubsection{Wind differences as a function of synoptic winds and stability}

We chose to investigate the impact of ambient stability and synoptic wind speed and direction on the wind representativeness of the baseline site because of the large impact these variables have on wind representativeness (see: Chapter 1: Introduction). Pasquill stability class and synoptic wind speed and direction categories are used to divide the tower data into subsets for qualitative and quantitative comparisons between each tower and the baseline tower for each subset. The synoptic wind direction is categorized as either from the NW (direction of regional topographic gradient) or not from the NW. The synoptic wind direction categorizations were chosen because if the synoptic flow, and/or ambient surface flow, is not in the same direction as a topographically induced flow, the topographic flow may be more easily identified. The synoptic wind speed is categorized as either $>10 \mathrm{~m} / \mathrm{s}$ or $<10 \mathrm{~m} / \mathrm{s}$ (table 6). The synoptic wind 
speed and direction categories contain similar amounts of wind data for all towers. The categorizations of the synoptic wind speed were determined based on the general distribution of the synoptic wind speed climatology: $\sim 50 \%>10 \mathrm{~m} / \mathrm{s}$ and $\sim 50 \%<10 \mathrm{~m} / \mathrm{s}$.

Table 6: The different categories for synoptic wind speed, and synoptic wind direction. Synoptic winds are derived from the $700 \mathrm{mb}$ height output from the NARR model.

\begin{tabular}{|c|c|c|}
\hline $\begin{array}{c}\text { Synoptic Wind } \\
\text { Speed }\end{array}$ & $\begin{array}{c}\text { Relatively Weak } \\
(700 \mathrm{mb} \text { winds }<10 \mathrm{~m} / \mathrm{s})\end{array}$ & $\begin{array}{c}\text { Relatively Strong } \\
(700 \mathrm{mb} \text { winds }>10 \mathrm{~m} / \mathrm{s})\end{array}$ \\
\hline $\begin{array}{c}\text { Synoptic Wind } \\
\text { Direction }\end{array}$ & $\begin{array}{c}\text { From NW } \\
(270-360)\end{array}$ & $\begin{array}{c}\text { Not from NW } \\
(0-270)\end{array}$ \\
& $\begin{array}{c}* \text { Not in direction of } \\
\text { topographically induced flow }\end{array}$ \\
\hline
\end{tabular}

A non-parametric version of a t-test, called the Mann-Whitney $U$ test, was used to compare wind speed data and circular one-way ANOVA's were used to compare wind direction data between each tower and the baseline tower. The comparisons were done for the tower wind data separated by every possible combination of 1) synoptic wind speed category, 2) synoptic wind direction category and 3) Pasquill stability class. The results from the statistical tests are presented in table $\mathbf{7 b}$. The degree of the representativeness of the baseline site is judged based on the number of sites that are statistically significantly different from the baseline site in terms of wind speed and/or wind direction. The possible degrees of representativeness include 1) Representative, 2) Marginally Representative, or 3) Not Representative. Careful consideration was given to how to identify the conditions that correspond to the aforementioned degrees of representativeness. The sensitivity of the degree of representativeness was explored using varying requirements for the number of statistically significant differences and an educated decision was made to set the criteria for the degree of representativeness. Inherent differences that would occur regardless of topography and the fact that minimal variations in winds are 
acceptable for this application were taken into account and contributed to the determination of the criteria for the degrees of representativeness. Table $\mathbf{7 b}$ contains boxes, which represent each subset of tower wind data based on the different stability and synoptic wind categories. Depending on the number of significant differences between the baseline site and the additional sites, each box is shaded green, yellow or red, which represents representative, marginally representative or not representative, respectively. When wind speed and wind direction representativeness is considered separately, $0-1$ significantly different additional towers is representative, 2 significantly different towers is marginally representative and 3 or 4 significantly different towers is unrepresentative (Table 7a). The individual results from the wind speed and wind direction statistics were combined to determine the overall wind representativeness of the baseline site, as indicated in the rightmost column of table 7b1-4 and further explained below.

Table 7: The results of the statistical comparisons of wind speed and wind direction between the baseline site and the additional sites. The level of representativeness is indicated by the color shading in each box (table above). For each comparison, the tower wind data were divided into subsets based on the baseline Pasquill stability class and synoptic wind speed and wind direction and are separated into four different tables based on the combination of conditions.

\begin{tabular}{|c|c|c|}
\hline & \# Towers sig. different than baseline & $\begin{array}{c}\text { Index of } \\
\text { Representativeness }\end{array}$ \\
\hline & $0-1$ & Rep. \\
\hline & 2 & Marginally Rep. \\
\hline & $3-4$ & Not Rep. \\
\hline
\end{tabular}




\begin{tabular}{|c|c|c|c|c|}
\hline Synoptic Flow & Stability & WS & WD & Both \\
\hline $\mathbf{0 - 2 7 0 ^ { 0 }}$ & $\mathbf{A B}$ & & & \\
$0-10 \mathrm{~m} / \mathrm{s}$ & $\mathbf{C}$ & & & \\
\hline & D & & & \\
\hline & E & & & \\
\hline & FG & & & \\
\hline & & & & \\
& &
\end{tabular}

7B2)

\begin{tabular}{|c|c|c|c|c|}
\hline Synoptic Flow & Stability & WS & WD & Both \\
\hline \multirow{5}{*}{$\begin{array}{c}\mathbf{0 - 2 7 0 ^ { 0 }} \\
10+\mathrm{m} / \mathrm{s}\end{array}$} & $A B$ & & & \\
\hline & C & & & \\
\hline & D & & & \\
\hline & $E$ & & & \\
\hline & FG & & & \\
\hline
\end{tabular}

7B3)

\begin{tabular}{|c|c|c|c|c|}
\hline Synoptic Flow & Stability & WS & WD & Both \\
\hline \multirow{5}{*}{$\begin{array}{l}\mathbf{2 7 0 - 3 6 0} \\
0-10 \mathrm{~m} / \mathrm{s}\end{array}$} & $A B$ & & & \\
\hline & C & & & \\
\hline & D & & & \\
\hline & E & & & \\
\hline & FG & & & \\
\hline
\end{tabular}




\begin{tabular}{|c|c|c|c|c|}
\hline Synoptic Flow & Stability & WS & WD & Both \\
\hline \multirow{3}{*}{$\begin{array}{c}270-360^{\circ} \\
10+\mathrm{m} / \mathrm{s}\end{array}$} & AB & & & \\
\hline & C & & & \\
\hline & D & & & \\
& E & & & \\
& FG & & & \\
\hline
\end{tabular}

The concept of representativeness is highly subjective, but the thresholds for the determination of the degree of representativeness were defined after careful consideration and sensitivity tests using different thresholds. For example, if conditions that caused only one significant difference were considered not representative, there would be no account for any 'false positive' instances and conditions that actually are representative would be incorrectly labeled. The baseline site is considered representative if it is either representative for both wind speed and wind direction or representative for wind speed or direction and marginally representative for the other. The baseline site is considered marginally representative of the winds if one of the wind variables is representative while the other is unrepresentative or if both wind speed and direction are marginally representative. Finally, the baseline site is considered unrepresentative if one either wind speed or wind direction marginally representative while the other is unrepresentative or if both wind speed and wind direction are unrepresentative. The statistical results are compared to the corresponding wind roses to confirm the accuracy of the statistical tests and to qualitatively describe the differences in wind characteristics between each tower and the baseline tower. The wind roses that correspond to the subsets of data are found in 
the following figures: figure 11 (synoptic flow $0-270^{\circ},<10 \mathrm{~m} / \mathrm{s}$ ), figure 12 (synoptic flow 0 $270^{\circ},>10 \mathrm{~m} / \mathrm{s}$ ), figure 13 (synoptic flow $270-360^{\circ},<10 \mathrm{~m} / \mathrm{s}$ ), and figure 14 (synoptic flow $\left.270-360^{\circ},>10 \mathrm{~m} / \mathrm{s}\right)$ 

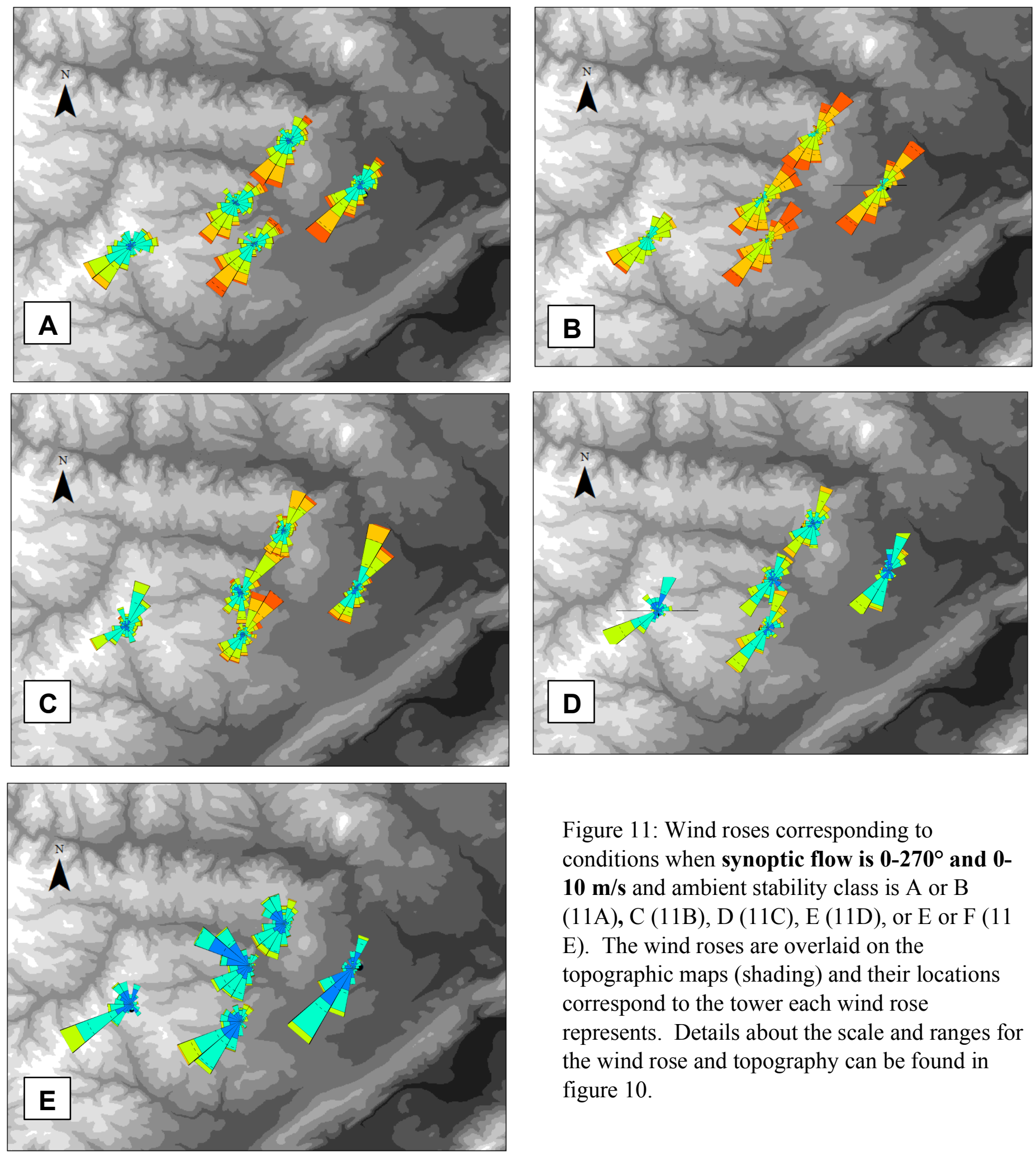

Figure 11: Wind roses corresponding to conditions when synoptic flow is $\mathbf{0 - 2 7 0 ^ { \circ }}$ and $\mathbf{0 -}$ $10 \mathbf{~ m} / \mathbf{s}$ and ambient stability class is A or B (11A), C (11B), D (11C), E (11D), or E or F (11 E). The wind roses are overlaid on the topographic maps (shading) and their locations correspond to the tower each wind rose represents. Details about the scale and ranges for the wind rose and topography can be found in figure 10 . 

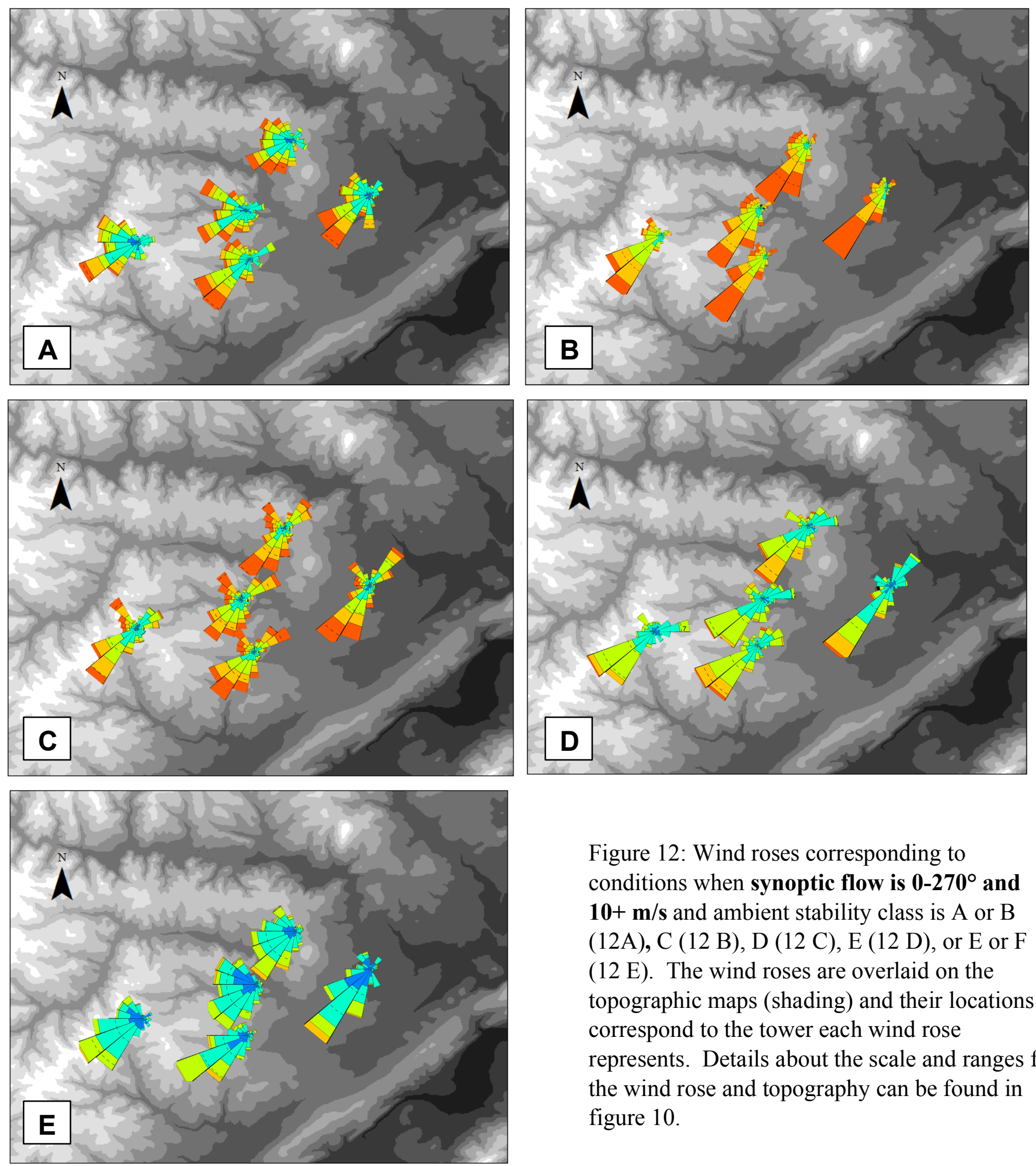

Figure 12: Wind roses corresponding to conditions when synoptic flow is $\mathbf{0 - 2 7 0 ^ { \circ }}$ and $\mathbf{1 0}+\mathbf{m} / \mathbf{s}$ and ambient stability class is A or B (12A), C (12 B), D (12 C), E (12 D), or E or F $(12 \mathrm{E})$. The wind roses are overlaid on the topographic maps (shading) and their locations correspond to the tower each wind rose represents. Details about the scale and ranges for the wind rose and topography can be found in figure 10 . 

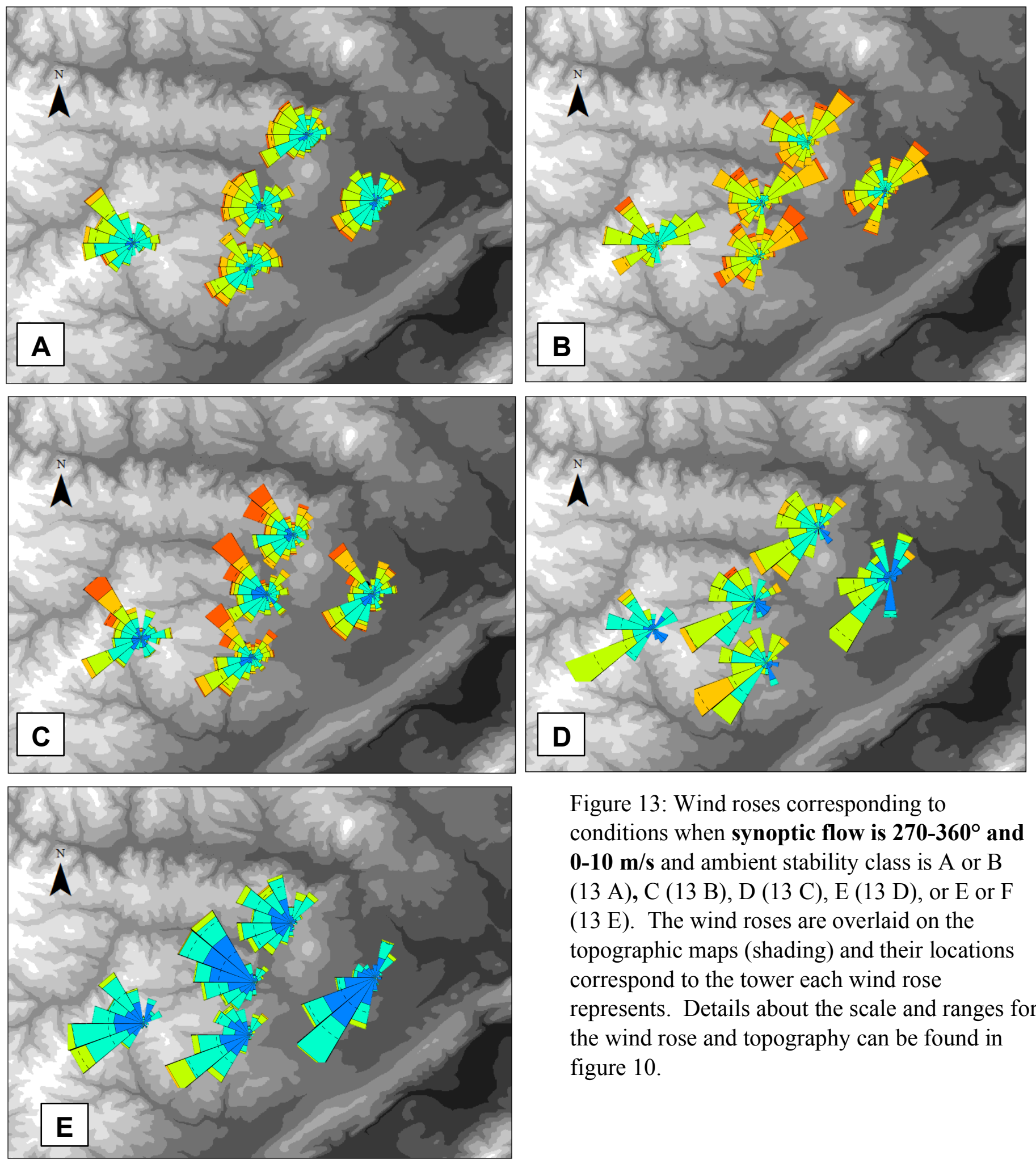

Figure 13: Wind roses corresponding to conditions when synoptic flow is $270-360^{\circ}$ and 0-10 $\mathbf{~ m} / \mathbf{s}$ and ambient stability class is A or B (13 A), C (13 B), D (13 C), E (13 D), or E or F $(13 \mathrm{E})$. The wind roses are overlaid on the topographic maps (shading) and their locations correspond to the tower each wind rose represents. Details about the scale and ranges for the wind rose and topography can be found in figure 10 . 

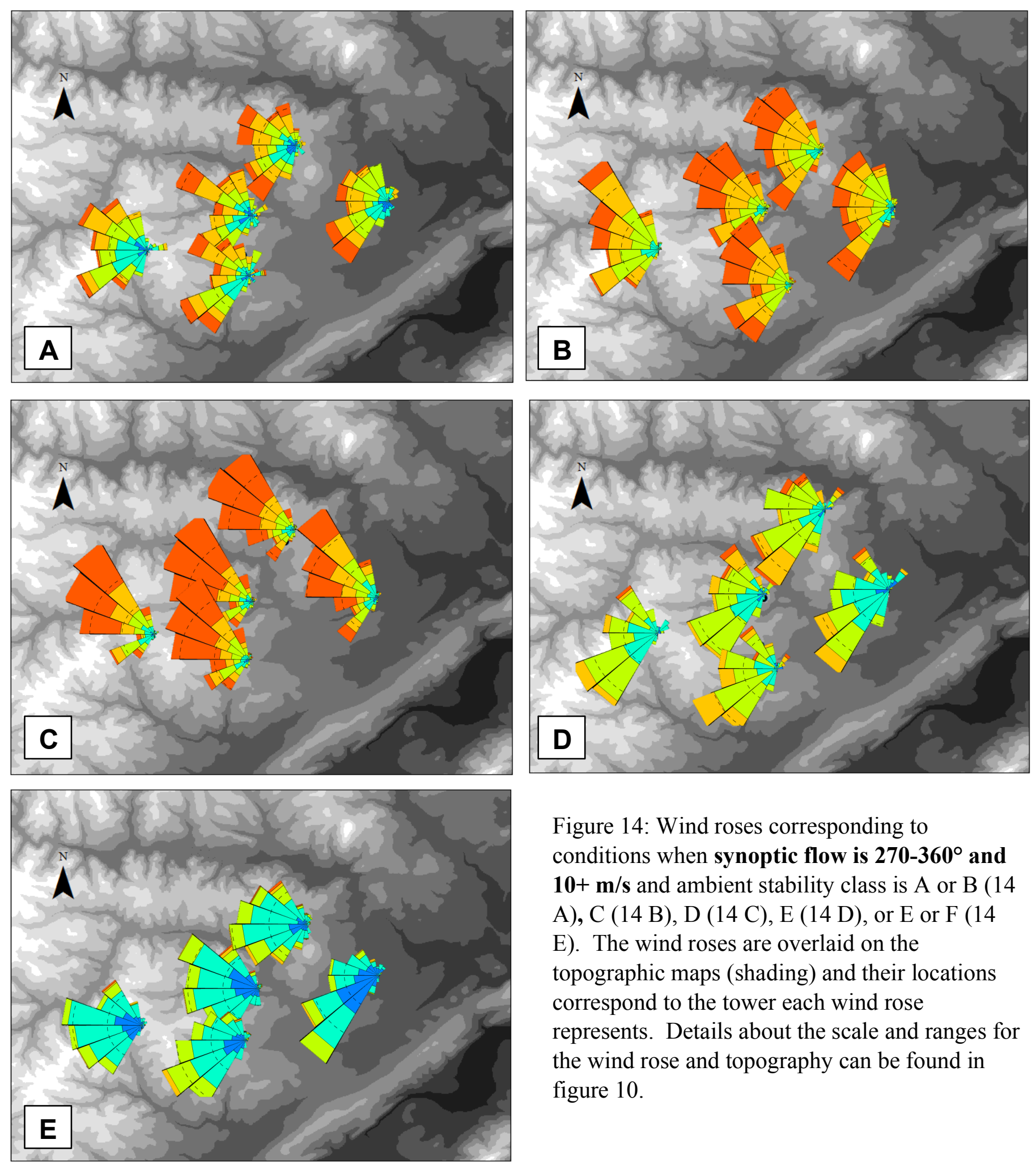

Figure 14: Wind roses corresponding to conditions when synoptic flow is $\mathbf{2 7 0 - 3 6 0 ^ { \circ }}$ and $\mathbf{1 0}+\mathbf{~ m} / \mathbf{s}$ and ambient stability class is A or B (14 A), C (14 B), D (14 C), E (14 D), or E or F (14 E). The wind roses are overlaid on the topographic maps (shading) and their locations correspond to the tower each wind rose represents. Details about the scale and ranges for the wind rose and topography can be found in figure 10 . 
The statistical results reveal that Pasquill stability class is the largest determinant of the representativeness of the baseline tower because the number of unrepresentative cases increases as stability increases. Overall, the baseline site is considered unrepresentative for Pasquill stability categories ' $F$ ' and ' $G$ ' (moderately or extremely stable), irrespective of synoptic wind condition. Synoptic wind direction is the second largest determinant of wind representativeness at the baseline site since a larger number of marginally representative cases occur when the synoptic wind direction is not from the NW, irrespective of synoptic wind speed. It is important to note that significant differences in terms of wind speed mostly cause synoptic wind direction to be the second largest determinant of representativeness. Synoptic wind speed does not seem to be as large of a determinant of representativeness compared to synoptic wind direction and ambient stability.

The baseline site was found to be unrepresentative during any synoptic flow condition when the ambient stability is either moderately or extremely stable. Under the aforementioned conditions, there is more northwesterly flow at the baseline site than at the other sites, which is evidence of an enhanced drainage flow effect. Based on the corresponding wind roses, this effect is most pronounced when the synoptic flow is not from the NW, less than $10 \mathrm{~m} / \mathrm{s}$ and the ambient stability is moderately or extremely stable, as shown in figure 11E. Alternatively, the ridge to the south of the towers reduces, eliminates, or changes the direction of the regional NW to SE drainage flow at the south and east sites through topographic flow deflection or flow blocking. The south and east sites show the greatest differences compared to the baseline site with an increased frequency of southwesterly flow. The south and east sites are located closest to the ridge, are on relatively small topographic gradients (Table 3), and are, therefore, most influenced by the flow deflection effects of the ridge. 
The baseline site is considered marginally representative of the region when the synoptic flow is not from the NW and stability is either slightly unstable or neutral, irrespective of synoptic wind speed. The marginal representativeness of the baseline site is due to significant differences in wind speed during these conditions between the baseline site and the additional sites. Table 8 indicates the average wind speed for an example of such conditions: synoptic flow $<10 \mathrm{~m} / \mathrm{s}$, not from NW, and neutral ambient stability.

Table 8: An example of a combination of conditions (synoptic wind speed $<10 \mathrm{~m} / \mathrm{s}$ and not from the NW and ambient stability is neutral) when the significant wind speed differences between each site and the baseline site caused the wind representativeness of the baseline site to be marginally unrepresentative. In this table, the bold wind speed values indicate significant differences between a particular tower and the baseline tower. Under certain conditions, such as this one, the wind speed differences are the reason for a marginal representative diagnosis, instead of the wind direction differences.

\begin{tabular}{|l|l|l|l|l|l|}
\hline & Baseline & East & West & North & South \\
\hline $\begin{array}{l}\text { Wind Speed } \\
(\mathbf{m} / \mathbf{s})\end{array}$ & 1.92 & 2.03 & $\mathbf{1 . 5 5}$ & $\mathbf{2 . 2 4}$ & $\mathbf{2 . 3 1}$ \\
\hline
\end{tabular}

This table shows the relative magnitude of the differences that caused significant wind speed differences between the west, north, and south sites and the baseline site. During these conditions, the baseline site has consistently weaker winds compared to the south and east sites, and consistently stronger winds compared to the western site. During all other conditions not previously described, the baseline site is considered representative. An example of a time when the baseline site is especially similar to the other sites is when synoptic flow is from the NW and is $>10 \mathrm{~m} / \mathrm{s}$ and ambient stability is neutral (figure 14c).

For any type of statistical analysis, inherent discrepancies may arise. There are more significant differences associated with wind speed comparisons, but the statistical results agree 
with the qualitative analyses of the wind roses and any suspect 'false positives' do not alter the overall outcome of the aforementioned results. As for wind direction, numerous sensitivity tests were conducted to ensure the accuracy of the circular ANOVA tests. The testing consisted of fabricating idealized datasets with known differences and creating wind roses and computing circular ANVOA tests on the datasets. The major finding of these tests was that the circular ANOVA tests are able to decipher differences between wind direction data sets that are not discernable to the eye in wind roses. In addition, the sensitivity of circular ANOVA to sensor accuracies (+/- 10 degrees) was tested and it was found that differences larger than those that may arise from sensor error range are not large enough to cause a significant difference. This was done by first creating an idealized data set. Next, the data set was duplicated and 10 or $20^{\circ}$ were uniformly added to the duplicated data set. Finally, a circular ANOVA was conducted and corresponding wind roses were made. The results from the sensitivity testing emphasize the benefit of the combination of quantitative and qualitative analyses to determine the degree of representativeness for combinations of conditions where the representativeness is difficult to decipher.

To add more insight into the understanding of the wind differences across the towers, qualitative wind rose comparisons were conducted based on varying thresholds of wind speed at the baseline site. The thresholds included $0.5-1.5 \mathrm{~m} / \mathrm{s}, 1.5-2.5 \mathrm{~m} / \mathrm{s}, 2.5-3.5 \mathrm{~m} / \mathrm{s}, 3.5-4.5 \mathrm{~m} / \mathrm{s}$, and $4.5+\mathrm{m} / \mathrm{s}$. The results from these comparisons indicate that as wind speed at the baseline site increases, the agreement of wind direction increases (figure 15). When the winds are the weakest $(0.5-1.5 \mathrm{~m} / \mathrm{s})$, which corresponds to mostly stable situations, the wind direction differences are the greatest and the differences are in agreement with the differences seen in the previous studies (i.e. more northwesterly flow at the baseline site, more southwesterly flow at the 
south and east sites) (figure 15a). As for wind speed, the wind speeds are most different between each tower and the baseline tower when flow is greater than 2.5 and less than $4.5 \mathrm{~m} / \mathrm{s}$ (figure 15c and 15d). 

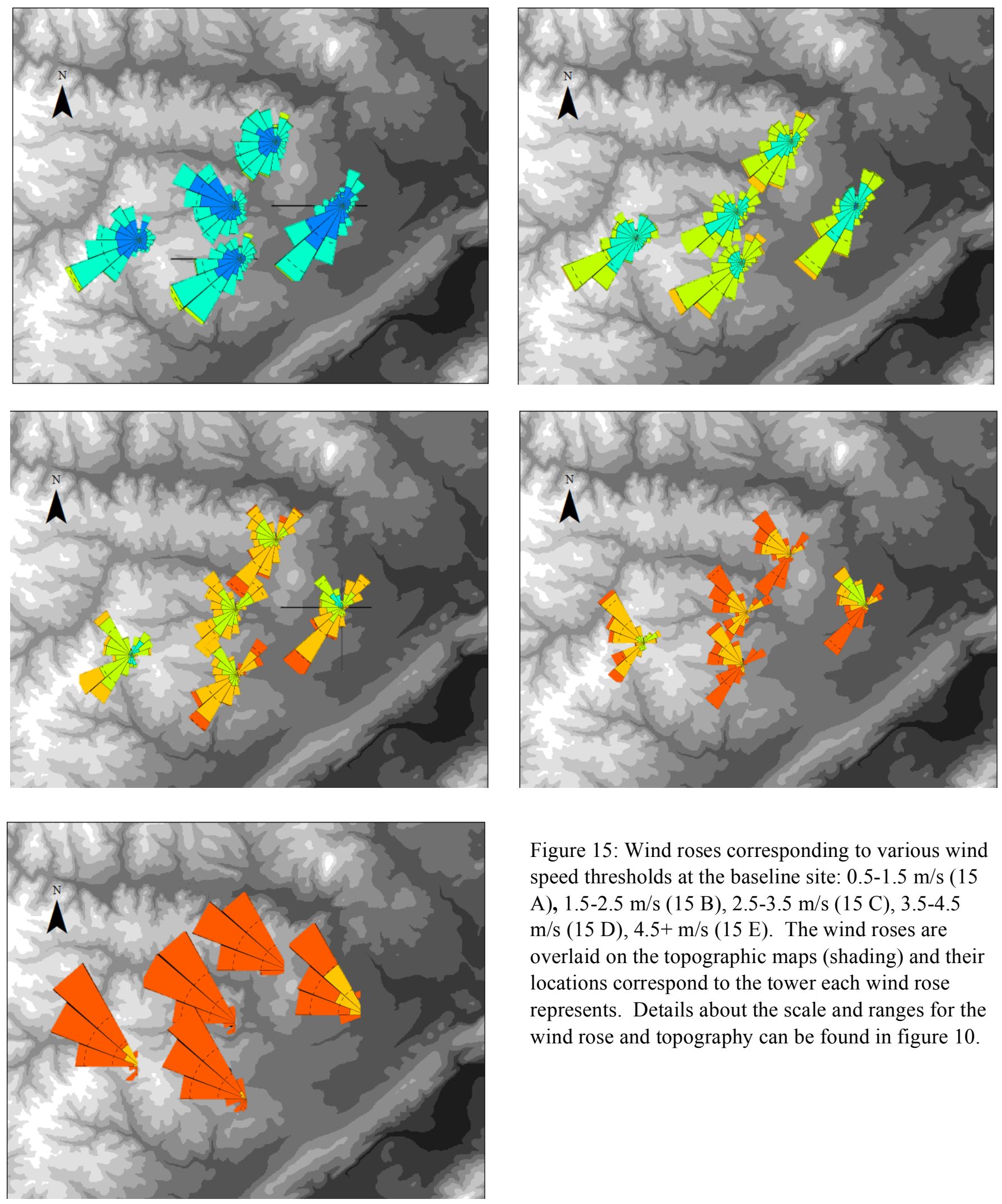

Figure 15: Wind roses corresponding to various wind speed thresholds at the baseline site: $0.5-1.5 \mathrm{~m} / \mathrm{s}(15$ A), $1.5-2.5 \mathrm{~m} / \mathrm{s}$ (15 B), $2.5-3.5 \mathrm{~m} / \mathrm{s}$ (15 C), 3.5-4.5 $\mathrm{m} / \mathrm{s}(15 \mathrm{D}), 4.5+\mathrm{m} / \mathrm{s}(15 \mathrm{E})$. The wind roses are overlaid on the topographic maps (shading) and their locations correspond to the tower each wind rose represents. Details about the scale and ranges for the wind rose and topography can be found in figure 10 . 


\subsubsection{Summary of method and assessment of baseline representativeness}

In this chapter, we determined and implemented a method for the assessment of wind representativeness in a region of semi-complex terrain. In this section, we present the method and diagnose the representativeness of the baseline tower. Based on the previously discussed findings, the recommendations made by the EPA for determining a location for baseline meteorological measurements in complex terrain prove insufficient in some regions. If the baseline site were chosen as a location for meteorological measurements meant for model input, potential errors could arise in the models during times when the baseline site is unrepresentative. For other regions, a similar method to what was carried out in this study can be conducted or the findings of this study can be applied. The steps to determine the representativeness of the baseline site can be summarized as follows:

1. Choose a baseline site to assess the representativeness based on factors such as site accessibility, proximity to the modeled region, and topography.

2. Carefully analyze a detailed topographic map of the region in question. If it appears that topographic effects play a role in the wind climatology at the baseline site, install a network of 4 meteorological towers surrounding the baseline site with a minimum of wind measurements at $10 \mathrm{~m}$. The baseline tower should contain wind measurements at $10 \mathrm{~m}$, temperature measurements at $2 \mathrm{~m}$ and $10 \mathrm{~m}$, and a pyrometer. The inter-tower distance should be determined based on the spatial scale of the modeled region and the characteristics of the potential emissions (3x3 $\mathrm{km}$ for this study) and should represent the most dominant topographic characteristics of the region.

3. Collect at least one year of measurements at all sites 
4. Obtain synoptic wind data from a pressure level that is roughly $300 \mathrm{mb}$ above the surface (in our case, the $70 \mathrm{mb}$ level), using the NARR U and V wind output from the grid box located over the baseline site. Using the synoptic wind speed and direction categories, and the stability measurements from the baseline site, subset the tower wind data based on synoptic wind speed, synoptic wind direction, and stability condition. The thresholds for the synoptic wind speed and direction variables are determined based the general direction of topographic gradient of the region. The stability parameters are determined using the SRDT method for Pasquill stability classes.

5. For every possible combination of the variables listed in step $\# 4$, create wind roses for each site and conduct t- tests (or a non-parametric equivalent) and circular ANOVA's comparing wind speed and wind direction between each site to the baseline site, respectively. If the tower wind data do not sufficiently meet the assumptions of linear or circular ANVOA, non-parametric options can be used (see Tasdan and Yeniay 2014).

6. Subjectively (qualitatively) assess the agreement of the wind roses between each site and the baseline site and objectively (quantitatively) evaluate which conditions cause statistically significant differences in wind direction between each site and the baseline site.

7. Determine which combinations of conditions cause the most (representative) and least (unrepresentative) agreement between each site and the baseline site, placing most emphasis on the objective results, but using the subjective results as a verification or reenforcement of the results. 
All aforementioned steps were taken in the assessment of the representativeness of the baseline site in Chatham, VA.

With respect to moderately and extremely stable conditions, the differences in winds between the baseline site and the additional sites were surprisingly large for a region with relatively small topographic relief. This finding could be valuable to other endeavors attempting to identify a representative location in moderately complex terrain. In general, the results of this analysis show that if the relative topographic relief of a roughly $3 \times 3 \mathrm{~km}$ region is on the order of $50-100 \mathrm{~m}$ or greater, similar to the Chatham region, it can be expected that topographic induced flows will be prominent enough to influence the representativeness of wind measurements under stable conditions at any location in this region. In particular, nearby topographic features should be analyzed. For the determination of a representative site for wind measurements, it is also important to consider surrounding topographic features, such as larger ridges, that could cause channeling or drainage flow effects. We found that a ridge with a relief on the order of $150 \mathrm{~m}$ located in close proximity $(7 \mathrm{~km})$ of a tower can significantly change the measurements at $10 \mathrm{~m}$ AGL. Keeping in mind the findings of this study, a representative location could be identified from a detailed topographic map of the region where 1) the site is in an ideal location based on the aforementioned criteria (Section 1: Introduction), 2) the site is at least a few kilometers away from any nearby prominent topographic features that have the ability to impact the wind climatology and 3) the site is on a characteristic topographic gradient with respect to the general topography of the modeled region. Alternatively, another possibility for the collection of representative wind measurements would be to take measurements from a taller tower $(>10 \mathrm{~m})$ where the winds are less influenced by the underlying topography. Further investigations, including intensive field experiments and WRF model runs, were carried out to gather more 
information about the representativeness of the winds above the $10 \mathrm{~m}$ height at the baseline site in situations when $10 \mathrm{~m}$ winds are expected to be unrepresentative. The results and discussion of these investigations are included in the subsequent chapters.

\subsection{Field campaigns and WRF model runs}

A number of field campaigns were conducted during conditions identified to cause the least representative 10-m wind measurements at the baseline site (stable and synoptically quiescent) based on the aforementioned statistical analyses and the detailed literature review. The goal of the field campaigns was to use tethered balloon profiles to identify whether different topographic flows impact the baseline and south sites simultaneously and how these flows change vertically. Since the south site tends to be especially different in terms of winds compared to the baseline site, tethered balloon profiles were collected at the two sites during each field campaign. More specifically, the south site was selected because this site exhibits more flows from the southwest compared to the baseline site during stable conditions. This increased southwest flow is presumably caused by the presence of the ridge to the south of the towers that is obvious at the south and east towers and not at the baseline tower (figure 11e). The east site would have been an appropriate location as the second tether balloon site as well, but the south site was chosen because of the close proximity of the south site to the baseline site and the easy access of the south site compared to the east site. The large differences in wind characteristics between the south and baseline sites and the logistical benefits of the south site made this site the most ideal location for the second tethered balloon. The wind characteristics observed in the profiles were used to identify any possible terrain induced flow features at either site. In addition, the profiles provided a comparison between the winds at the two sites at the $10 \mathrm{~m}$ height and the $30 \mathrm{~m}$ height. These comparisons are important because one option for the collection of representative wind 
measurements is to use a tower at the $30 \mathrm{~m}$ height that is, ideally, situated above any terrain induced flow features. Three campaigns were conducted and subsequently simulated using the WRF model. The WRF simulations are meant to provide additional details about the flow characteristics at and around each of the five sites during each field campaign night. The WRF simulations are beneficial because they can show the 'big picture' flow patterns over the region of interest.

The following sections outline the synoptic and surface meteorological conditions, wind speed, direction and temperature profiles made from tethered balloon soundings, and the results from WRF model simulations for each night. At times the WRF simulations portray different wind scenarios that are not detected with the tethered balloon soundings. These differences are attributed to the intermittent nature of nocturnal drainage flows and the inability of the tethered balloon instrumentation to detect winds below a calm threshold of $0.5 \mathrm{~m} / \mathrm{s}$. Also, the WRF model results must be looked at with some apprehension since WRF can sometimes have difficulty resolving flow details at scales less than a few kilometers, especially under stable conditions. More specifically, a rule of thumb is that WRF can resolve 5-7 times or larger the horizontal resolution, or delta $\mathrm{X}$ of the WRF model run. For the model runs included in this thesis, delta $\mathrm{X}$ is $1 \mathrm{~km}$ for the inner-most domain of the model. Therefore, the tethered balloon measurements and the WRF model simulation output are used in combination to explain the representativeness of the baseline site during the field campaign nights.

The specific method for forecasting the field campaign nights is outlined in the methods section 2.8. In general, the field campaign nights were selected based on specific criteria: synoptically weak winds, synoptic flow not from the northwest, and clear, stable conditions. Based on the previous wind rose analysis, it was expected that under clear, calm and stable 
conditions the southern site would exhibit a terrain induced flow mostly from the southwest while the baseline site would show a northwesterly terrain induced flow. It was also expected that the south site could potentially also show a terrain induced flow from the northwest, similar to the baseline site. This is because the wind roses also show that a terrain induced flow from the northwest is evident to some extent at each site. In addition, a climatology of $50+$ clear nights that occurred between September 2012 and August 2013 was done to analyze differences in 10 $\mathrm{m}$ wind direction and wind speed between the baseline and the south site (figure 16). The clear nights were selected based on the incoming solar radiation curves, $10 \mathrm{~m}-2 \mathrm{~m}$ temperatures, and synoptic weather maps for each night. If the solar radiation curves before and after a particular night showed little evidence of clouds, if the vertical temperature was positive, and if no significant wind producing weather features (i.e. tightly packed isobars) were evident on the synoptic maps, the night was considered to be clear. It was found that the baseline site consistently experienced more westerly/northwesterly flow compared to the south site, which showed more southwesterly flow. The differences were steady throughout the night and were on the order of $10-20$ degrees. The differences in wind direction would begin around 19 LST and would cease around 8 LST. For the same times, the wind speed remain around $1 \mathrm{~m} / \mathrm{s}$ and the south site exhibits slightly stronger winds compared to the baseline site. 

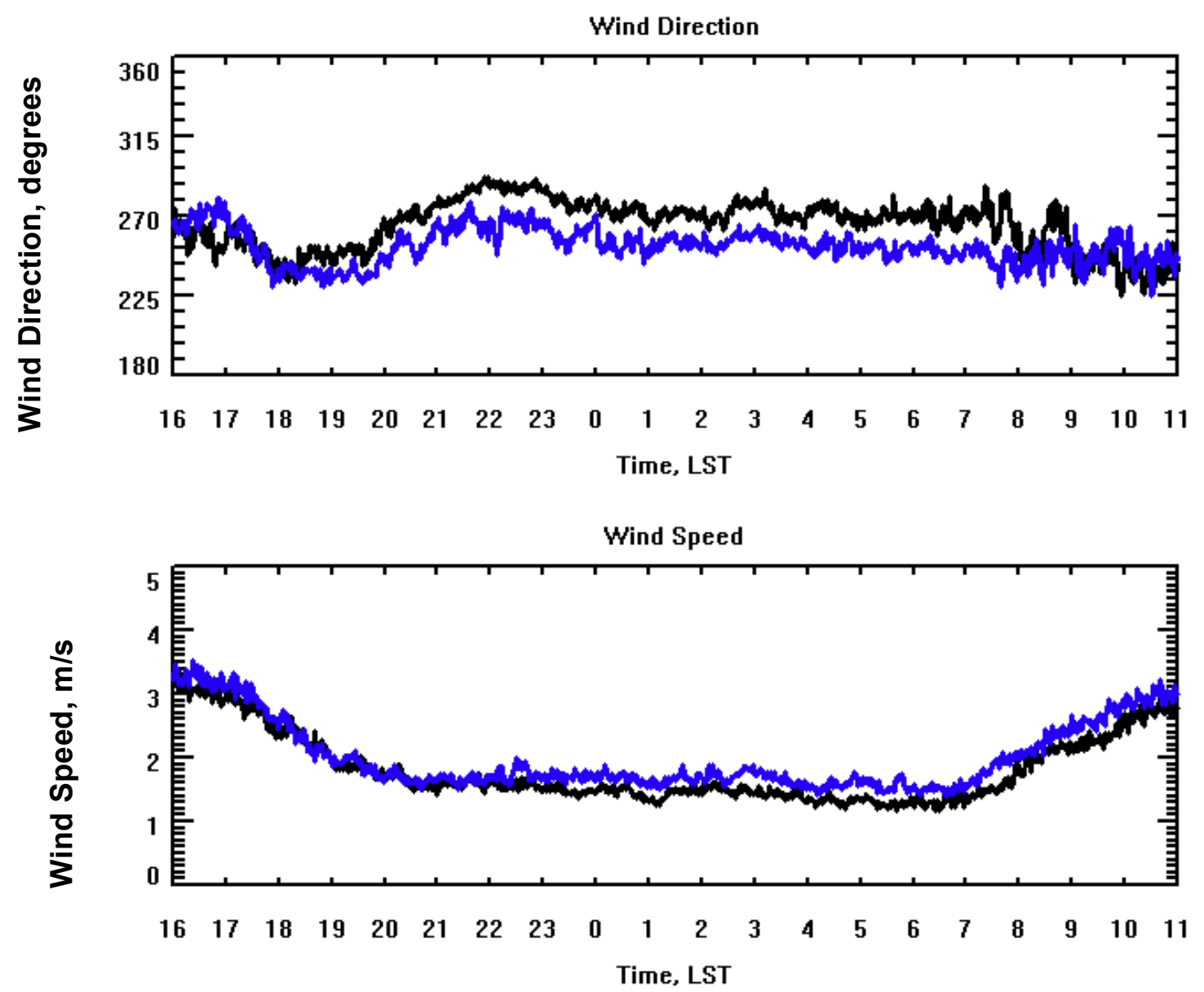

Figure 16: Climatology of winds during the night for clear nights (16 LST - 9 LST) between September 2012 and August 2013 for the central (black) and south (blue) sites. For each clear night, the wind direction (top) and speed (bottom) was averaged per hour.

\subsubsection{Field Campaign \#1: August 14-15, 2013}

\subsubsection{Synoptic and surface weather patterns}

During the first field campaign, there was a large center of high pressure located over the Ohio Valley (figure 17), which directly influenced the weather patterns in southern Virginia. A cold front had crossed the eastern seaboard days prior to this night, which led to relatively weak synoptic flow and clear skies and the location of the aforementioned high pressure system on the 
night of August 14. The day prior to this field campaign was characteristic of weak surface winds $(>3 \mathrm{~m} / \mathrm{s}$ ) from the northwest, with a shift to east/ northeast for most of the day (figure 18). There were some clouds present both the day before and after the field campaign. The winds during the day following the campaign were relatively weak and from the east/northeast, although the towers showed weak northwesterly flow during the night itself. The synoptic flows, based on NARR model output, were relatively weak $(<6 \mathrm{~m} / \mathrm{s})$ from the northwest, shifting to the east/northeast, throughout the day before the experiment, relatively weak and from the west during the night and relatively weak and from the west, shifting to northeast on the day following the campaign. This night experienced the weakest synoptic flow out of the three field campaigns. Based on the $10 \mathrm{~m}$ tower measurements, the evening progressed from stability class B (moderately unstable) to E (slightly stable) between 17 LST and 20 LST. All times after 20 LST, and before sunrise, were characterized by stability class F (moderately stable).

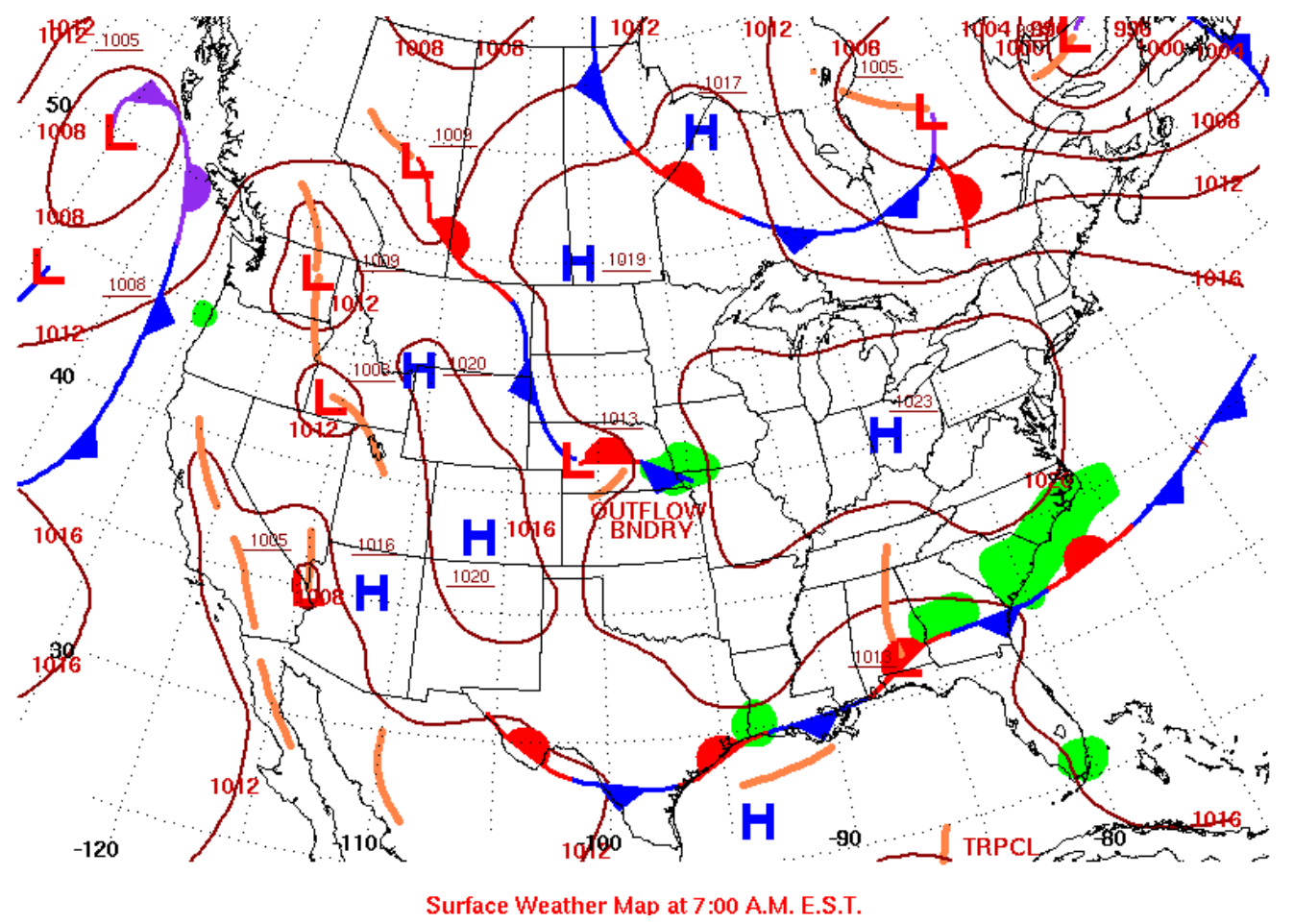

Figure 17: A synoptic weather map that is valid at 07:00 LST on August 15, 2014. 

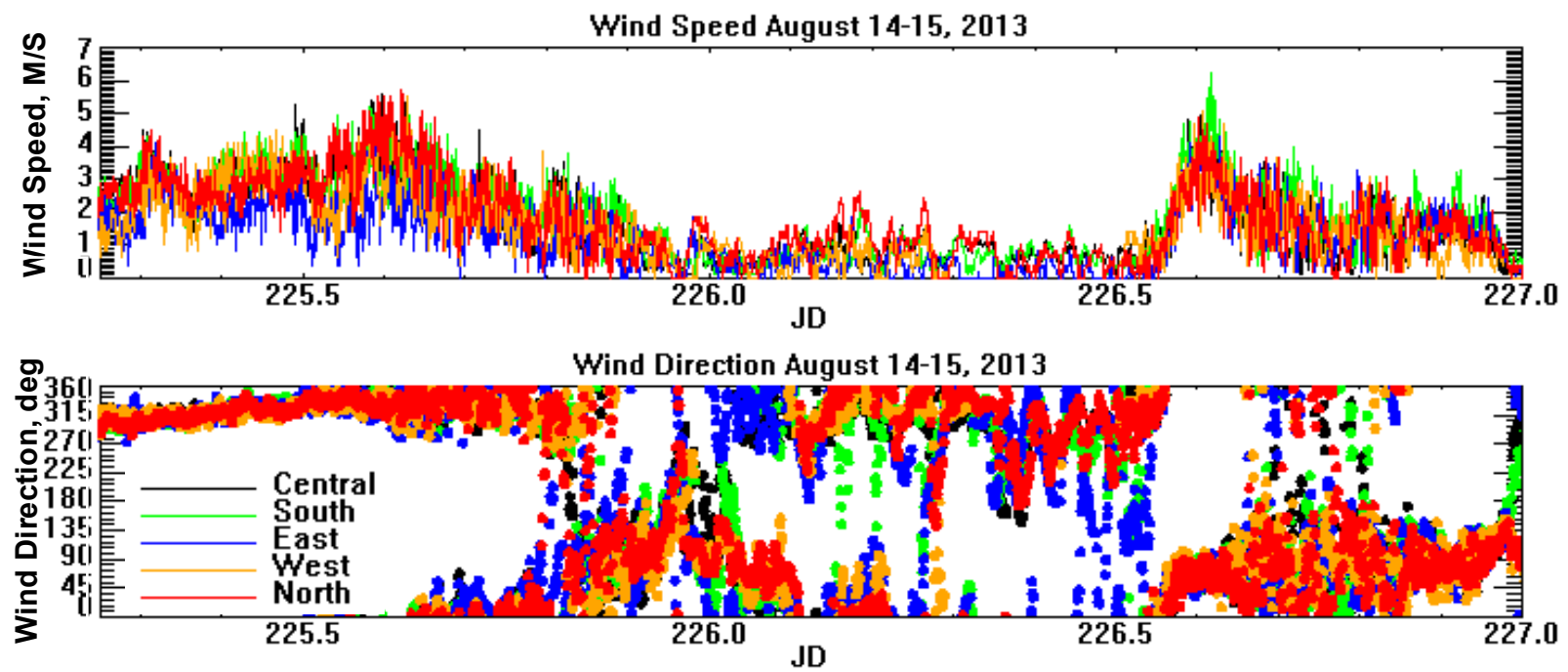

Solar Radiation August 14-15, 2013
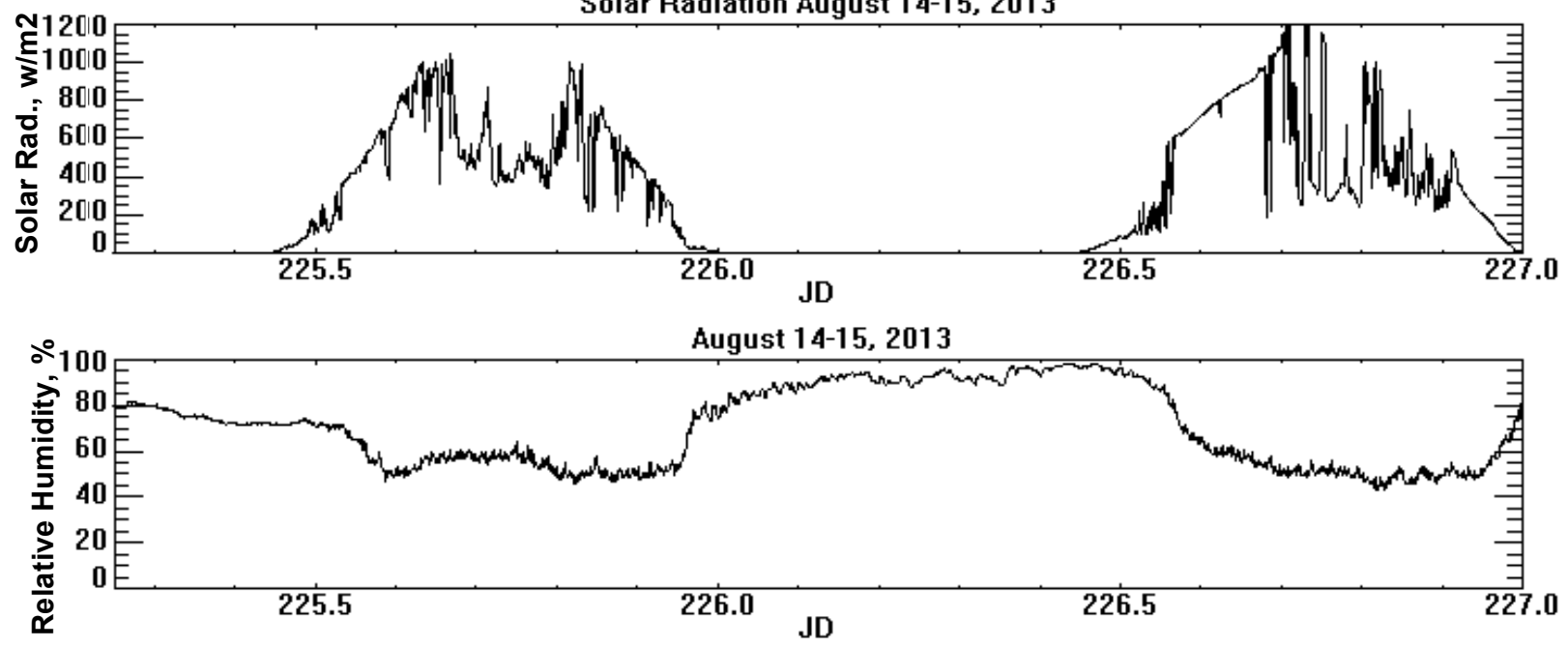

$10 m-2 m$ Temp August 14-15, 2013

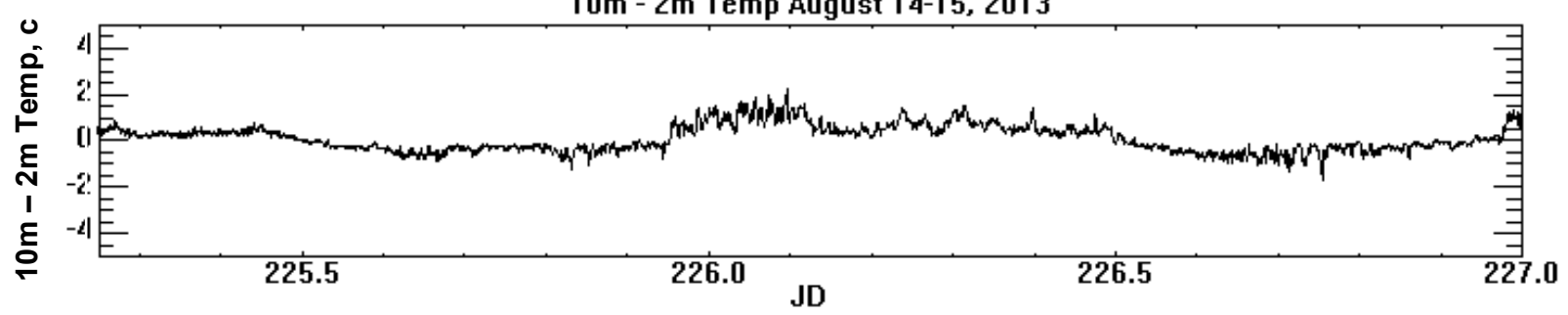

Figure 18: Tower measurements for the day before, the night of, and the day after the field campaign \#1. Each tower is represented with a different color for wind speed and direction and only solar radiation measurements, $\mathrm{RH}$ at $10 \mathrm{~m}$, and $10 \mathrm{~m}-2 \mathrm{~m}$ temperature are shown for the baseline site. 


\subsubsection{Field measurements during field campaign \#1}

During field campaign \#1, a total of 13 profiles were completed, as indicated in table 9. Each profile extended from the surface to the 100m AGL height. Large differences in the potential temperature profiles between the two sites were not clearly detectible for this night and vertical differences, between 0 and $100 \mathrm{~m}$, of about 4-5 K were observed (figure 18). The night was considered less stable compared to the other two nights given the weak temperature gradient between 0 and $100 \mathrm{~m}$ at each site throughout the night. Outstanding differences in wind speed were not evident between the two sites. All profiles showed weak and often calm winds at the surface with a gradual increase in speed with height (figure 19). Overall, the south and baseline sites portrayed similar shifts in wind direction from southerly flow at the start of the night throughout the profile to more northwesterly flow from $0 \mathrm{~m}$ to $20 \mathrm{~m}$ shifting to northeasterly flow above $20 \mathrm{~m}$ for the later profiles (figure 20). 

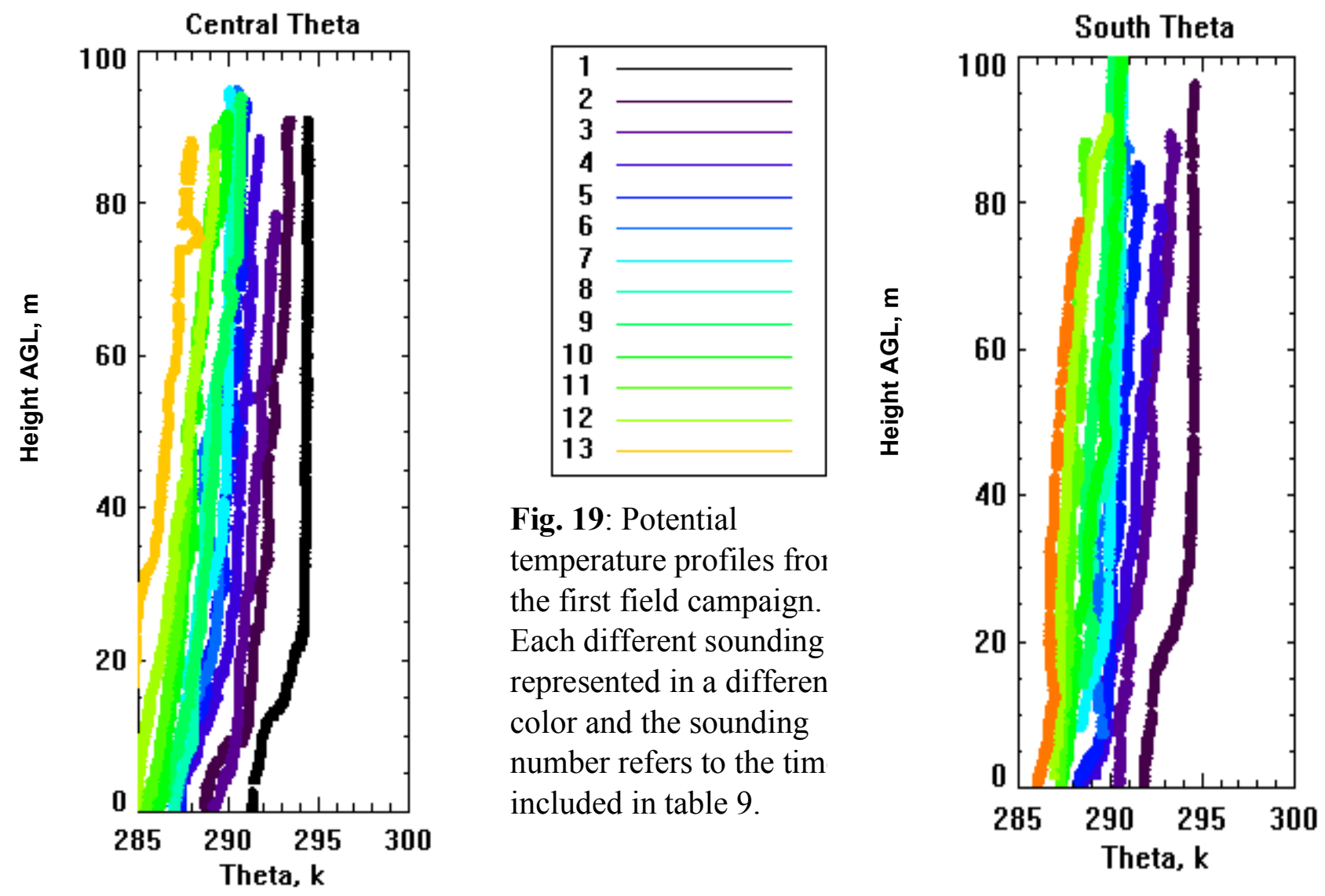
Table 9: The times of each tethered balloon sounding for the night of August 14-August 15 (Field campaign \#1).

\begin{tabular}{|c|c|}
\hline Profile Number & Profile Time (LST) \\
\hline 1 & $19: 20$ \\
\hline 2 & $20: 07$ \\
\hline 3 & $20: 55$ \\
\hline 4 & $21: 47$ \\
\hline 5 & $22: 30$ \\
\hline 6 & $23: 34$ \\
\hline 7 & $00: 08$ \\
\hline 8 & $00: 55$ \\
\hline 9 & $01: 37$ \\
\hline 10 & $02: 19$ \\
\hline 11 & $03: 00$ \\
\hline 12 & $04: 03$ \\
\hline 13 & $05: 00$ \\
\hline
\end{tabular}




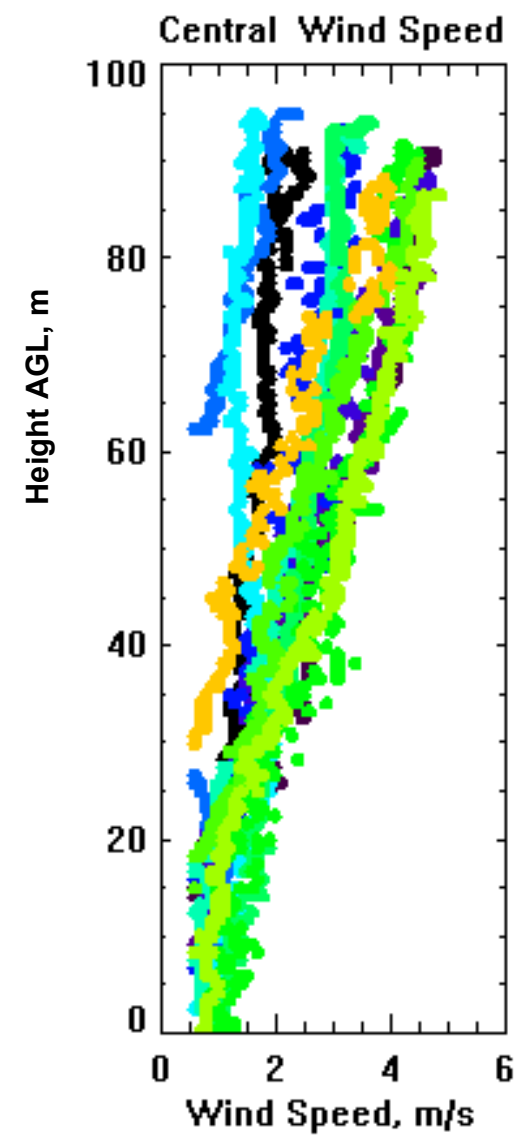

Central Wind Direction 100 गाता

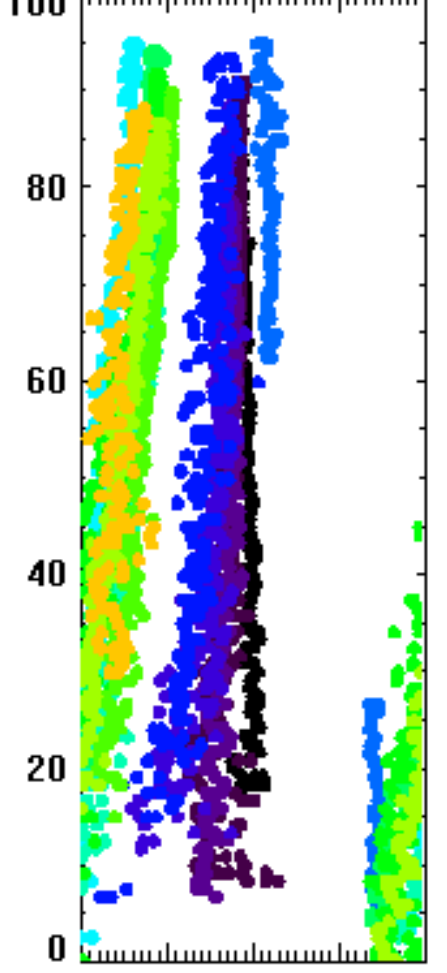

$\begin{array}{lllll}0 & 90 & 180 & 270 & 360\end{array}$ Wind Direction, degrees

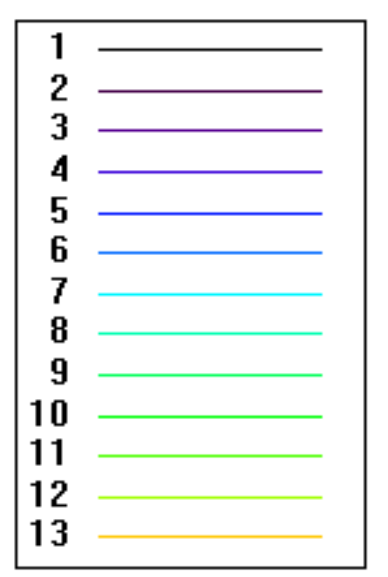

Fig. 20: Wind speed profiles from the first field campaign. Each different sounding is represented in a different color and the sounding number refers to the times included in table 9.
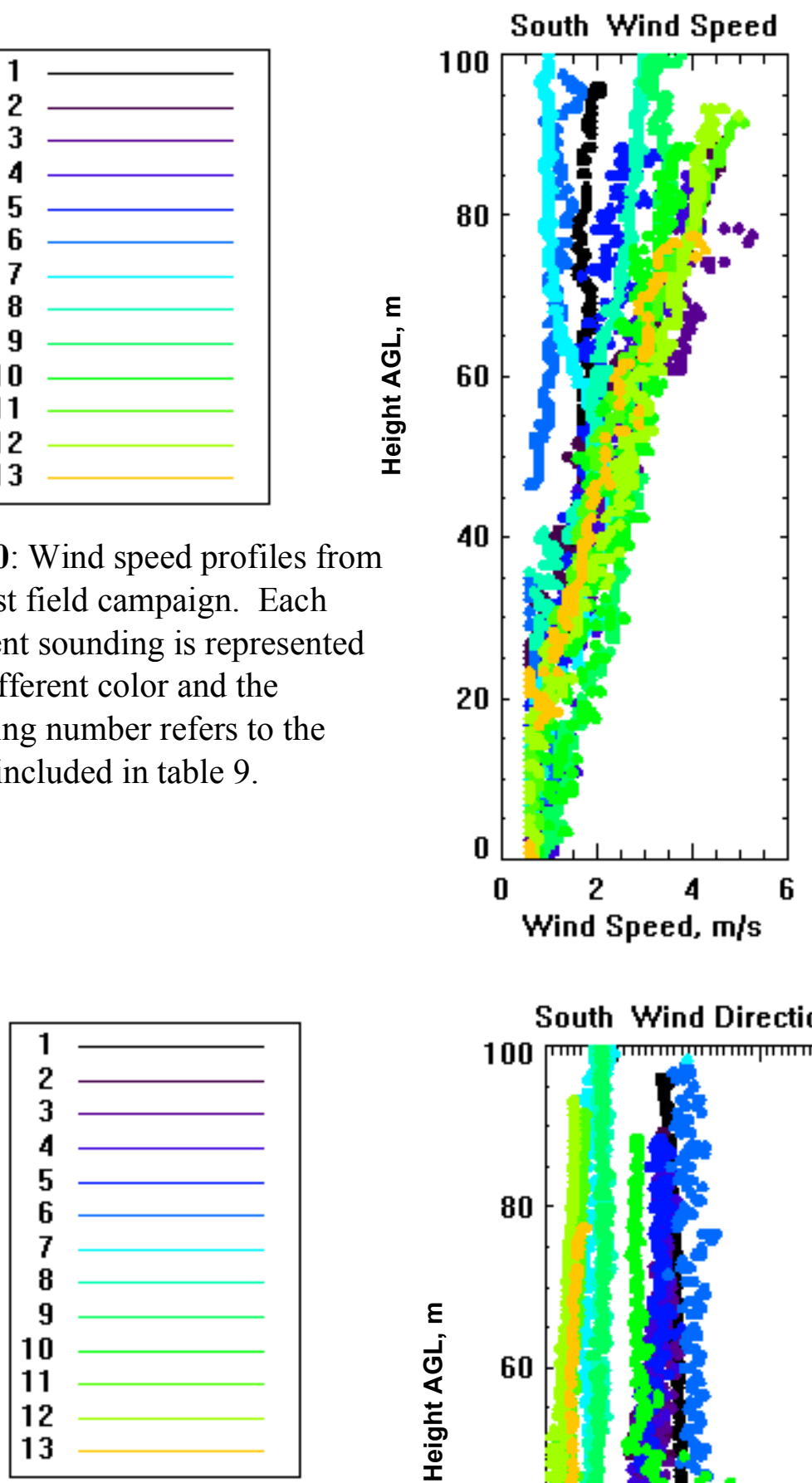

Fig. 21: Wind direction profiles from the first field campaign. Each different sounding is represented in a different color and the sounding number refers to the times included in table 9 .

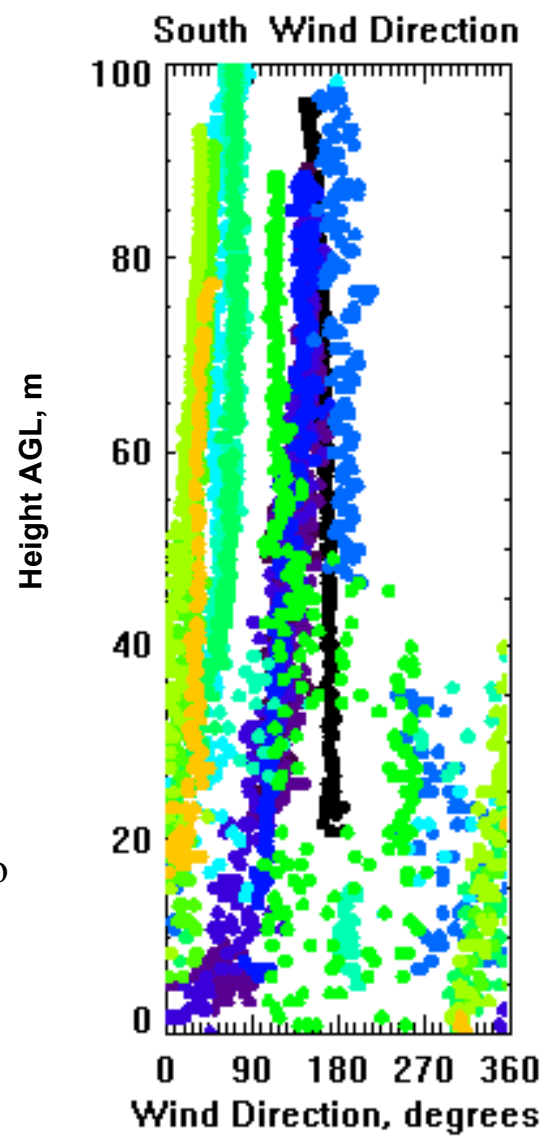


Subtle differences in the wind direction profiles revealed that different flows were occurring simultaneously at each site. For example, during the profile completed at 02:20 LST, the south site reports wind direction measurements between 90 and 270 degrees, while the baseline site reports wind directions between 300 degrees and 20 degrees near the surface (figure 22). During this profile, the wind speeds are relatively uniform between the two sites at $2 \mathrm{~m} / \mathrm{s}$ near the surface and increasing to $4 \mathrm{~m} / \mathrm{s}$ at the top of the sounding.
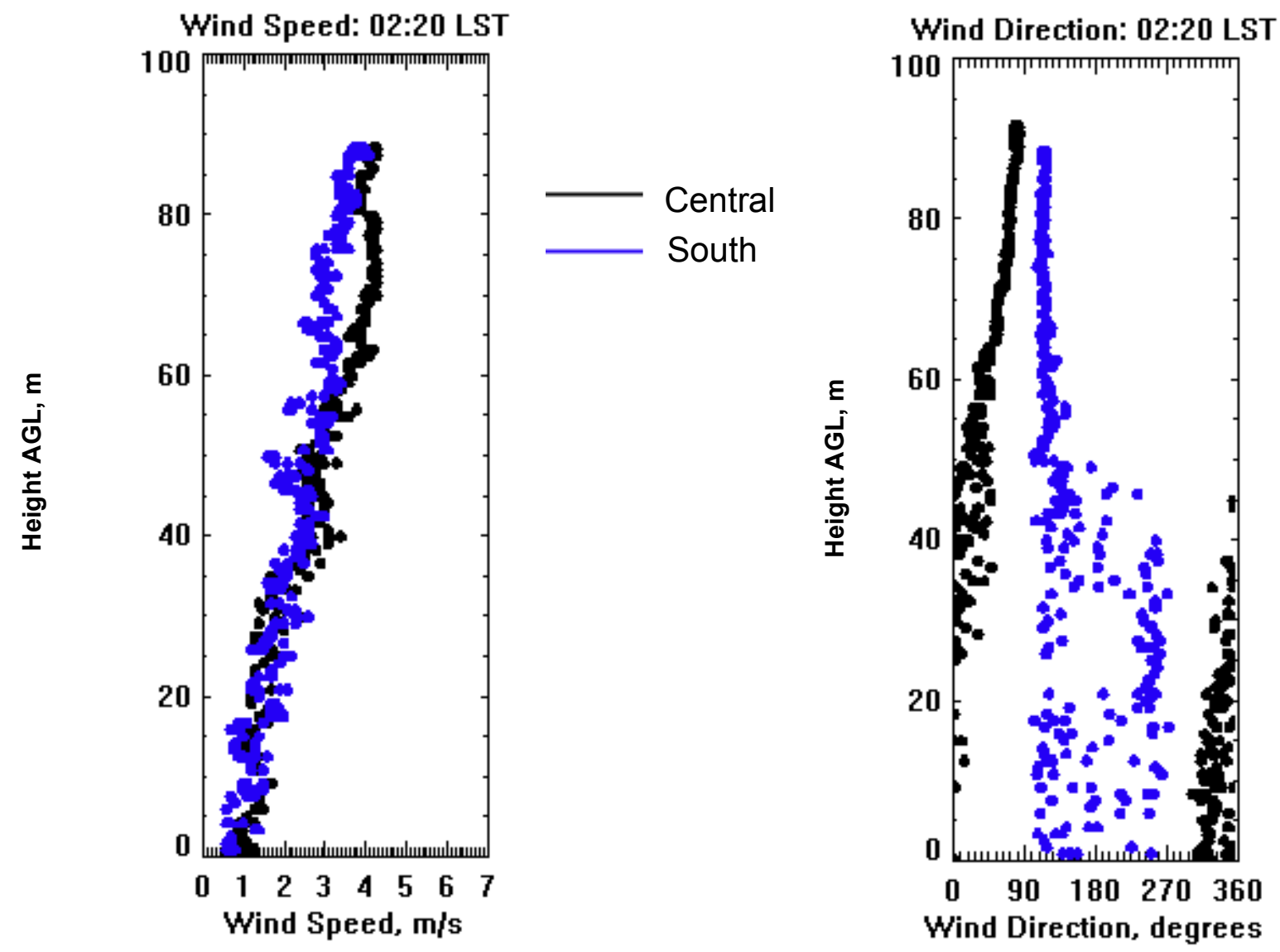

Figure 22: Wind speed (left) and direction (right) profiles for the $11^{\text {th }}$ profile of field campaign \#1. This profile occurred at 02:20 LST. 
During this night, a regional drainage flow turned the winds at the surface from the northeast direction to the north/northwest direction. Based on the profile and $10 \mathrm{~m}$ tower data, this drainage flow was felt earlier at the baseline site compared to the south site. This can be attributed to the proximity of the baseline site to the large slope to the west of the towers (figure 2, A), which amplifies the drainage flow locally, compared to the south site.

\subsubsection{WRF model simulation of field campaign \#1}

A 30-hour WRF model simulation was conducted for the field campaign \#1 starting at 12 UTC August 14, 2013. The results show the initiation of a regional drainage flow at $10 \mathrm{~m}$ height as the winds shift from northeasterly to northerly as the night progresses (figure 23). Although the tower and profile wind data show winds shifting to the northwest, the model does not fully resolve the regional flow and only shows the winds shifting to the north. This flow is described as regional since there are no significant wind direction differences over the entire region where the towers are located and the wind shifts equally within the proximity of the towers. At the onset of sunrise, the winds return to the northeasterly direction as the incoming solar radiation begins to break up the stable nocturnal boundary layer. To confirm that this wind shift is caused by the regional topographic gradient, the wind vectors from roughly the $30 \mathrm{~m}$ height were plotted in the same manner as the $10 \mathrm{~m}$ winds (figure 24). In these figures, as the night progresses, the wind shifts only slightly from east to northeast at the $30 \mathrm{~m}$ height, indicating that there is only a slight presence of this regional drainage flow at the $30 \mathrm{~m}$ height. Therefore it is concluded that a regional drainage flow caused the $10 \mathrm{~m}$ winds to shift more north/northwesterly during the night and was less influential at the $30 \mathrm{~m}$ height. 

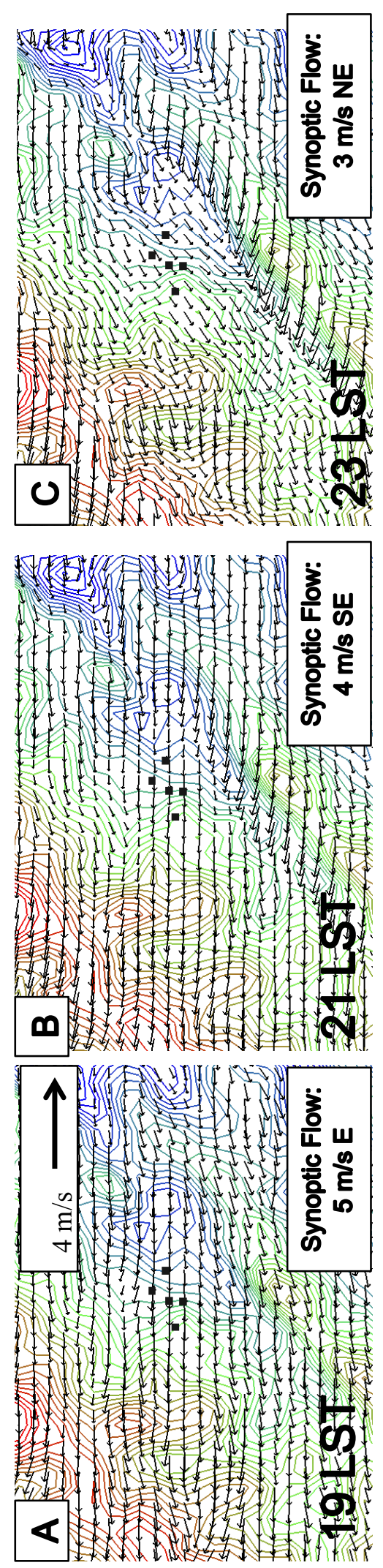

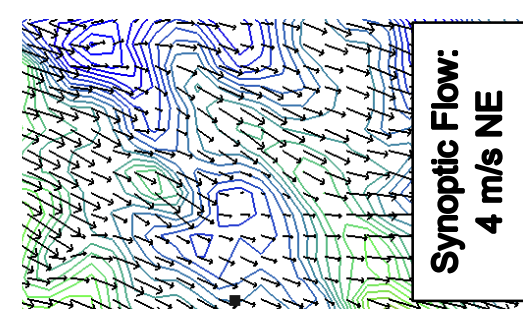

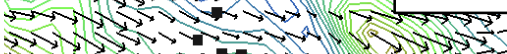

है

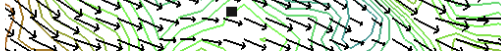

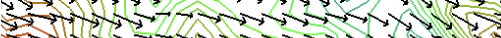

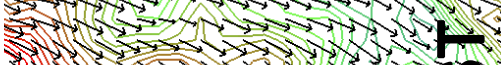

1. 100

- $12 \times 1$

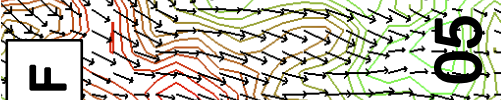
$\rightarrow-1$
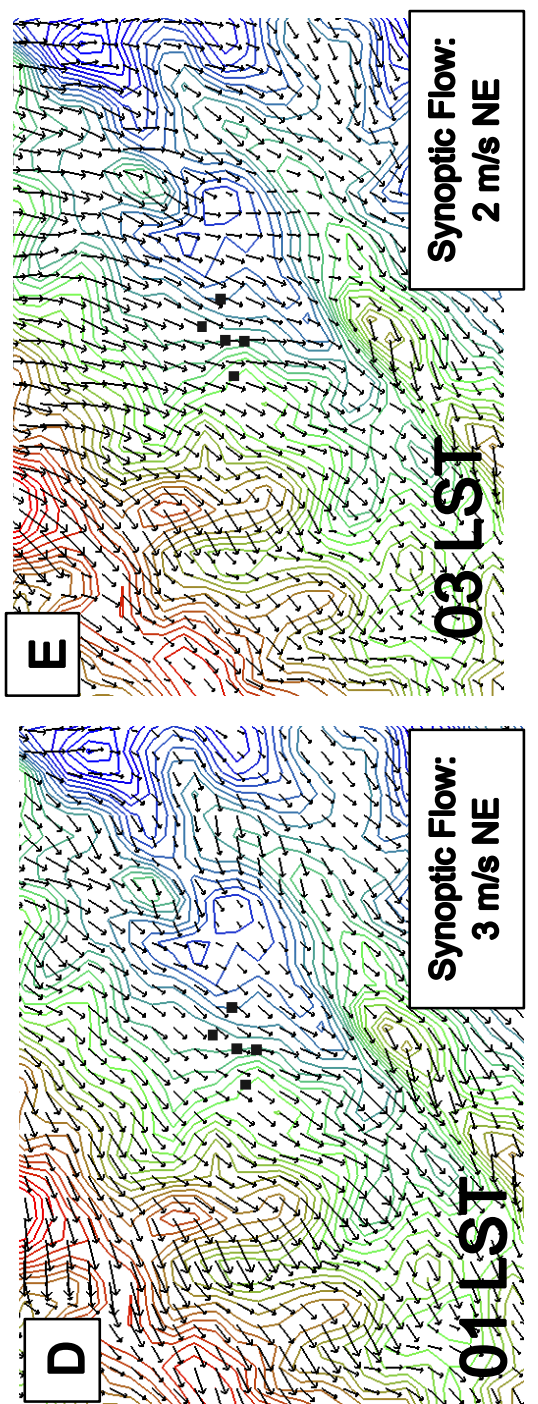

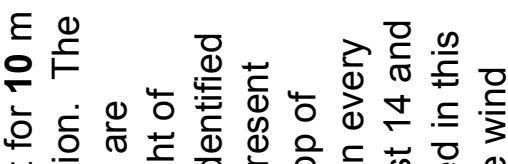

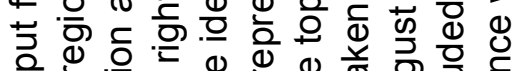

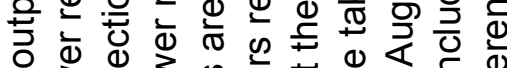

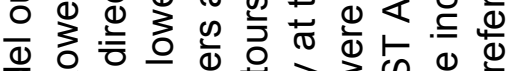
政。

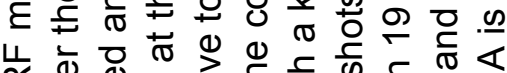

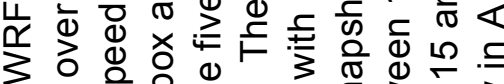
o

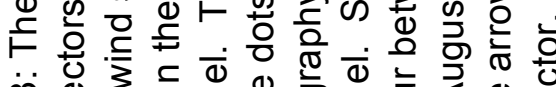
i 0

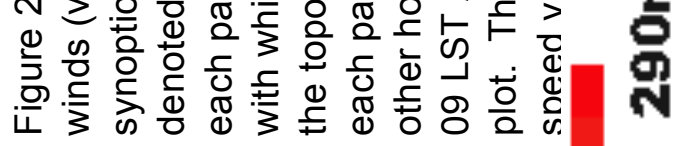
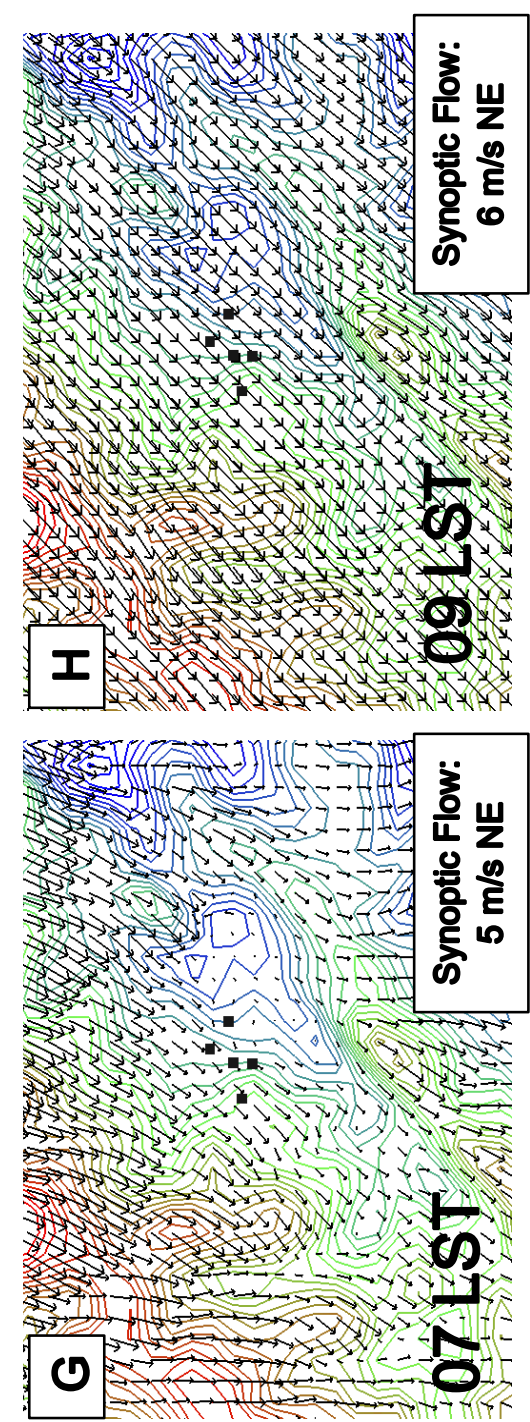

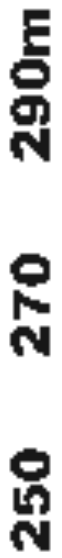

ำ

읏

号

P

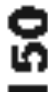

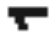



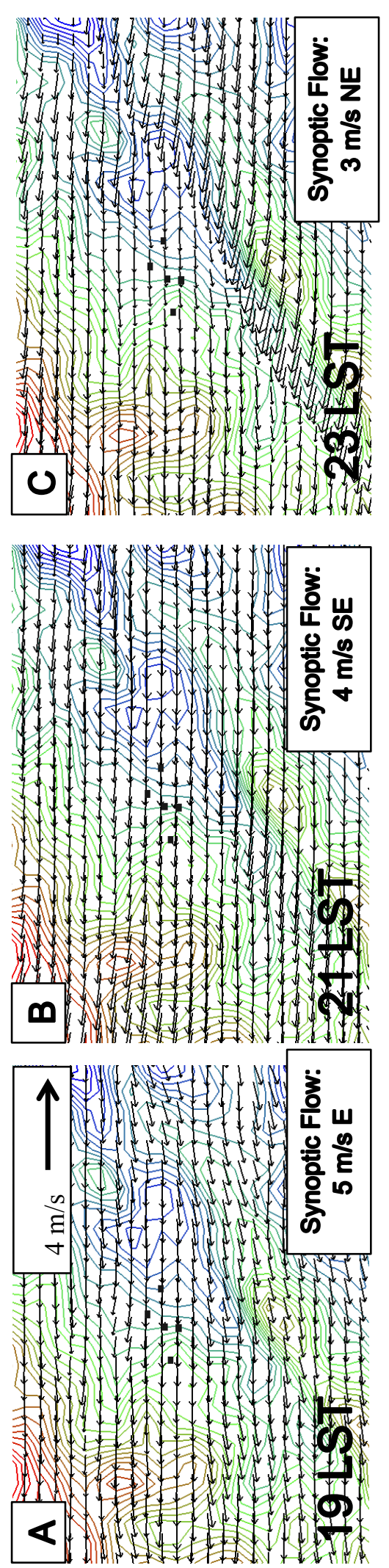
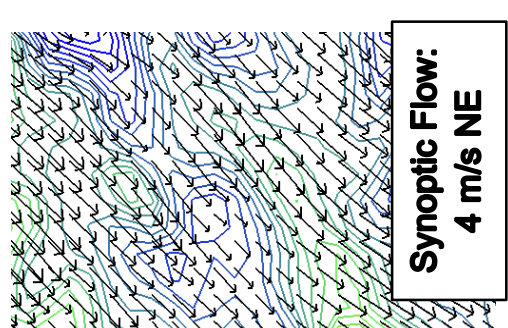

$, 1, \ldots,+, \ldots, y, 1,1$

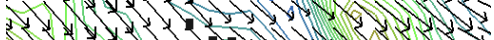
$1+x-1,1,1,12$

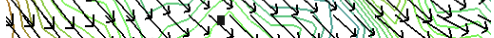

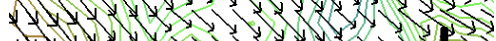

$5 \times 1,2,2,2,13$

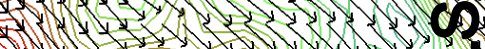

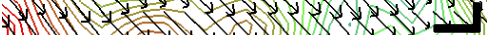

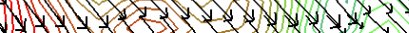

in

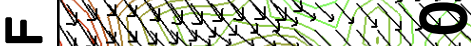
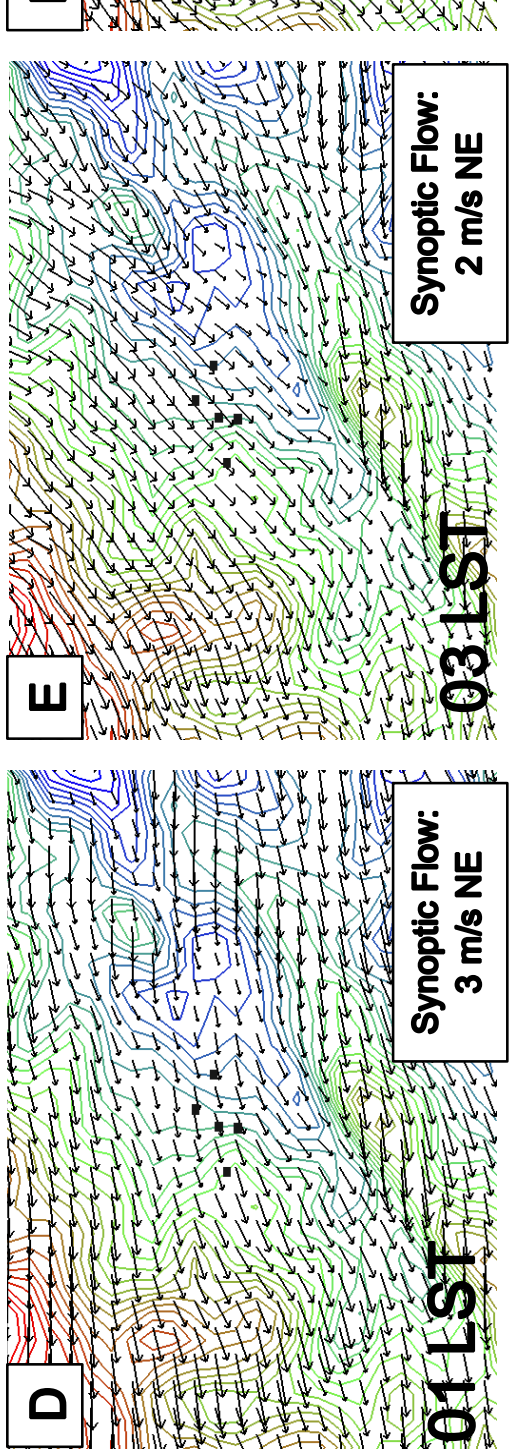

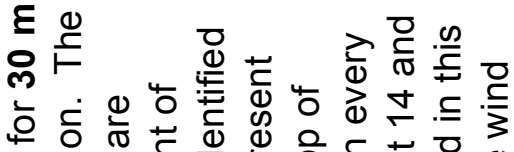

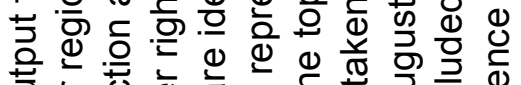

ठ

ब

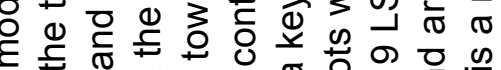

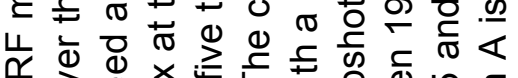

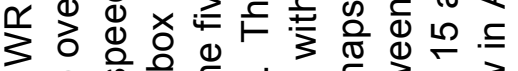

ब की की

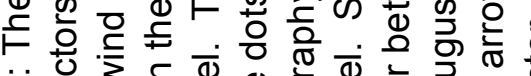

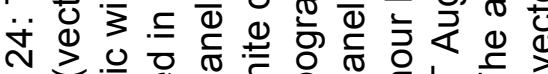

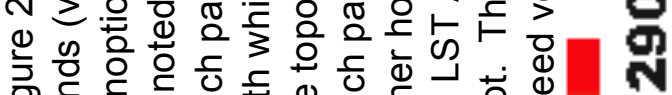

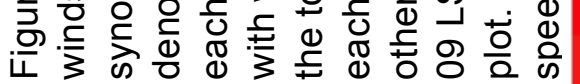

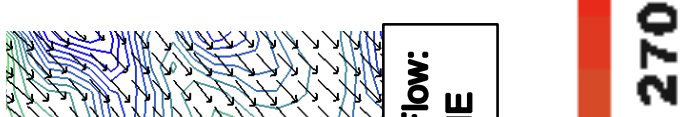

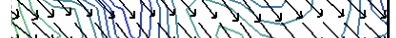

, $1,1,1, y$

$41,1,1,1,1$

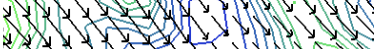

1. $12 \times 1 \times 1$

๘

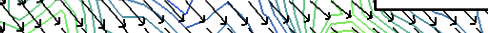

$1,1,+,-1,1,0,1,1$

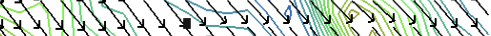

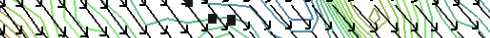

1 $+1,+1,1,1,1,1$

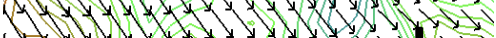

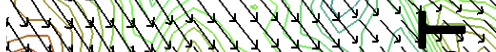

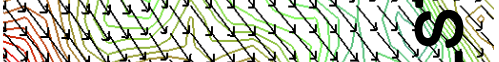

(1) $1,1,1,1$

I H

I

$\frac{9}{N}$

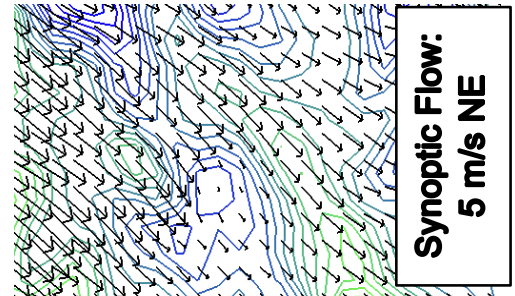

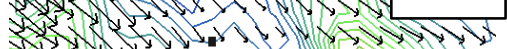

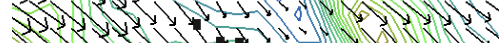

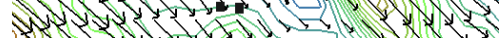

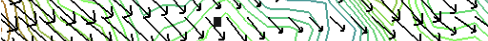

a 140 


\subsubsection{Field Campaign \#2: April 9-10, 2014}

\subsubsection{Synoptic and surface weather patterns}

The synoptic set up for field campaign \#2 was unique compared to the other field campaigns with a large low pressure system centered over central Canada (figure 25). High pressure was centered over the southeast, which directly impacted the synoptic flow regime. Relatively weak $(10-12 \mathrm{~m} / \mathrm{s})$ northwesterly synoptic flow existed over the region the day before, the night of, and the day after the field campaign. This field campaign night experienced the strongest synoptic flow. The days before and after the field campaign experienced stronger winds, from the northwest, compared to the first field campaign with surface flows larger than $5 \mathrm{~m} / \mathrm{s}$ (figure 26). During the night, the winds were weak and often reduced to calm and were variable from northwest to southwest at the towers. This night remained clear throughout with a strong nocturnal stable boundary layer development. During the evening prior to the experiment, the PG stability class, based on the $10 \mathrm{~m}$ tower measurements, changed from $\mathrm{D}$ (neutral) to $\mathrm{E}$ (slightly stable) between 17 LST and 20 LST. After 20 LST, and before sunrise, the stability class was characterized as F (moderately stable). The day prior to this field campaign had some cloud presence and the following day was clearer. 


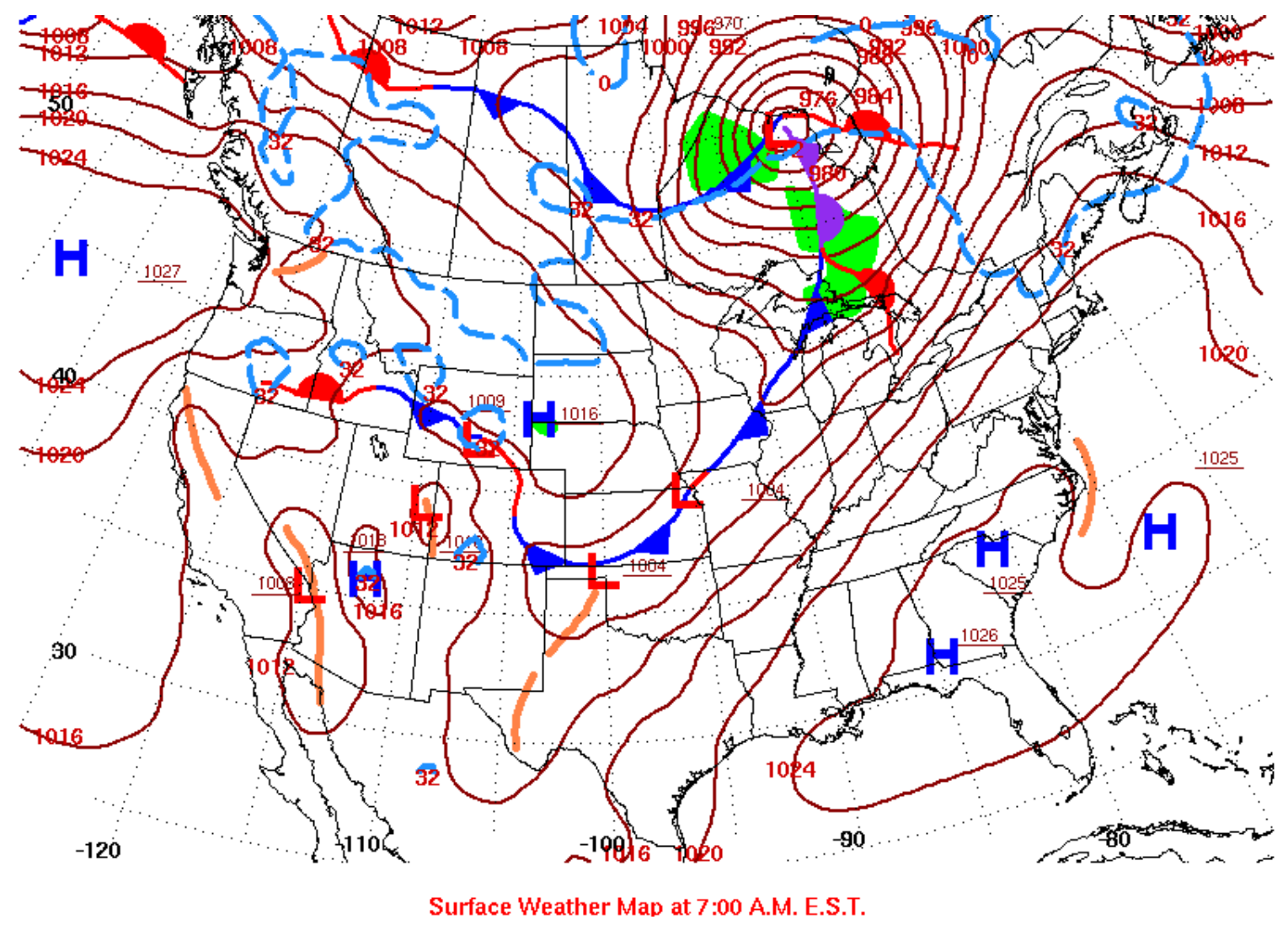

Figure 25: A synoptic weather map that is valid at 07:00 LST on April 10, 2014. 

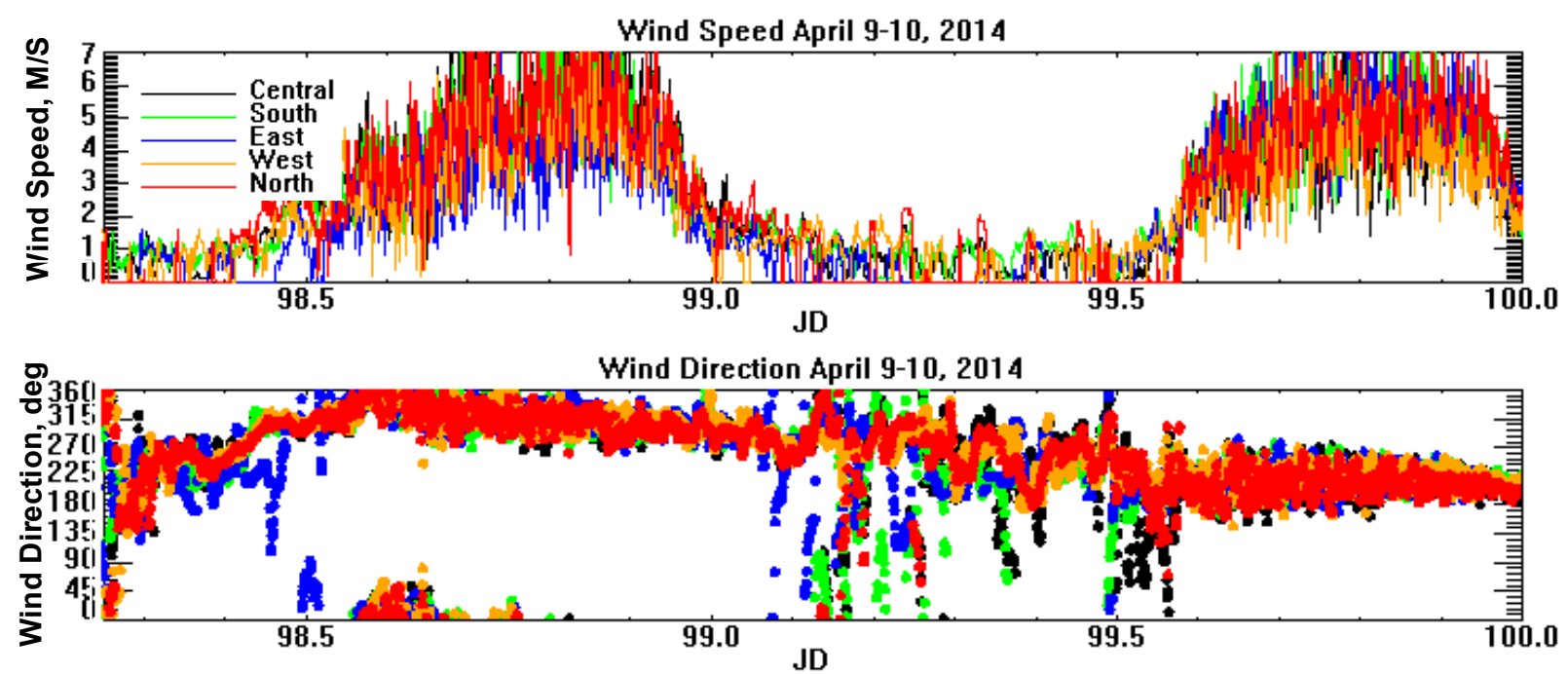

Solar Radiation April 9-10, 2014
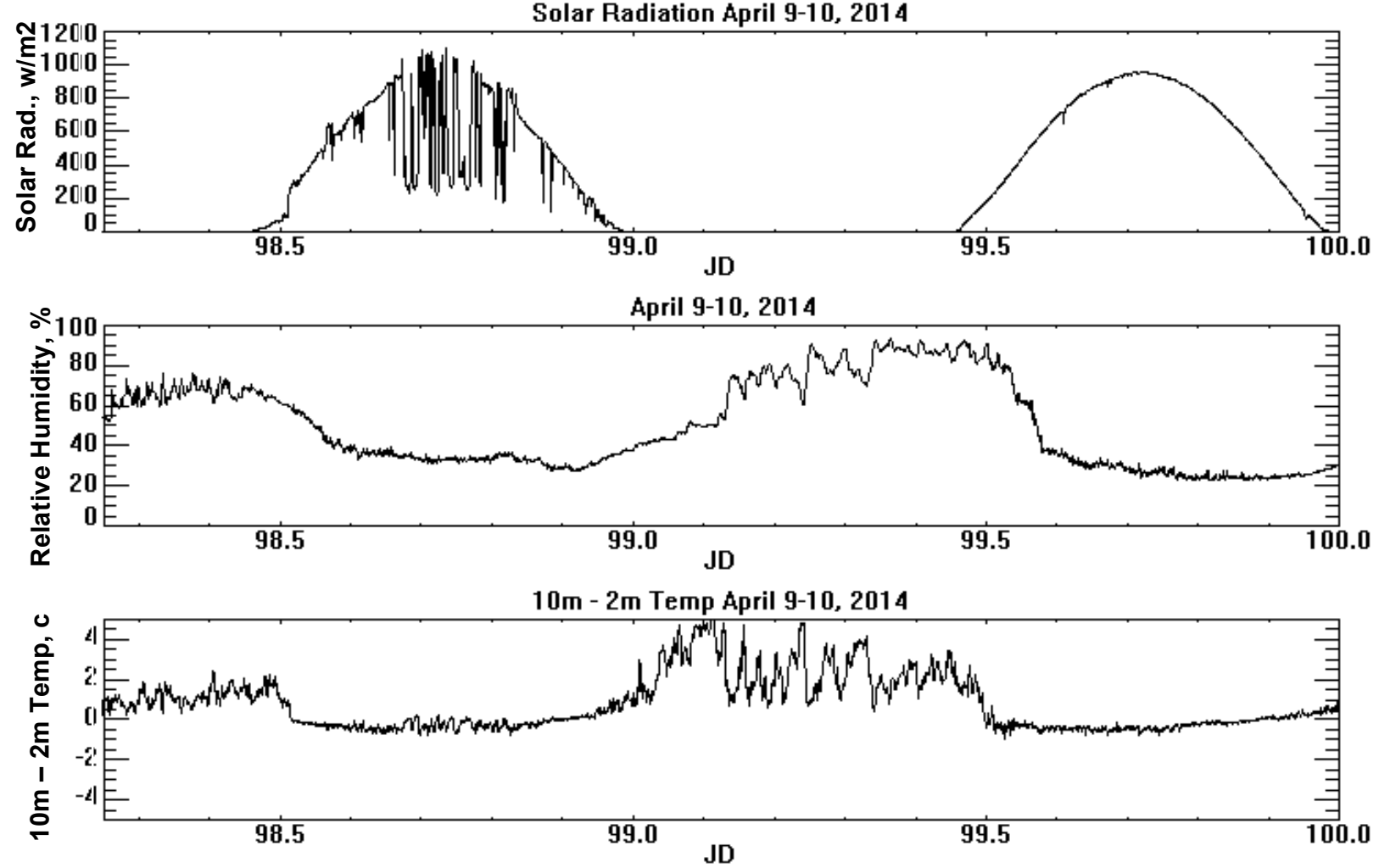

Figure 26: Tower measurements for the day before, the night of, and the day after the field campaign \#2. Each tower is represented with a different color for wind speed and direction and only solar radiation measurements, $\mathrm{RH}$ at $10 \mathrm{~m}$, and $10 \mathrm{~m}-2 \mathrm{~m}$ temperature are shown for the baseline site. 


\subsubsection{Field measurements during field campaign \#2}

12 profiles were conducted during field campaign \#2 (Table 9). This night observed the strongest stable boundary layer development out of all three field experiments, with temperature differences on the order of 8-9 $\mathrm{K}$ throughout the $100 \mathrm{~m}$ profile (figure 27). The wind speeds on this night were somewhat stronger compared to the other nights with speeds that ranged from calm to $4 \mathrm{~m} / \mathrm{s}$ at the surface up to $5 \mathrm{~m} / \mathrm{s}$ at a wind speed maximum around $80 \mathrm{~m}$ (figure 28). The wind direction profiles for this night were very similar between the two sites with a large scatter of direction measurements, between 225 degrees and 360 degrees, between the surface and 20 meters. Above 20 meters the wind direction measurements converge and are uniform between the two sites from the southwest at the beginning of the night and shifting slightly northwest by the end of the night (figure 29).

\begin{tabular}{|l|l|}
\hline Profile Number & Profile Time (LST) \\
\hline 1 & $19: 30$ \\
\hline 2 & $20: 15$ \\
\hline 3 & $20: 55$ \\
\hline 4 & $21: 45$ \\
\hline 5 & $22: 35$ \\
\hline 6 & $23: 10$ \\
\hline 7 & $23: 50$ \\
\hline 8 & $00: 30$ \\
\hline 9 & $01: 16$ \\
\hline 10 & $02: 15$ \\
\hline 11 & $02: 55$ \\
\hline 12 & $03: 35$ \\
\hline
\end{tabular}

Table 10: The times of each tethered balloon sounding for the night of April 9-April 10 (Field campaign \#2). 

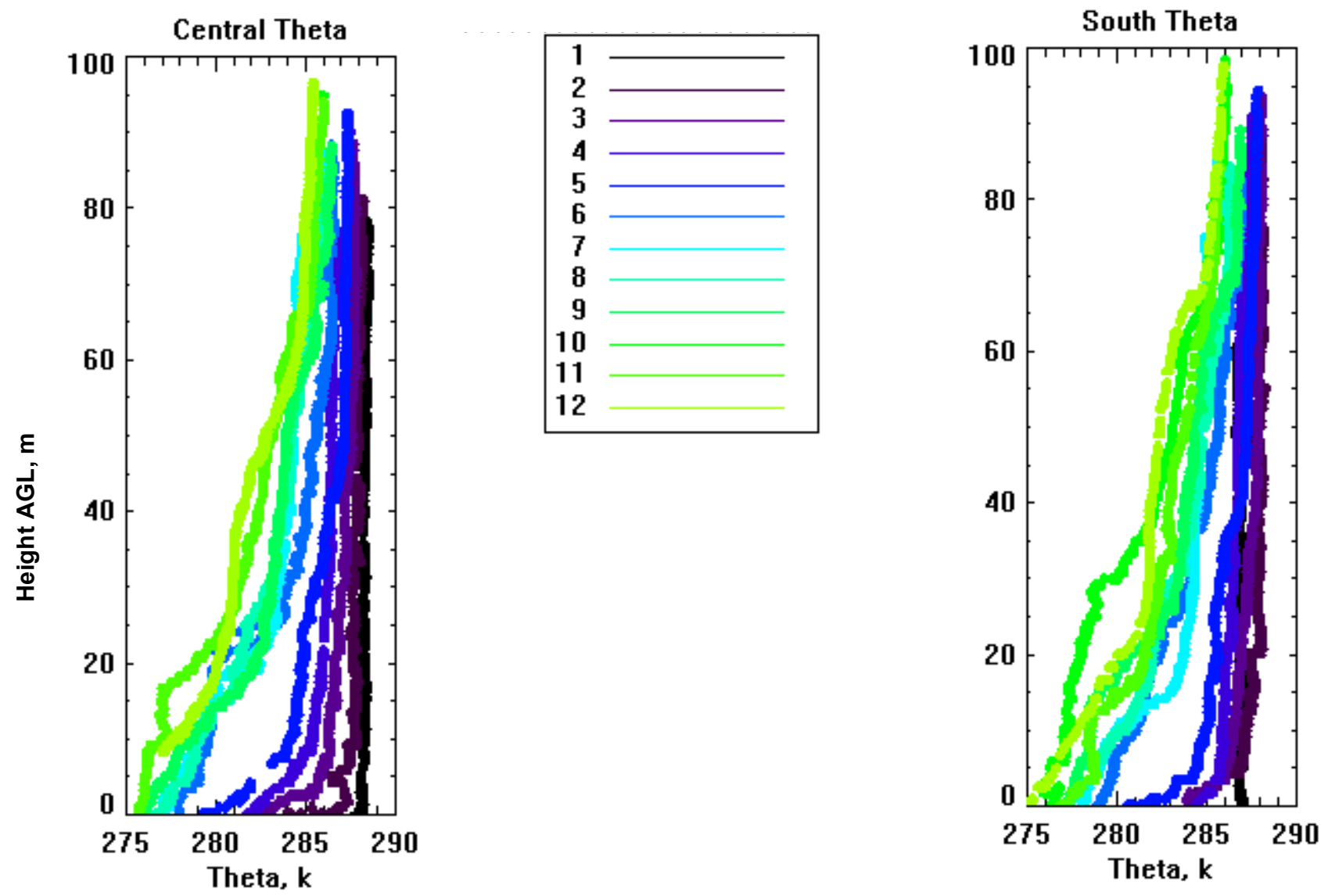

Fig. 27: Potential temperature profiles from the second field campaign. Each different sounding is represented in a different color and the sounding number refers to the times included in table 10 . 

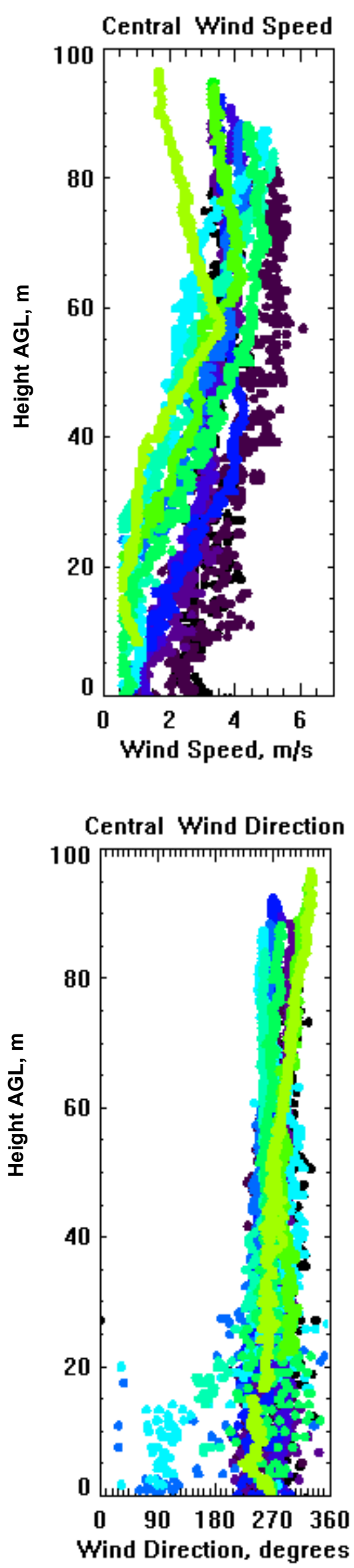

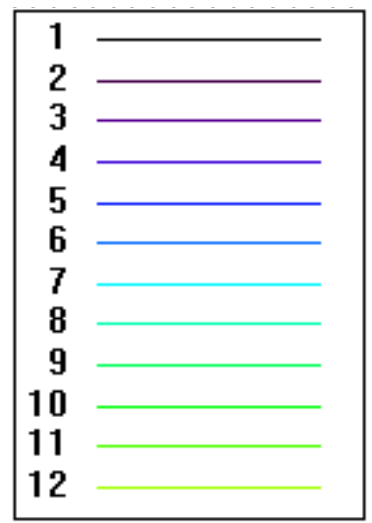

Figure 28: Wind speed profiles from the second field campaign. Each different sounding is represented in a different color and the sounding number refers to the times included in table 10.

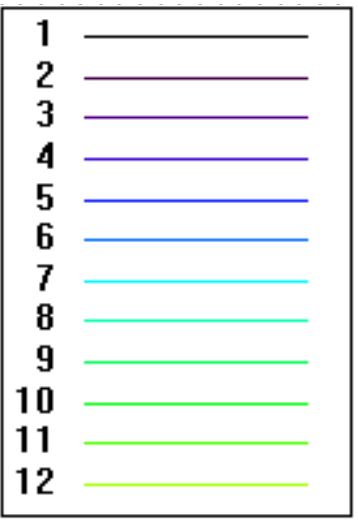

Figure 29: Wind direction profiles from the second field campaign. Each different sounding is represented in a different color and the sounding number refers to the times included in table 10.

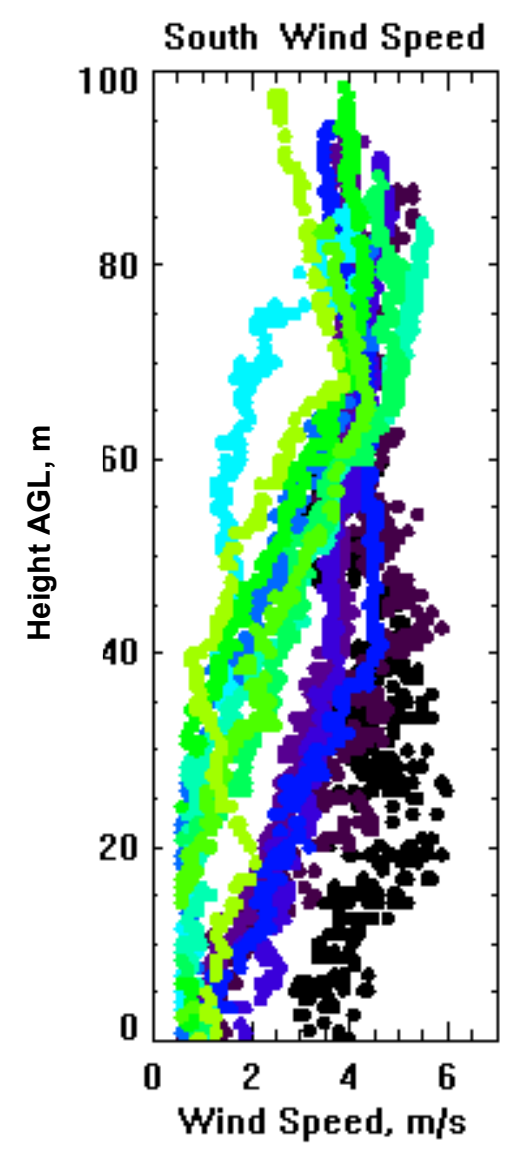

South Wind Direction

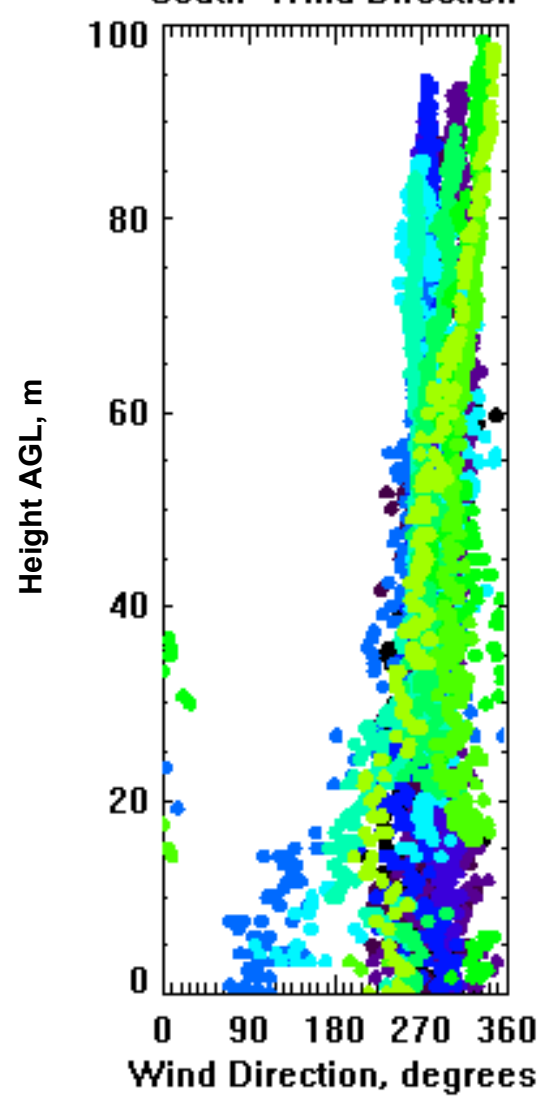


During two of the earlier profiles, 23:10 LST and 23:50 LST, an abnormal easterly flow was recorded first at the south site and then at both sites (Figure 29). Although most of the tower wind measurements were often disregarded as calm this night, the easterly trend is also evident in the tower wind data (figure 26). It is difficult to explain this random easterly flow. One explanation could be that some type of turning or flow rotation, caused by the valley to the south of the towers (figure 2, B), is occurring. The most notable difference found in the soundings between the two sites was that during some of the profiles, especially at the beginning of the night, the south site showed slightly more northwesterly flow compared to the central site (20:55,21:45, and 22:35) (figure 30).
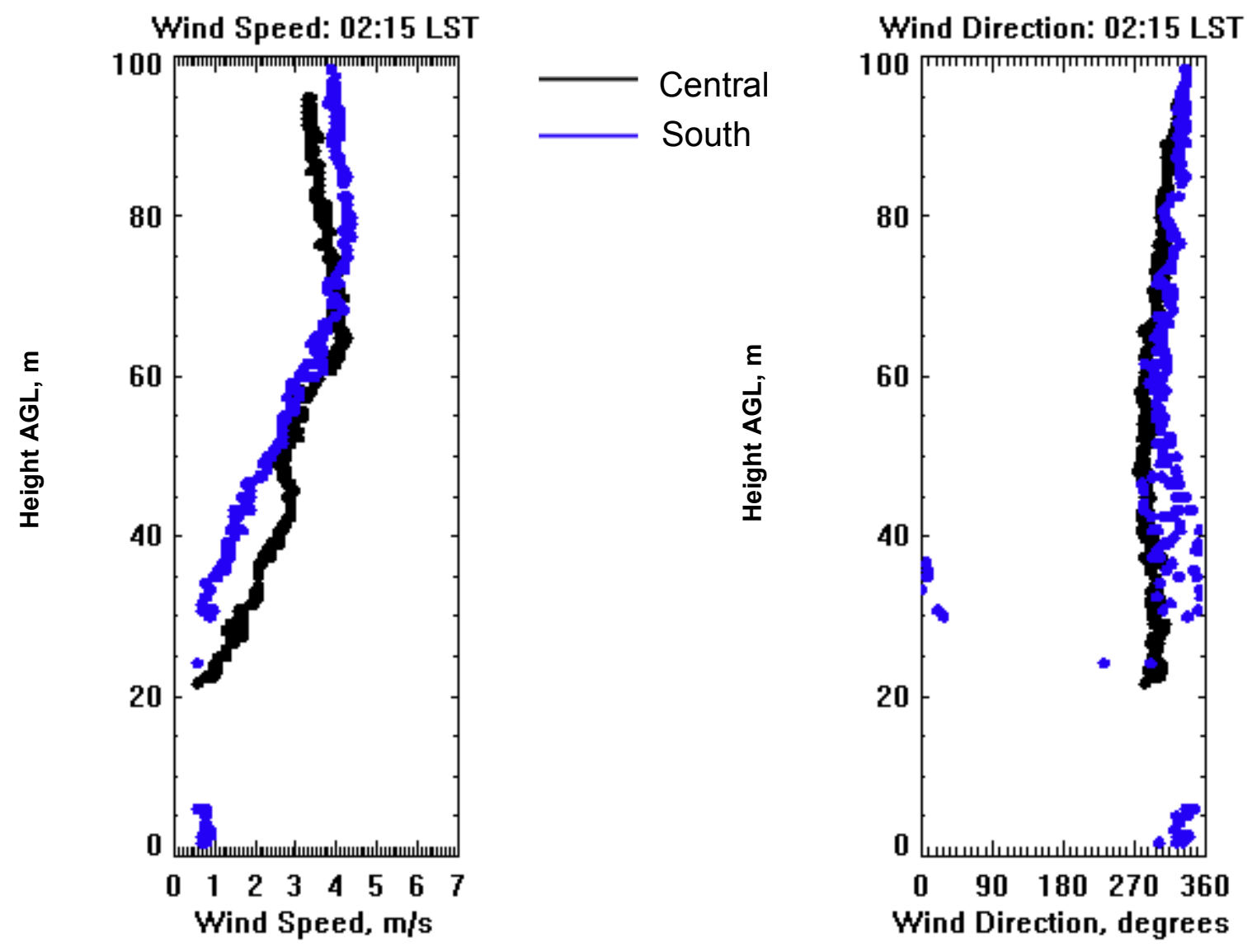

Figure 30: Wind speed (left) and direction (right) profile for the $10^{\text {th }}$ profile of field campaign \#2. This profile occurred at 02:15 LST. 
During some of the profiles later in the night the winds at the surface were often too weak to be captured by the Kestrel 4500 , although it appears that some interesting differences may have occurred (i.e. figure 28). For reasons such as this, the WRF model is used to further explain the winds during this night.

\subsubsection{WRF model simulation of field campaign \#2}

The WRF model was used to simulate the meteorological conditions at and above the surface during this night. The model simulation of the $10 \mathrm{~m}$ winds reveals that during this night topographic influence over the flow occurred. Between April 10 03z (figure $31 \mathrm{C}$ ) and April 10 $13 \mathrm{z}$ (Fig. $31 \mathrm{H})$ a strong difference in wind direction occurred between the sites. Based on the WRF results, this gradient in wind direction is identified to exist, although the exact location of the wind difference (i.e. exactly between the baseline and south sites?) cannot be stated explicitly because of the resolution of the model output. When the northwesterly flow impinges on this ridge to the south of the towers, the flow tends to be too weak, or too stable, to continue over the ridge, and it is therefore turned or deflected to a southwesterly direction. At the same time, the slope to the west of the towers amplifies the existing drainage flow due to larger temperature gradients between the slope and the air away from the slope at the same height, causing a stronger local northwest flow to develop. The combination of these flows leads to a convergence of flows within close proximity of the five towers. Based on the WRF output, it is clear that there is a gradient in wind direction between flow from the northwest, caused by drainage off of the slope to the west of the towers, and flow from the southwest, caused by the flow being deflected by the ridge to the south of the towers. Although the exact location of the sharp gradient in wind direction cannot be resolved by the WRF model, the southwest flow is likely to influence the south and eastern sites the most given their proximity to the ridge to the south of 
the towers. Since there is uniform ambient northwesterly flow throughout most of the night, the regional drainage flow from NW to SE is masked because it is oriented the same as the overall synoptic flow regime.

The exact location of this flow convergence is dependent on a number of factors (strength of inversion, intermittency of drainage flows, etc.) and can fluctuate throughout the night (figure 31). The spread of the wind directions from the tethered balloon soundings below the $20 \mathrm{~m}$ height at both sites is attributed to the existence of the flow convergence and its variable location. The greatest differences in wind direction between the two sites, as indicated by WRF, occur later in the night when the winds are too weak to be captured with the tethered balloon soundings or once the soundings have ceased. To confirm that the flow direction differences in the $10 \mathrm{~m}$ model output are caused by underlying topography, the model output wind data are analyzed at roughly the $30 \mathrm{~m}$ height (figure 32). At this height, the flow is at a high enough altitude and/or is strong enough to flow over the ridge to the south of the towers and the southwesterly flow is mostly eliminated from the region. The terrain induced flows impact the winds somewhat at the $30 \mathrm{~m}$ height, although there is not a well defined wind direction gradient located within close proximity of the towers, as seen in the $10 \mathrm{~m}$ wind model output. 


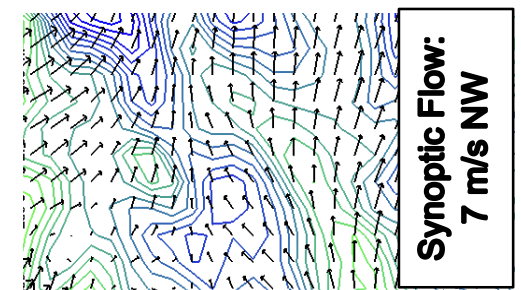

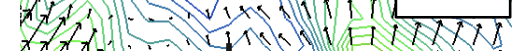

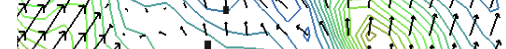

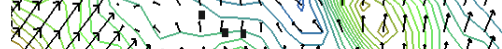

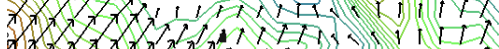
1027

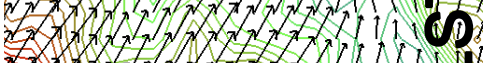

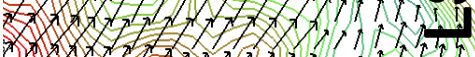

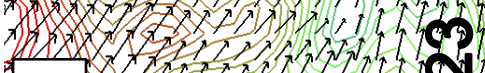
(0)
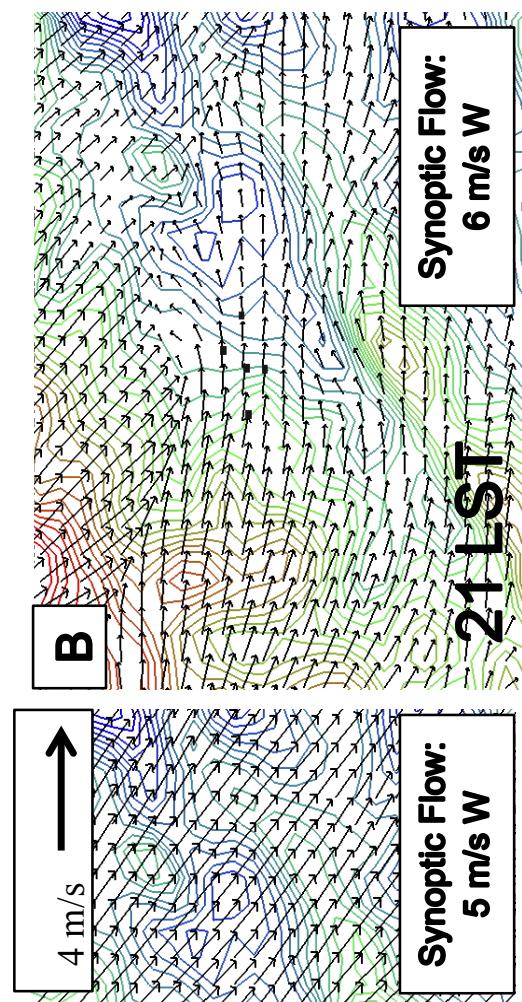

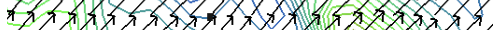

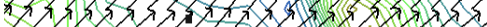

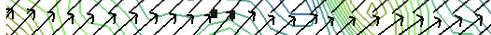

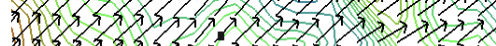

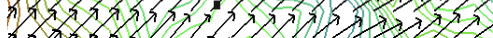
㓊

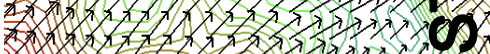

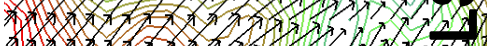

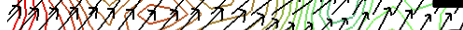

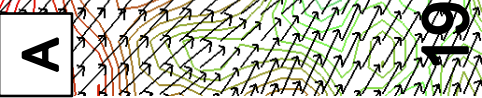

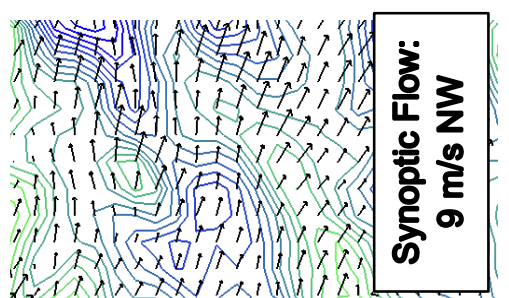

a 0 in is

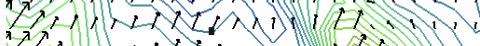

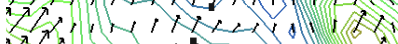

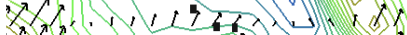

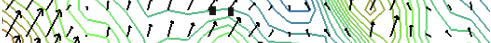

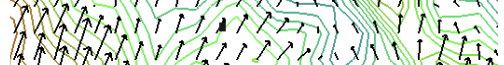
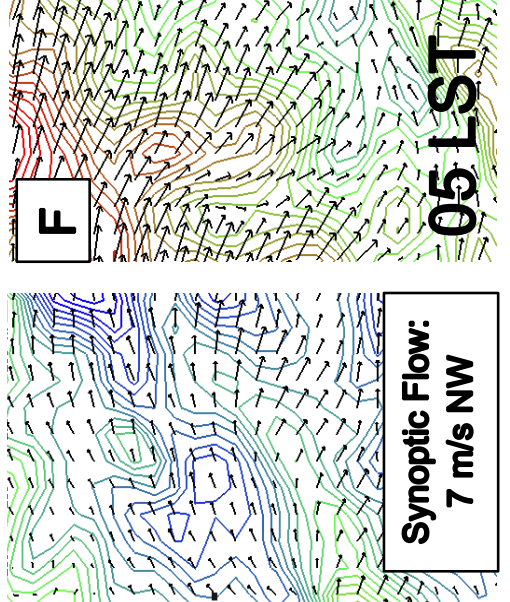

To.

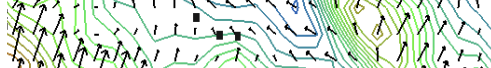

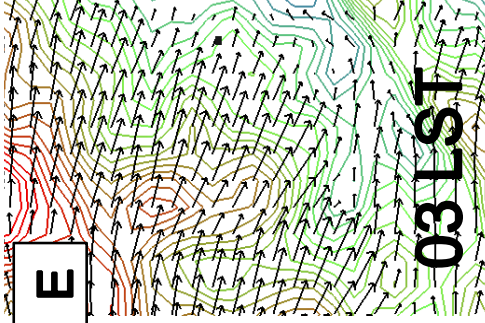

U1

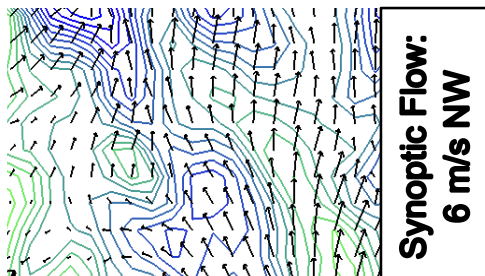

(7) 1 -

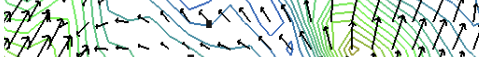

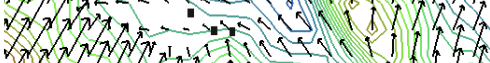

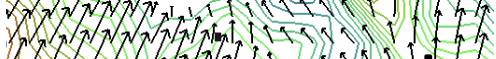

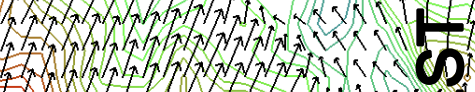

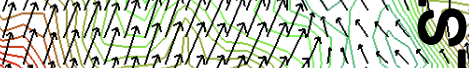

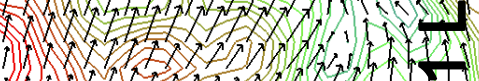

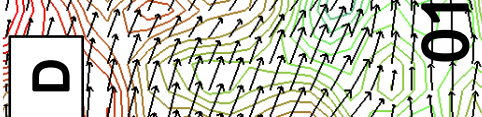

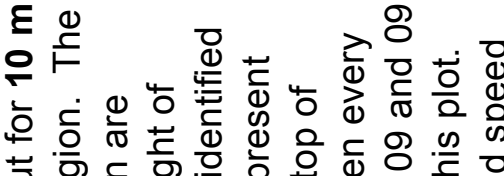

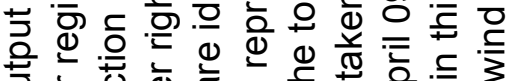

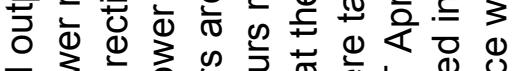

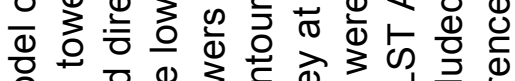

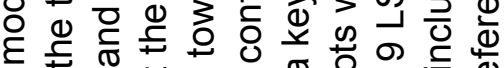

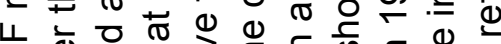

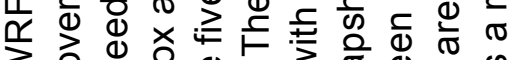
300

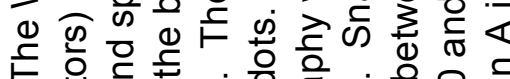

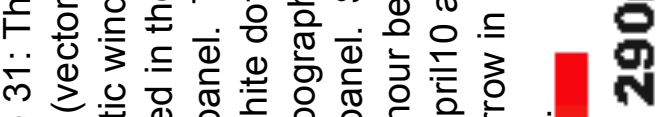

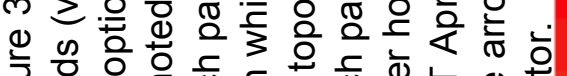
泣
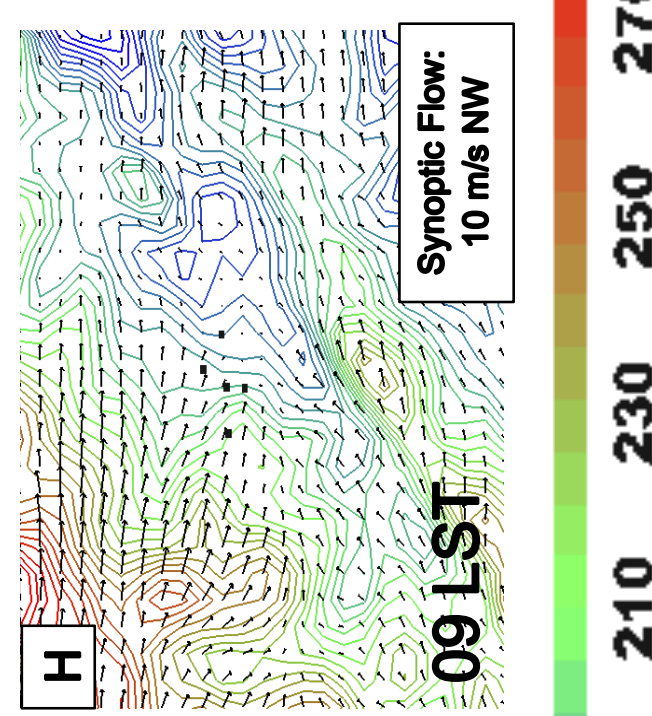

(

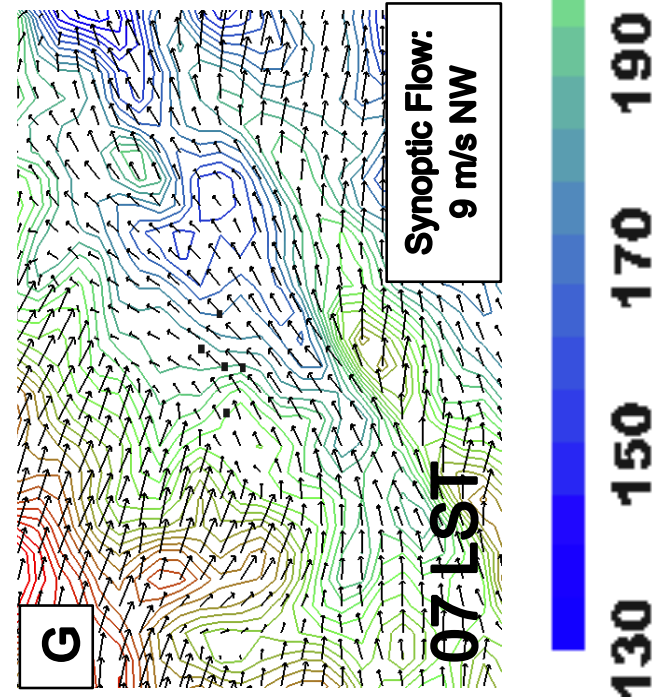




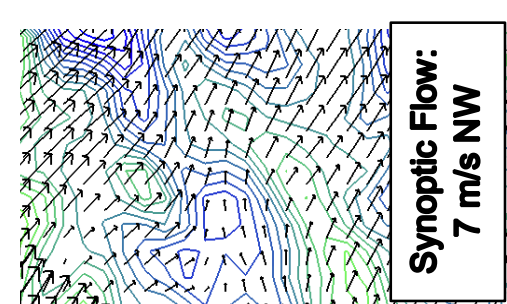

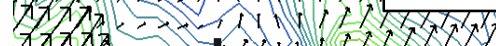

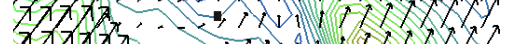

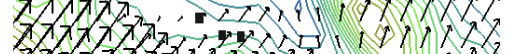

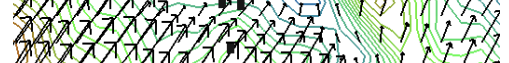

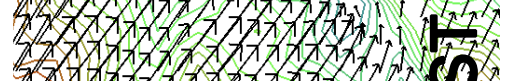
780

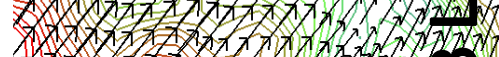

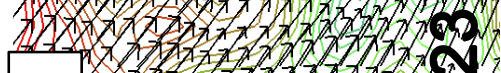

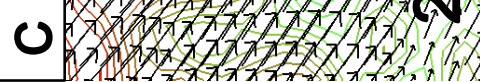

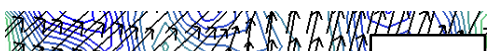

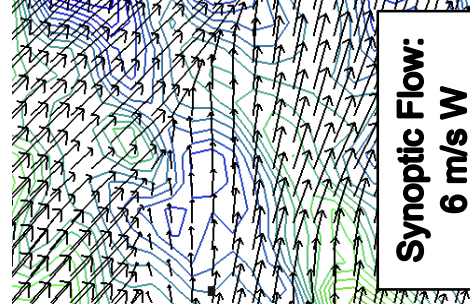
7rnar

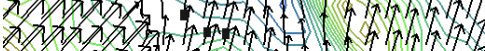

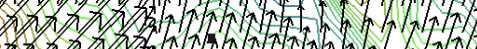

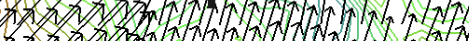

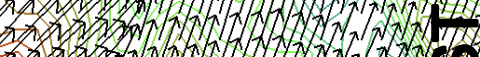

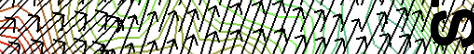

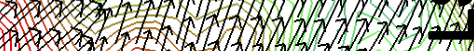

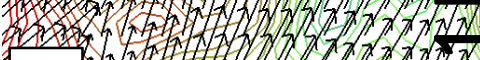
0 $(2)=171712$

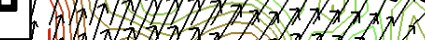

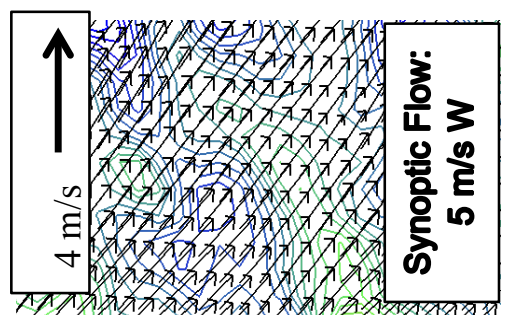

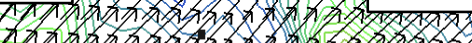

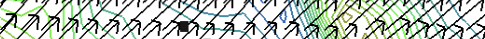

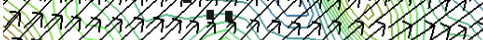

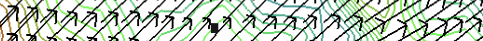

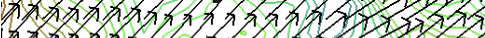

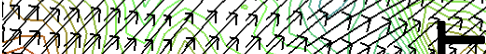

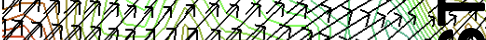

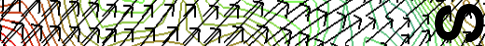

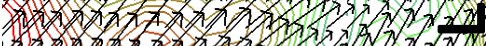

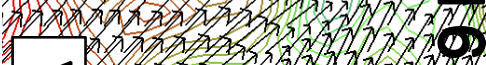

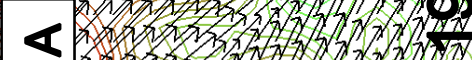
<
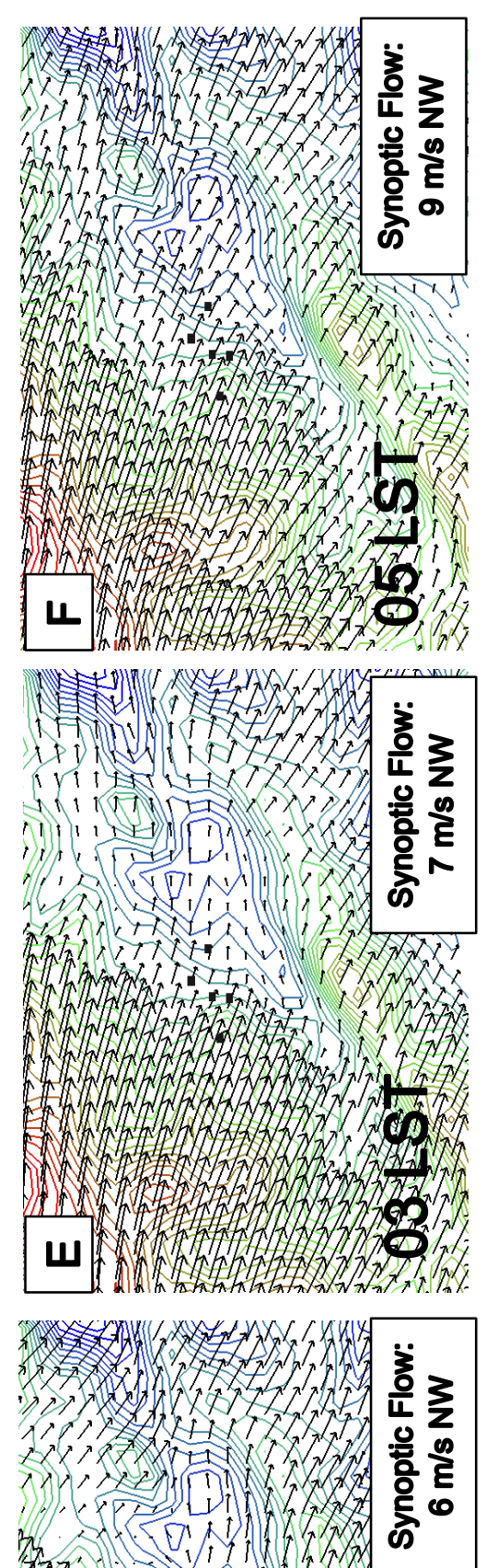

th 7 . $77770-1$ ।

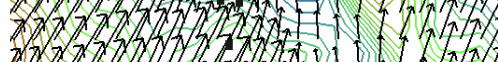

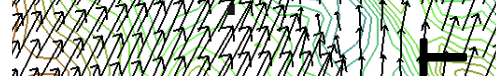

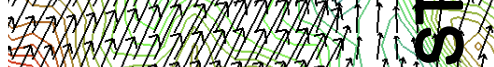

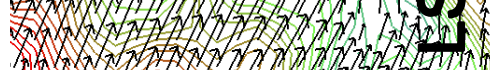

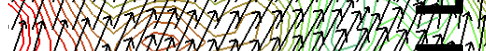

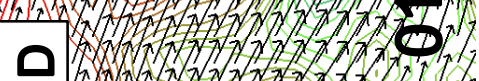

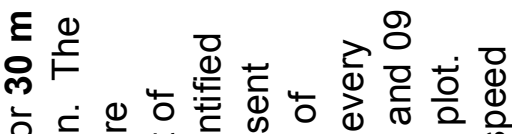

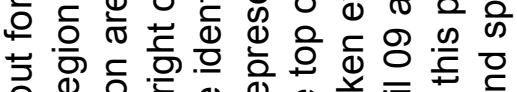

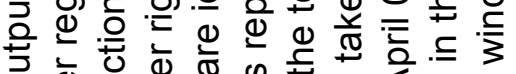

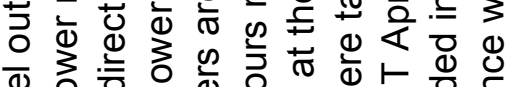

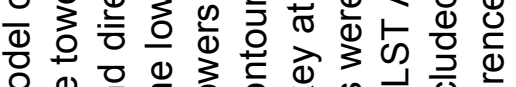

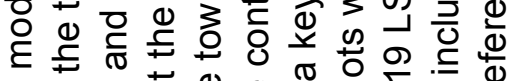

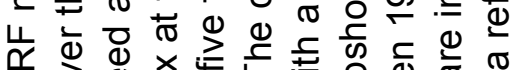

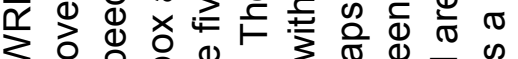

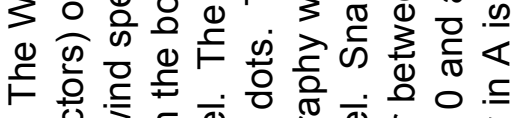

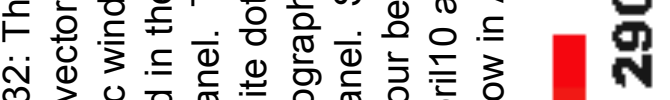

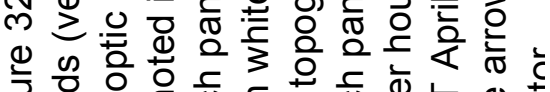

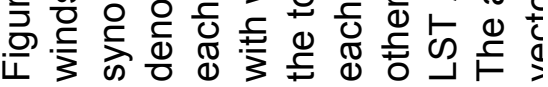
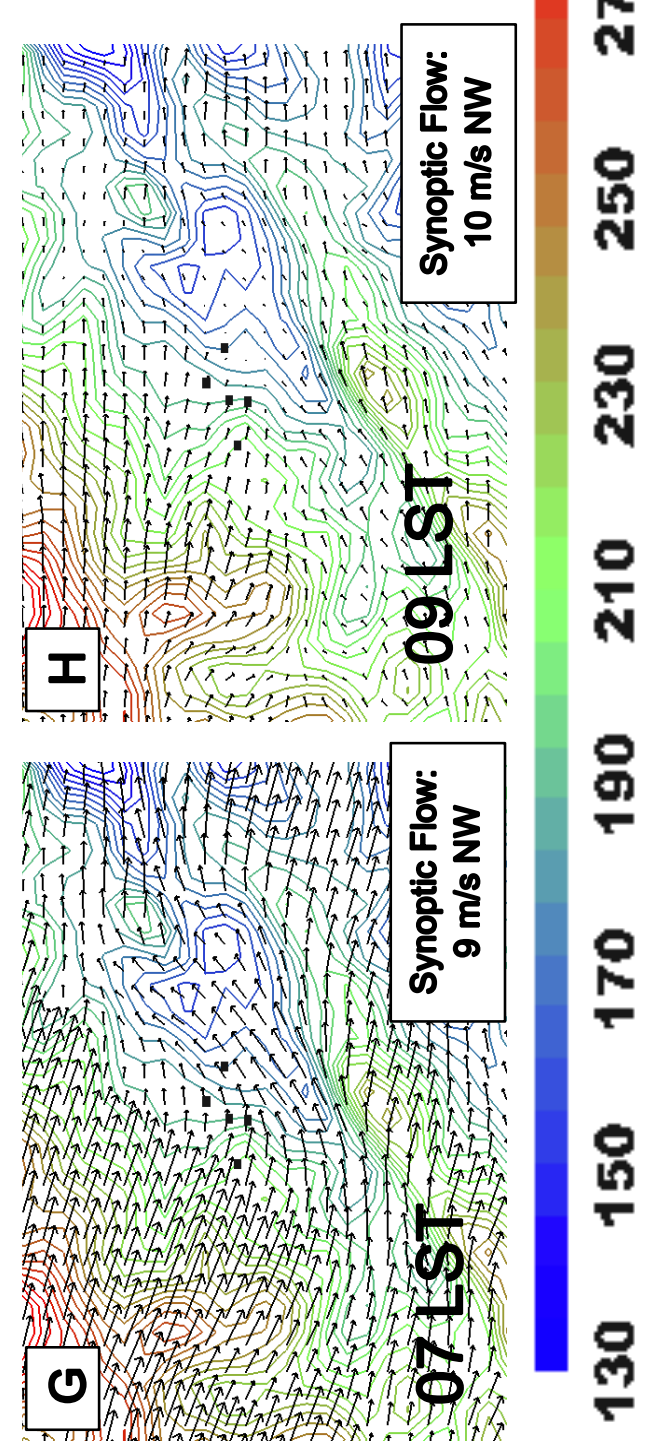


\subsubsection{Field Campaign \#3: May 19-20, 2014}

\subsubsection{Synoptic and surface weather patterns}

During the night of the third field campaign, a high pressure system dominated the eastern seaboard (figure 33). A weak fontal system, associated with a low pressure system centered over northern North Dakota, existed west of the Chatham region. The synoptic flow the day before and during the night of this field campaign was very weak $(<5 \mathrm{~m} / \mathrm{s})$ from the south/southwest. The flow at the $10 \mathrm{~m}$ height the day before the experiment was rather weak with variable direction throughout most of the day but shifting to the southwest during the latter part of the day (figure 34). A sharp increase in wind speed from mostly calm to nearly $4 \mathrm{~m} / \mathrm{s}$ occurred once incoming solar radiation began to increase in the morning with a consistent southwesterly flow direction. Some clouds were observed on the day prior to the experiment and clear conditions persisted the day after. The $10-\mathrm{m}$ winds at all sites during the night of the field experiment were very weak and were mostly below the calm threshold of $0.5 \mathrm{~m} / \mathrm{s}$. During the evening before this field campaign, the stability class changed from B (moderately unstable) to E (slightly stable) between 17 LST and 20 LST. After 20 LST, the stability class was F (moderately stable) throughout the night. 


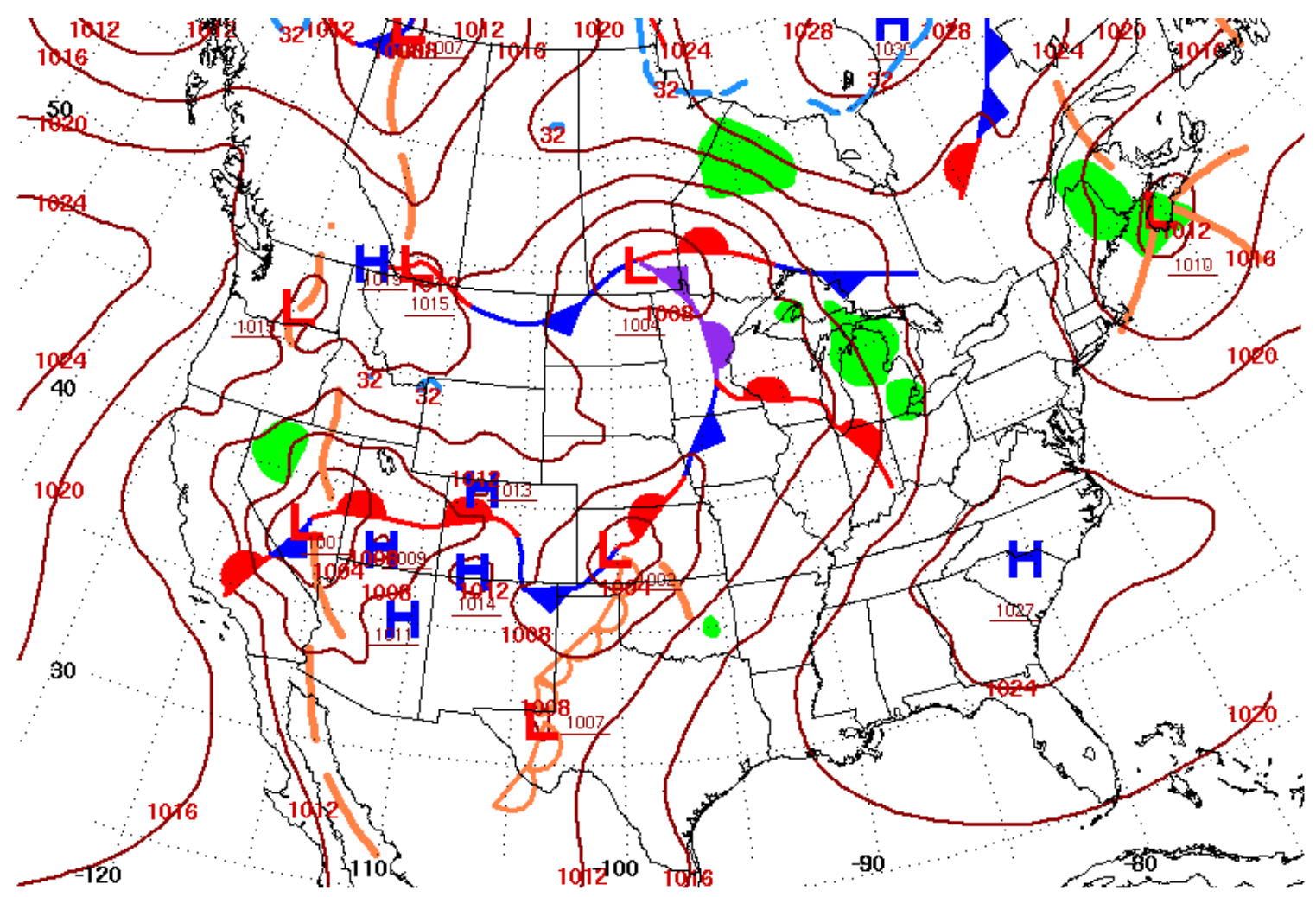

Surface Weather Map at 7:00 A.M. E.S.T.

Figure 33: A synoptic weather map that is valid at 07:00 LST on May 20, 2014. 

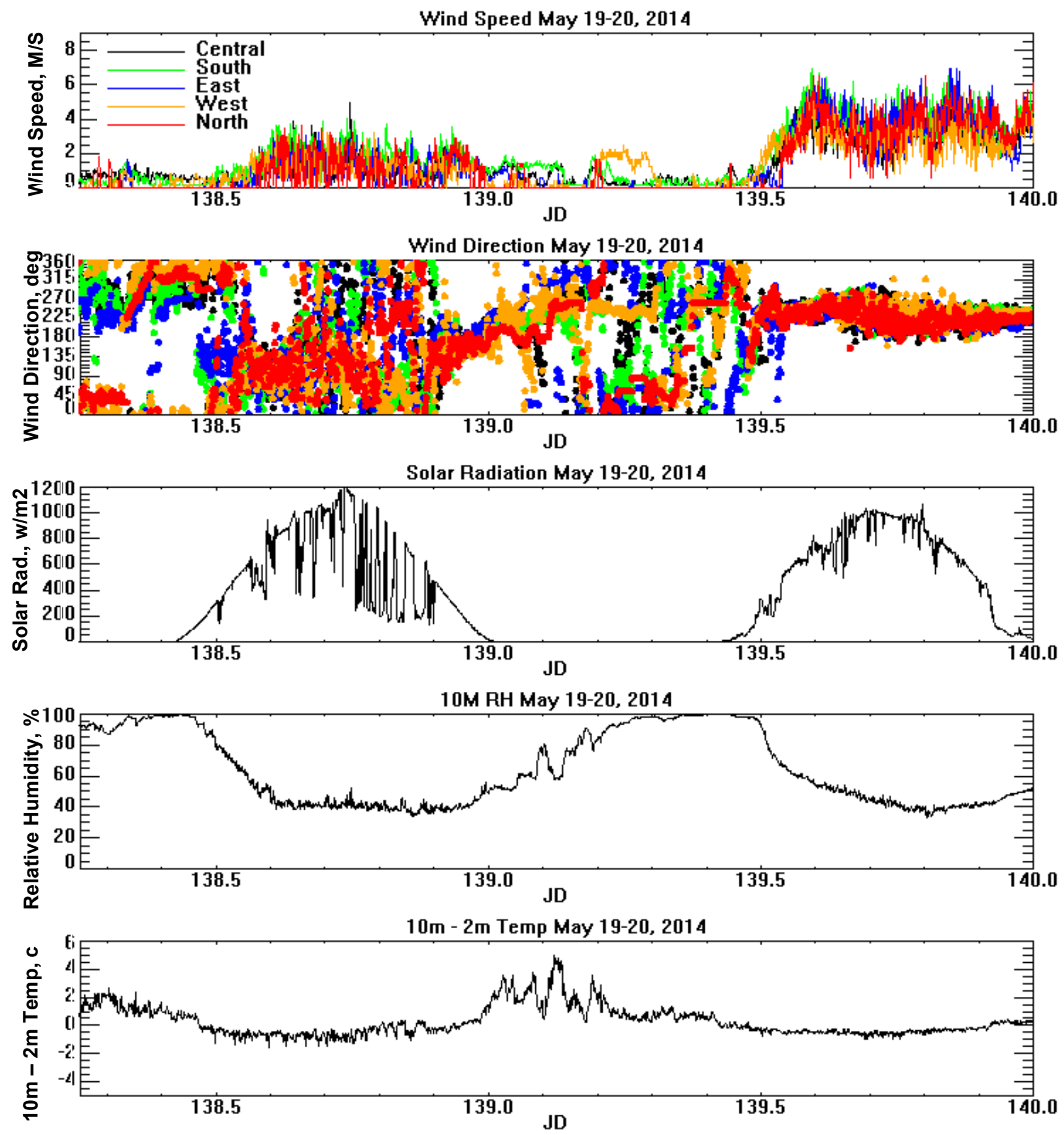

Figure 34: Tower measurements for the day before, the night of, and the day after the field campaign \#3. Each tower is represented with a different color for wind speed and direction and only solar radiation measurements, $\mathrm{RH}$ at $10 \mathrm{~m}$, and $10 \mathrm{~m}-2 \mathrm{~m}$ temperature are shown for the baseline site. 


\subsubsection{Field measurements during field campaign \#3}

During this night, 12 profiles were conducted and the times of the profiles are included in table 11. The potential temperature profiles indicate that during this night a stable nocturnal boundary layer developed with temperature differences around $5 \mathrm{~K}$ between 0 and $100 \mathrm{~m}$ AGL. Although this night was not quite as stable as the second field experiment, it was more stable than the first field experiment (figure 35). The winds were quite weak during this night and often times the winds below the $20 \mathrm{~m}$ height were disregarded as calms (figure 36). When the winds were not disregarded as calm, the wind direction below $20 \mathrm{~m}$ was often variable between southerly to northwesterly with the most scatter evident at the central site (figure 37). Throughout the night, the winds above the $20 \mathrm{~m}$ height shift uniformly between the two sites, from south to west/southwest.

\begin{tabular}{|l|l|}
\hline Profile Number & Profile Time (LST) \\
\hline 1 & $19: 30$ \\
\hline 2 & $20: 30$ \\
\hline 3 & $21: 15$ \\
\hline 4 & $22: 00$ \\
\hline 5 & $22: 45$ \\
\hline 6 & $23: 30$ \\
\hline 7 & $00: 15$ \\
\hline 8 & $01: 00$ \\
\hline 9 & $01: 46$ \\
\hline 10 & $02: 30$ \\
\hline 11 & $03: 15$ \\
\hline 12 & $04: 00$ \\
\hline
\end{tabular}

Table 11: The times of each tethered balloon sounding for the night of May 19-May 20 (Field campaign \#3). 

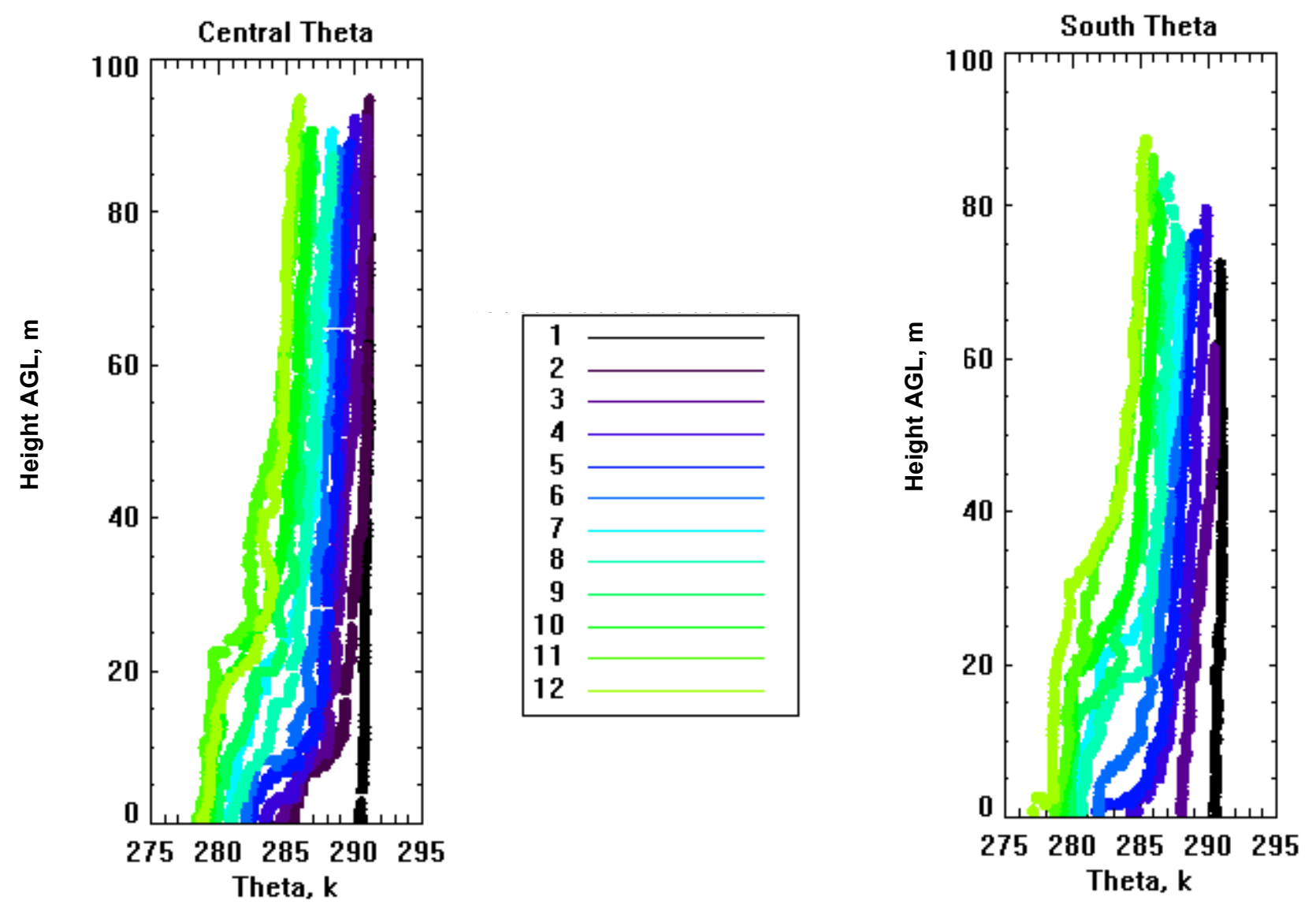

Fig. 35: Potential temperature profiles from the third field campaign. Each different sounding is represented in a different color and the sounding number refers to the times included in table 11. 

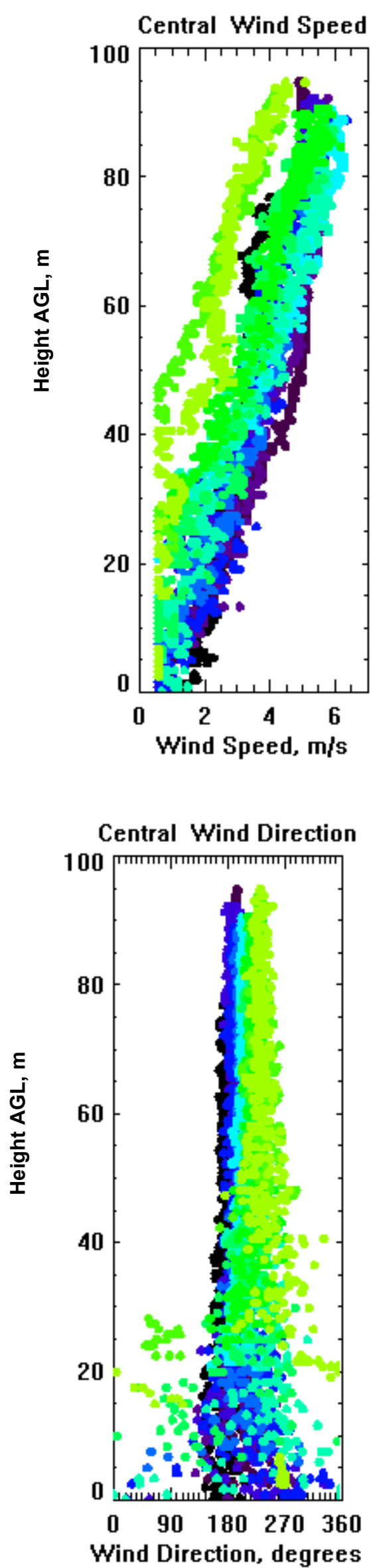

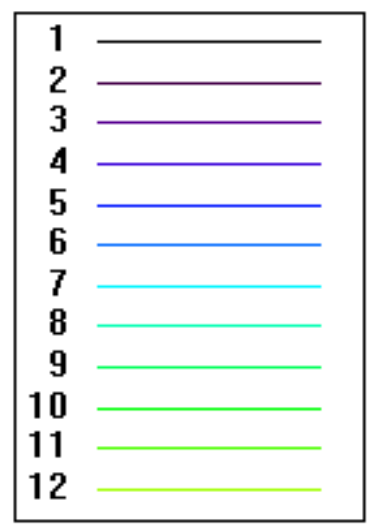

Fig. 36: Wind speed profiles from the third field campaign. Each different sounding is represented in a different color and the sounding number refers to the times included in table 11 .

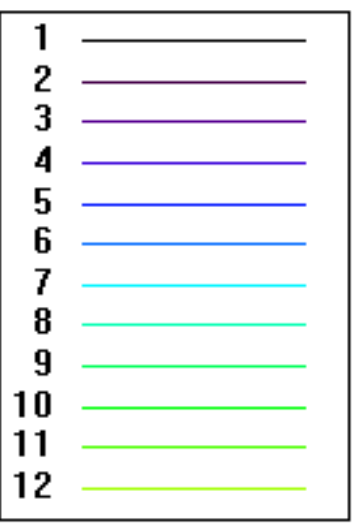

Fig. 37: Wind direction profiles from the third field campaign. Each different sounding is represented in a different color and the sounding number refers to the times included in table 11.

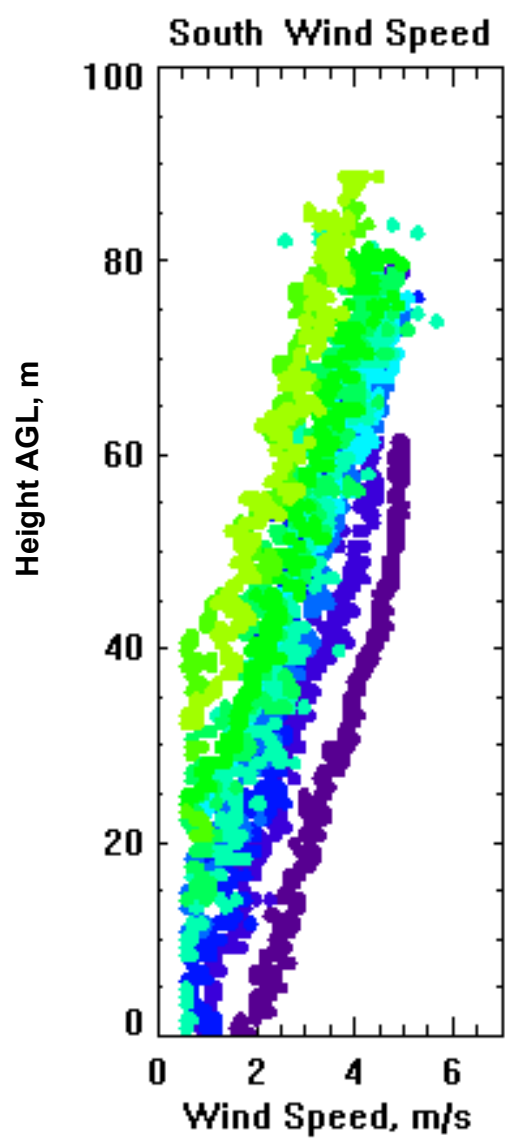

South Wind Direction

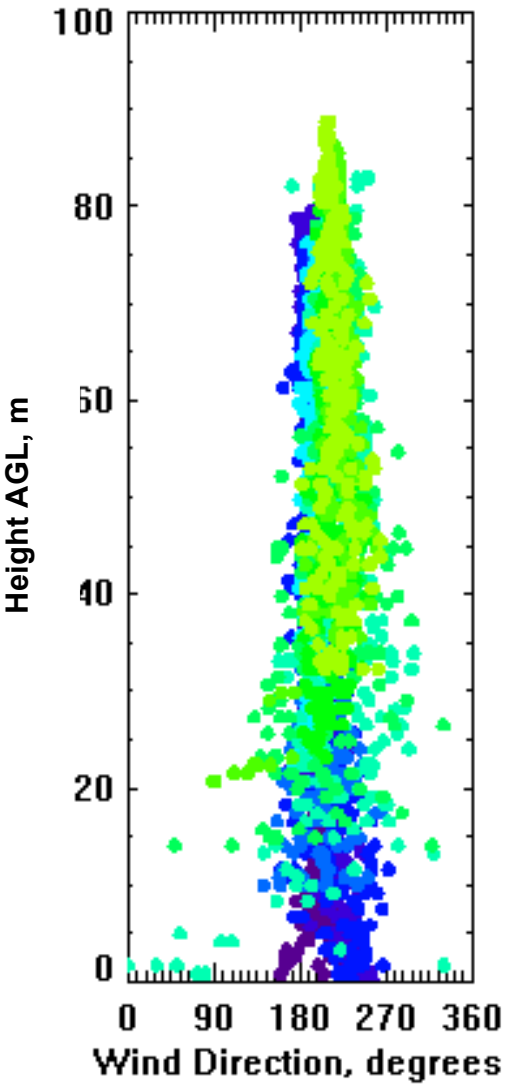




\subsubsection{WRF model simulation of field campaign \#3}

Interesting topographic effects over the winds during this night were revealed with a 30 hour WRF model simulation. As for the $10 \mathrm{~m}$ winds, the ambient flow regime started out southerly in the beginning of the night and shifted to the southwest by the morning (figure 38). The mostly southerly ambient flow during this night provided an interesting investigation of how the winds are influenced by the ridge to the south of the towers when the wind impinges on the ridge from the south. The results from WRF indicate that at first, the southerly flow was strengthened as it descended the northern side of the ridge (figure 38 B - 38 D). There is also some sort of rapid deceleration of the flow as it reaches the valley (figure 2, B) to the north of the ridge. Once the ambient flow begins to shift to a more southwesterly direction, the local terrain begins to influence the flow in a similar way compared to the second field campaign, although to a lesser extent and for a shorter duration. The drainage flow from the northwest from the slope to the west of the towers and the flow channeling caused by the ridge to the south of the towers become apparent and the convergence of the two flows once again occurs within close proximity of the towers (figure 38 F). In this instance, the west/northwest flow is very weak and infrequent, but is nonetheless present. The overall topographic influence is less pronounced during this night compared to field campaign \#2 because the flow is impinging on the ridge at a perpendicular angle and then becomes more in line with the ridge, and is therefore not forced or deflected into a largely different direction. As previously done, the $30 \mathrm{~m}$ winds from the WRF output were analyzed to assess the wind differences between the $10 \mathrm{~m}$ and $30 \mathrm{~m}$ heights (figure 39). The 30 $\mathrm{m}$ height is influenced by the westerly regional drainage flow but there are no significant differences in flow characteristics within the local tower region. Large differences in wind characteristics within close proximity of the towers are not evident at the $30 \mathrm{~m}$ height. 

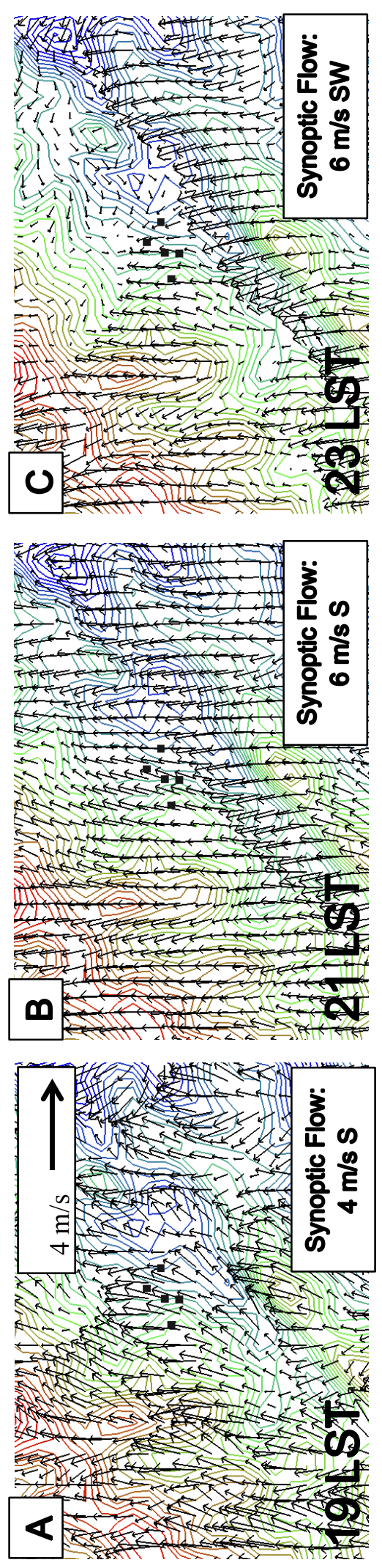

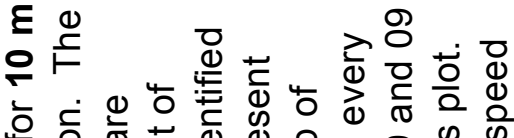

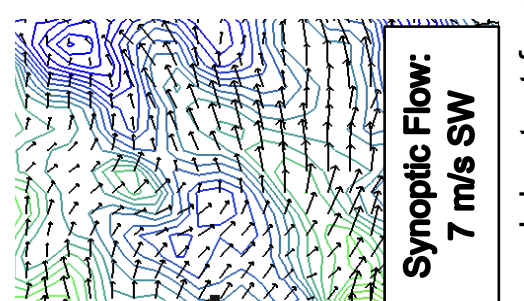

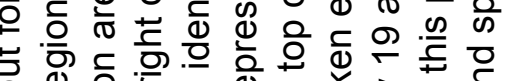

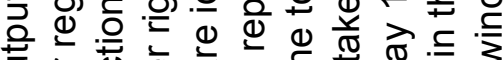
亏 ब ब

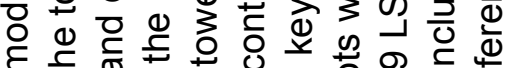

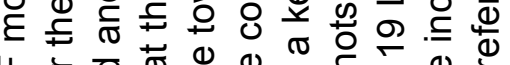
7.

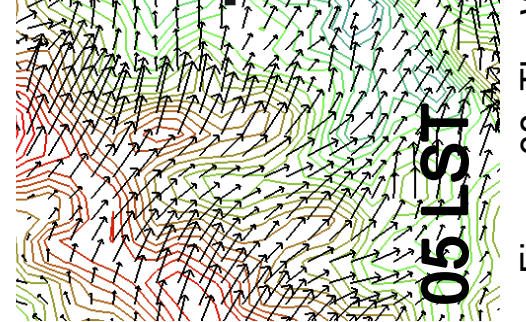
ब क क ळ F

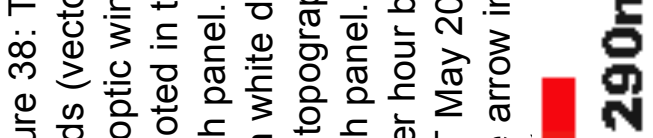

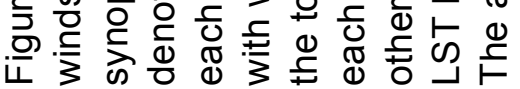
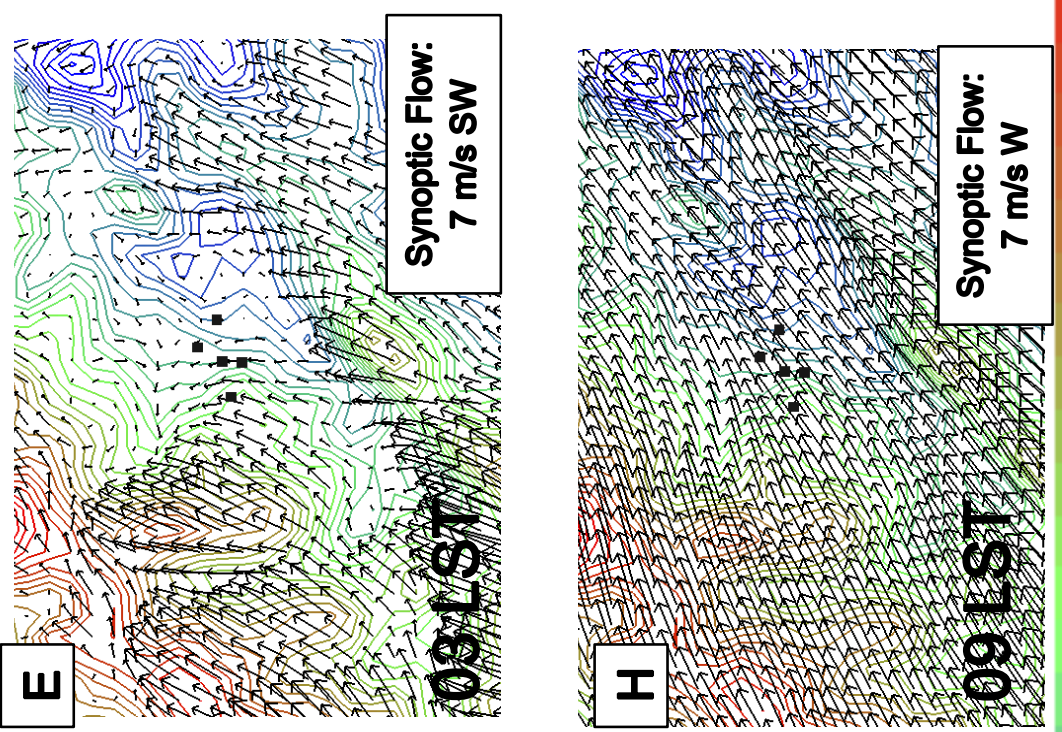

$\mathbf{N}$
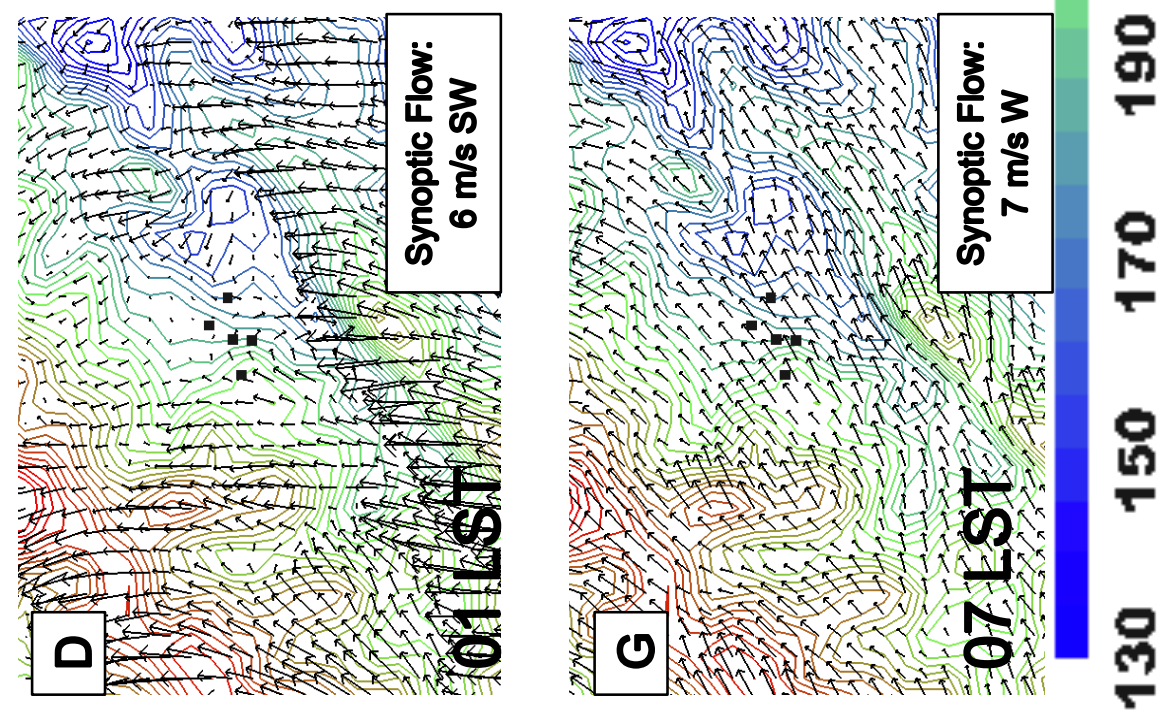


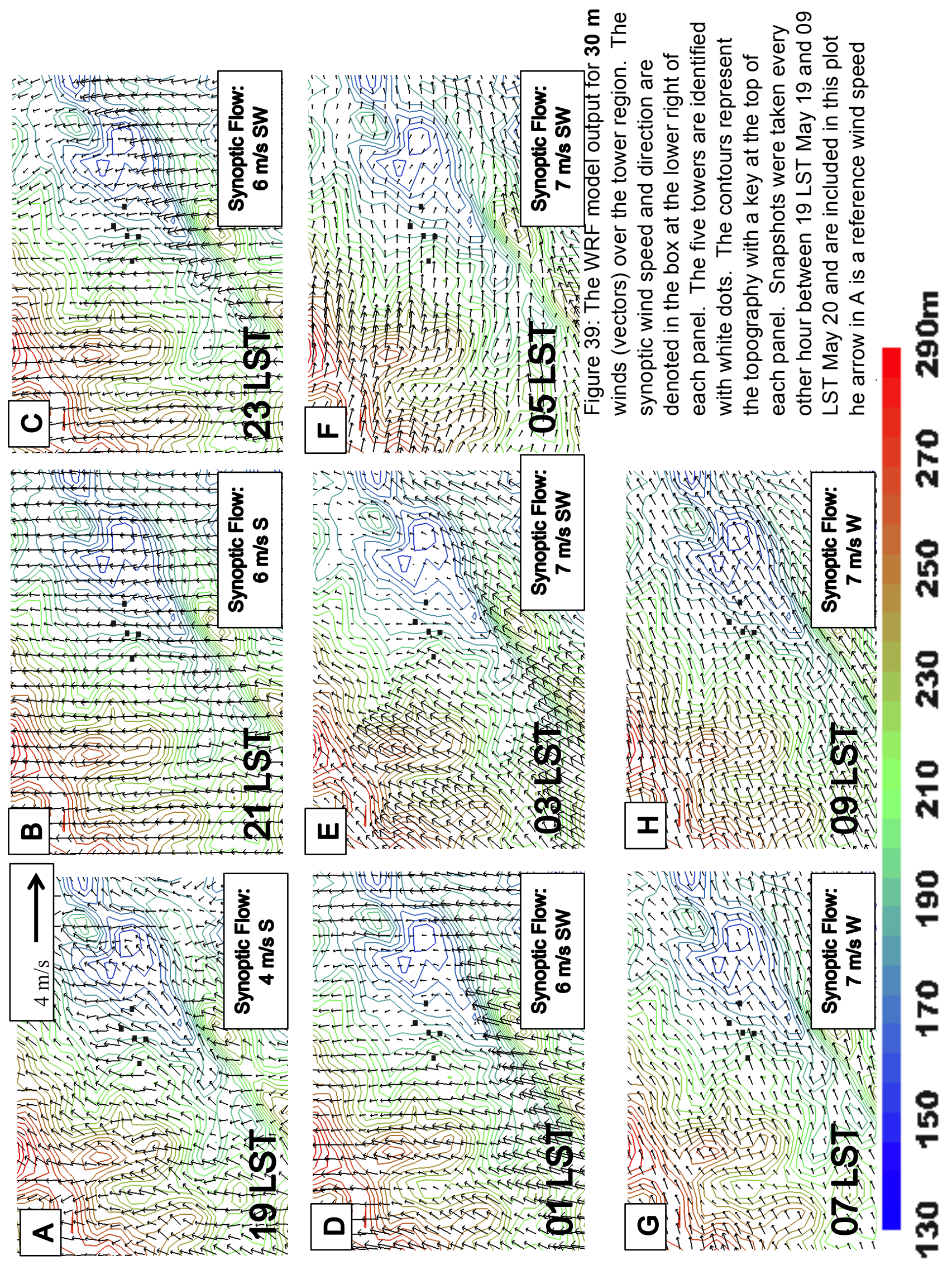




\section{Chapter 4: Discussion}

Statistical and wind rose analyses, field campaigns, and WRF model simulations revealed that significant wind differences exist between each site and the baseline site under specific conditions. The statistical analyses indicate that under stable conditions, the largest differences occur. The analyses also indicate that significant differences do not occur under unstable and neutral conditions and only some neutral and unstable conditions lead to moderately representative wind conditions. The wind roses reveal that under stable conditions, the baseline site exhibits more frequent northwesterly flow compared to other sites and is especially different compared to the south and east sites. Meanwhile, under unstable and neutral conditions, there is much homogeneity in wind conditions across all the sites. After a careful investigation of the topography, key differences between the topography surrounding the south and east sites compared to the other three sites were identified and determined to cause the differences seen in the winds. The south and east sites are located on a smaller topographic gradient compared to the other three sites and the south site is closest to the small ridge to the south of the towers. These topographic differences around the towers are used to explain the differences in winds that we see during stable conditions. Also based on the wind rose analyses, the representativeness of the baseline site significantly increases with wind speed and is considered representative of the region anytime winds are above $3 \mathrm{~m} / \mathrm{s}$ at the baseline site.

In order to investigate what causes these large differences during stable conditions, three field campaigns were conducted and simulations were made using the WRF model. One motivation of the field campaigns and modeling was to enhance the knowledge of how the winds differ between the two sites at the $30 \mathrm{~m}$ height, which is a tower height option for the collection of representative baseline meteorological measurements. Following these investigations, the 
hypothesis that the ridge to the south and the slope to the west of the towers play a large role in the local wind climatology at the sites was confirmed. Each of the three field campaigns occurred during different synoptic flow situations, 1) relatively weak $(<10 \mathrm{~m} / \mathrm{s})$ from the east/northeast, 2) somewhat stronger flow $(10-12 \mathrm{~m} / \mathrm{s})$ from the northwest, and 3$)$ weak flow (< $5 \mathrm{~m} / \mathrm{s}$ ) from the south/southwest. The variety of synoptic conditions investigated allowed for a thorough analysis of the role of topography under stable conditions with varying synoptic flow conditions. Given the orientation of the ridge to the south of the sites and the relatively large slope to the west of the sites, the topography plays the largest role when the ambient flow is from the west or northwest or southwest. When the flow is from the southeast, northeast, or east the local topography plays a negligible role because there are no large-scale topographic features to the (north/south) east of the towers. In other words, besides the ridge and associated valley to the south of the towers and the large slope to the west of the towers, there are not any other significant topographic features, besides the regional slope of the land, that influence the local climatology of the winds. In addition to the local topographically induced flows, there is also a regional northwesterly drainage flow that equally affects each of the towers.

A synthesis of the results of this analysis show that the baseline site is unrepresentative during stable conditions when synoptic flow is not between northeast (45 degree) and southeast (135 degree), regardless of synoptic wind speed (table 7). It should be noted that winds are infrequently from the southeast but do occur occasionally from the northeast. The slope to the west of the towers and the ridge to the south of the sites mainly cause the wind differences observed in the 18-month climatology of tower winds.

There are various options to improve the representativeness of wind measurements during unrepresentative conditions at the baseline site. One option is to increase the height of the 
measurements to $30 \mathrm{~m}$, which involves installing a taller $30-\mathrm{m}$ tower. It is expected that the influence of the drainage flows and channeling effects become smaller with height and, therefore, a tower at the $30 \mathrm{~m}$ height would be considered representative for the collection of baseline meteorological measurements. This statement is further supported by the wind direction profiles obtained during the three field campaigns and by the WRF model simulations. In the profiles, it was found that the wind characteristics became uniform between the south and baseline sites around the 30-meter height. However, it is still possible that some topographic effects caused by the ridge to the south of the sites will remain present at $30 \mathrm{~m}$, as seen in the WRF model runs. This is especially true when ambient flow is from the NW and is forced to a SW direction by the ridge to the south of the towers. Another (more expensive) option is to install a remote wind sensor at the baseline site capable of profiling the winds up to a height of a few hundred meters. A remote instrument such as a Doppler sodar or Doppler lidar would be most suitable and would allow measurements at a number of heights throughout the boundary layer. Ideally, a height just above $30 \mathrm{~m}$ would be more representative of the surface flow although a height higher than $\sim 50 \mathrm{~m}$ would no longer be characteristic of the surface flow. For the site in Chatham, Virginia, we suggest that the wind data from the baseline tower are not representative during moderately and extremely stable conditions and a $30 \mathrm{~m}$ tower should be installed and utilized for the collection of representative meteorological measurements.

\section{Conclusions}

This study investigated the wind characteristics and the representativeness of $10-\mathrm{m}$ wind measurements at a proposed uranium mining and milling site using statistical and wind rose analyses, intensive field campaigns, and WRF model simulations. Representative wind meteorological measurements are vital to the accuracy of air quality and dispersion models. The 
representativeness of 10-m wind measurements at a baseline site was first assessed through qualitative (wind roses) and quantitative (Mann-Whitney U and circular ANOVA) comparisons between measurements at the baseline site and at four other sites a few kilometers away from the baseline site. We focused on the impact of ambient stability and synoptic wind speed and direction on the representativeness of the baseline site because of the pivotal role these variables play in the characteristics of topographically induced flows. It was found that stability plays the largest role in the determination of the representativeness of the baseline site. All unrepresentative and marginally unrepresentative conditions occurred during stable conditions at the baseline site. During stable conditions, there is evidence of a more frequent drainage flow at the baseline site compared to the other sites, which cause the baseline site to be unrepresentative of the region. In addition, a terrain-forced flow is evident at the south and east sites caused by flow deflection near the ridge located southeast of the region.

Subsequent investigations, prompted by the results of the wind rose and statistical analyses, included tethersonde measurements of wind and temperature up to $100 \mathrm{~m}$ AGL during three nights characteristic of unrepresentative conditions (stable, synoptically quiescent, clear). The purpose of these measurements was to assess 1) the depth of any topographic influence over the winds and 2) the difference in near surface flows between the baseline and one additional site, the south site. The same nights were simulated using the WRF model to gather a broader understanding of the wind characteristics during each night. The results of these investigations provided evidence for the previously suspected northwesterly drainage flow and the southwesterly flow due to flow deflection. The presence of these different flows along with the presence of local drainage flows near gullies and creeks, lead to large wind differences over small spatial scales and lead to the reduced representativeness of the baseline site. 
The EPA recommendations for the siting of a representative baseline meteorological monitoring tower may not be sufficient in regions of complex terrain. Additional recommendations, which include the knowledge from studies such as ours, seem necessary including the use of mesoscale model simulations. The WRF results added an understanding of the regional flow characteristics that is not possible through tower measurements since only a finite number of towers are possible. For regions of semi-complex topography, a detailed analysis of the topography and simulations of the wind fields for clear calm and stable conditions using WRF might be sufficient for determining a representative location for meteorological measurements. Since representative wind measurements are vital to e.g. dispersion models and to data assimilation in numerical weather prediction models, the results of this thesis can contribute to improving the accuracy of such models. 


\section{References}

C. Agostinelli and U. Lund (2013). R package 'circular': Circular Statistics (version 0.4-7). URL https://r-forge.r-project.org/projects/circular/

Ashton, B., 2012: 2005-2009 AERMOD Meteorological Data, Iowa Department of Natural Resources, 177 pp.

Banta, R., Cotton, W., 1981: An Analysis of the Structure of Local Wind Systems in a Broad Mountain Basin, Journal of Applied Meteorology, 20, 1255-1266.

Brode, R., R. Stoner, D. L. Elliott, W. R. Barchet, and R. L. George. 1980. Wind Energy Resource Atlas: Volume 5 - The East Central Region. PNL-3195, WERA-5, Pacific Northwest Laboratory, Richland, Washington.

Deligiorgi, D., Philippopoulos, K., Karvounis, G., 2013: Estimation of pollution dispersion patterns of a power plant plume in complex terrain, Global NEST Journal, 15, 227-240.

Environmental Protection Agency (2000), Meteorological Monitoring Guidance for Regulatory Modeling Applications, Regulatory Guide EPA-454/R-99-005, 171 pp.

Ha, K., Shin, S., Mahrt, L., 2009: Spatial Variation of the Regional Wind Field with LandSea Contrasts and Complex Topography, Journal of Applied Meteorology and Climatology, 48, 1929-1940.

Hanna, S., 1982: Applications in Air Pollution Modeling, Atmospheric Turbulence and Air Pollution Modeling, 275-310.

Hanna, S., Chang, J.C., 1992: Representativeness of Wind Measurements on a Mesoscale Grid With Station Separations of $312 \mathrm{~m}$ to $10 \mathrm{~km}$, Boundary Layer Meteorology, 60, 309-324.

Hong, Song-You, Yign Noh, Jimy Dudhia, 2006: A new vertical diffusion package with an explicit treatment of entrainment processes. Mon. Wea. Rev., 134, 2318-2341.

Jammalamadaka, S., Sengupta, A., 2001: Topics in Circular Statistics, World Scientific Pub Co, $336 \mathrm{pp}$.

Janjic, Zavisa I., 1994: The Step-Mountain Eta Coordinate Model: Further developments of the convection, viscous sublayer, and turbulence closure schemes. Mon. Wea. Rev., 122, 927-945.

Kanj, G., 2006: 100 Statistical Tests, SAGE Publications Ltd., 256 pp.

Lockhart, T., Irwin, J., 1980: Methods for Calculating the Representativeness of Data, Proceedings, DOE Symposium on Intermediate Range Atmospheric Transport Processes and Technology Assessment, 169-176.

Mahrt, L., Vickers, D., Nakamura, R., Soler, M., Sun, J., Burns, S., Lenschow, D., 2001: Shallow Drainage Flows, Boundary Layer Meteorology, 101, 243-260 
Mahrt, L.: 1990, 'Relation of Slope Winds to the Ambient Flow over Gentle Terrain', BoundaryLayer Meteorol. 53, 93-102.

Nakanishi, M., and H. Niino, 2006: An improved Mellor-Yamada level 3 model: its numerical stability and application to a regional prediction of advecting fog. Bound. Layer Meteor. 119, 397-407.

Nappo, C.J., et al., 1981: The Workshop on the Representativeness of Meteorological Observations, June 1981, Boulder, Colo., Bulletin American Meteorological Society, 63, 761-766.

NOAA Satellite and Information Service, cited 2014: Surface Hourly Abbreviated Format. [http://www7.ncdc.noaa.gov/CDO/cdo]

Pasquill, F., 1961: The estimation of the dispersion of windborne materials, Meteorological Magazine, 90, 33-49.

Sreenivasa, R., Jammalamadaka, R., Lund, U., 2006: The effect of wind direction on ozone levels: a case study, Environmental and Ecological Statistics, 13, 287-298.

Tasdan, F., Yeniay, O., Power Study of Circular ANOVA Test Against

Nonparametric Alternatives, Hecettaepe Journal of Mathematics and Statistics, 2013.

Tewari, M., F. Chen, W. Wang, J. Dudhia, M. A. LeMone, K. Mitchell, M. Ek, G. Gayno, J. Wegiel, and R. H. Cuenca, 2004: Implementation and verification of the unified NOAH land surface model in the WRF model. 20th conference on weather analysis and forecasting/16th conference on numerical weather prediction, pp. 11-15.

Turner, D., 1964: A diffusion model for an urban area. Journal of Applied Meteorology, 3, 8391.

US Nuclear Regulatory Commission (1980), Radiological Effluent and Environmental Monitoring at Uranium Mills, Regulatory Guide 4.14, 23pp.

US Nuclear Regulatory Commission (1988), Onsite Meteorological Measurement Program for Uranium Recovery Facilities - Data Acquisition and Reporting, Regulatory Guide 3.63, $7 \mathrm{pp}$.

Whiteman, D., Doran, C., 1993: The Relationship between Overlying Synoptic-Scale Flows and Winds within a Valley, Journal of Applied Meteorology, 32, 1669-1682

Wilks, D., 2011: Statistical Methods in the Atmospheric Sciences. Academic Press, 704 pp.

Zardi, D., and C. D. Whiteman, 2012: Diurnal Mountain Wind Systems. Chapter 2 in: Mountain weather research and forecasting (Chow, F. K., S. F. J. DeWekker, and B. Snyder (Eds.)). Springer Publishing Co, 750 pp. Published, 10/2012.

Zhang, D.-L., and R.A. Anthes, 1982: A high-resolution model of the planetary boundary layersensitivity tests and comparisons with SESAME-79 data. J. Appl. Meteor., 21, 15941609. 


\section{Appendix A: Data and Tower Details}

Some details about the towers and data collected at the five towers are included in the 'Data and Methods' chapter of this thesis, but additional details are provided in this appendix.

\section{A.1: Tower overview}

The south tower has instruments from Climatronics (www.climatronics.com) identical to the instruments on the central tower. The north, west and east towers have instruments from Onset (www.onsetcomp.com) and RM Young (www.youngusa.com). The Climatronics instruments on the south tower serve as temporary spares for the baseline tower in case of malfunctioning instruments. This was never necessary during the duration of the study. All towers are powered by solar panels. Some important details about the instruments installed on the central and south tower are found in table A.1. Table A.2 outlines exactly which instruments are found on the additional towers. Pictures of each tower and pictures pointing in each cardinal direction away from the each tower are included in figures A.1 - A5. All towers are located on grassy cow pastures and any nearby obstruction to each tower is trees. The proximity of each tower to nearby trees is included in Table A.3. It should be noted that all obstructions are sufficiently far (10x the height of the obstruction) from each tower to ensure unobstructed measurements. In addition, a $3 \mathrm{~m}$ tripod was installed at the baseline site with the instruments included in the table below. Finally, a ceilometer was installed and running at a location between the south and baseline sites to collect cloud base measurements between July 17, 2012 and March 21, 2014. 
Table A.1: The instrument name, manufacturer, model, and accuracy of all instruments that are installed on the baseline tower.

\begin{tabular}{|c|c|c|c|c|}
\hline Variable & Instrument & Manufacturer & Model & $\begin{array}{c}\text { Instrument } \\
\text { Accuracy }\end{array}$ \\
\hline $\begin{array}{l}\text { Wind at } 10 \mathrm{~m} \\
\text { (speed and } \\
\text { direction) }\end{array}$ & $\begin{array}{l}\text { Anemometer/ Wind } \\
\text { Direction Sensor }\end{array}$ & $\begin{array}{l}\text { Climatronics } \\
\text { Corporation }\end{array}$ & $\begin{array}{c}\text { F460 P/N } \\
\text { M100075 (6) } \\
\text { Rev E (C) }\end{array}$ & $\begin{array}{c} \pm 0.07 \mathrm{~m} / \mathrm{s} \text { or } \pm \\
1 \%, \text { whichever is } \\
\text { greater } / \pm 2 \\
\text { degrees }\end{array}$ \\
\hline $\begin{array}{l}\text { Temperature } \\
\text { and relative } \\
\text { humidity at } 2 \\
\text { and } 10 \mathrm{~m} \\
\text { (aspirated) }\end{array}$ & $\begin{array}{l}\text { Temperature Sensor/ } \\
\text { Relative Humidity } \\
\text { Sensor / Motor } \\
\text { Aspirated Radiation } \\
\text { Shield }\end{array}$ & $\begin{array}{l}\text { Climatronics } \\
\text { Corporation }\end{array}$ & $\begin{array}{c}\mathrm{P} / \mathrm{N} \\
\mathrm{M} 100093 \\
\text { Rev E }\end{array}$ & $\begin{array}{l} \pm 0.15^{\circ} \mathrm{c} / \pm 3 \% \\
\mathrm{RH}\left(0-40^{\circ} \mathrm{c}\right) \text { or } \pm \\
5 \% \mathrm{RH}\left(-40-0^{\circ} \mathrm{c}\right)\end{array}$ \\
\hline $\begin{array}{c}\text { Incoming Solar } \\
\text { radiation }\end{array}$ & Pyranometer & Kipp and Zonen & CMP3 & $\begin{array}{c}< \pm 5 \% \text { of } \\
\text { observed }\end{array}$ \\
\hline Rainfall & Rain Gauge & Met One & $370 \mathrm{C} / 10097$ & $\pm 1 \%$ observed \\
\hline Evaporation & $\begin{array}{c}\text { Evaporation Pan/ } \\
\text { Gauge }\end{array}$ & Nova Lynx & $\begin{array}{c}103005 \mathrm{G} / \\
255-100\end{array}$ & $0.25 \%$ \\
\hline Pressure & Pressure Sensor & $\begin{array}{l}\text { Climatronics } \\
\text { Corporation }\end{array}$ & $\mathrm{P} / \mathrm{N} 102663$ & $\pm 1 \mathrm{mb}$ \\
\hline $\begin{array}{l}\text { Vertical wind } \\
\text { component }\end{array}$ & $\begin{array}{c}\text { Vertical Component } \\
\text { Anemometer }\end{array}$ & $\begin{array}{l}\text { Climatronics } \\
\text { Corporation }\end{array}$ & $\begin{array}{c}\mathrm{P} / \mathrm{N} \\
\mathrm{M} 102236\end{array}$ & $\begin{array}{c} \pm 0.07 \mathrm{~m} / \mathrm{s} \text { or } \pm \\
1 \%, \text { whichever is } \\
\text { greater }\end{array}$ \\
\hline
\end{tabular}

Table A.2 Instruments that are installed at each of the additional towers.

\begin{tabular}{|l|l|l|l|l|}
\hline East Tower & West Tower & North Tower & South Tower & Central Tripod \\
\hline $\begin{array}{l}\text { Wind at } 10 \mathrm{~m} \\
\text { speed and } \\
\text { direction) }\end{array}$ & $\begin{array}{l}\text { Wind at } 10 \mathrm{~m} \\
\text { (speed and } \\
\text { direction) }\end{array}$ & $\begin{array}{l}\text { Wind at } 10 \mathrm{~m} \\
\text { (speed and } \\
\text { direction) }\end{array}$ & $\begin{array}{l}\text { Wind at } 10 \mathrm{~m} \\
\text { (speed and } \\
\text { direction) }\end{array}$ & $\begin{array}{l}\text { Wind at } 3 \mathrm{~m} \\
\text { (speed and } \\
\text { direction) }\end{array}$ \\
\hline $\begin{array}{l}\text { Temperature and } \\
\text { relative humidity } \\
\text { at } 2 \text { and } 10 \mathrm{~m}\end{array}$ & $\begin{array}{l}\text { Temperature and } \\
\text { relative humidity } \\
\text { at } 2 \text { and } 10 \mathrm{~m}\end{array}$ & $\begin{array}{l}\text { Temperature and } \\
\text { relative humidity } \\
\text { at } 2 \text { and } 10 \mathrm{~m}\end{array}$ & $\begin{array}{l}\text { Temperature and } \\
\text { relative humidity } \\
\text { at } 2 \text { and } 10 \mathrm{~m} \\
\text { (aspirated) }\end{array}$ & $\begin{array}{l}\text { Temperature and } \\
\text { relative humidity } \\
\text { at } 3 \mathrm{~m}\end{array}$ \\
\hline $\begin{array}{l}\text { Incoming Solar } \\
\text { radiation }\end{array}$ & & $\begin{array}{l}\text { Incoming Solar } \\
\text { radiation }\end{array}$ & $\begin{array}{l}\text { Incoming solar } \\
\text { radiation }\end{array}$ \\
\hline Rainfall & & & $\begin{array}{l}\text { Pressure } \\
\text { Vertical wind }\end{array}$ & \\
\hline & & & & \\
\hline
\end{tabular}


Table A.3 Proximity of each tower to the nearest obstruction. All obstructions are rows of trees or forestlands.

\begin{tabular}{|l|l|l|}
\hline Tower & $\begin{array}{l}\text { Distance to nearest } \\
\text { obstruction }\end{array}$ & $\begin{array}{l}\text { Height of nearest } \\
\text { obstruction }\end{array}$ \\
\hline Baseline & $205 \mathrm{~m}$ to the north & 15 meters \\
\hline West & $152 \mathrm{~m}$ to the northeast & 20 meters \\
\hline East & $115 \mathrm{~m}$ to the northwest & 25 meters \\
\hline North & $68 \mathrm{~m}$ to the west & 9 meters \\
\hline South & $152 \mathrm{~m}$ to the northeast & 12 meters \\
\hline
\end{tabular}



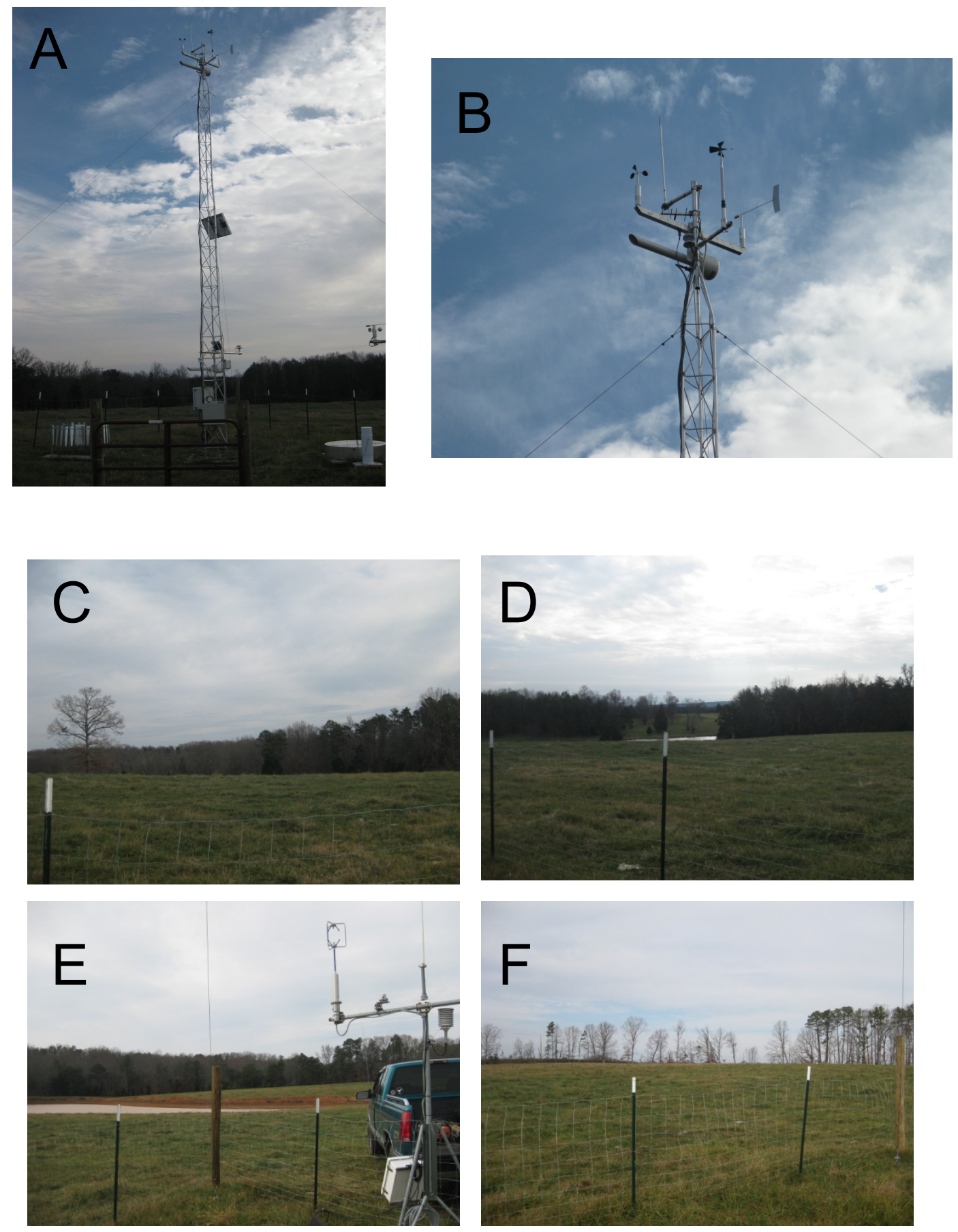

Figure A.1: Photos of the baseline tower (A), close up of the anemometer at $10 \mathrm{~m}(\mathrm{~B})$, and views to the east $(C)$, north $(\mathrm{D})$, west $(\mathrm{E})$, and south $(\mathrm{F})$ facing away from the tower. 


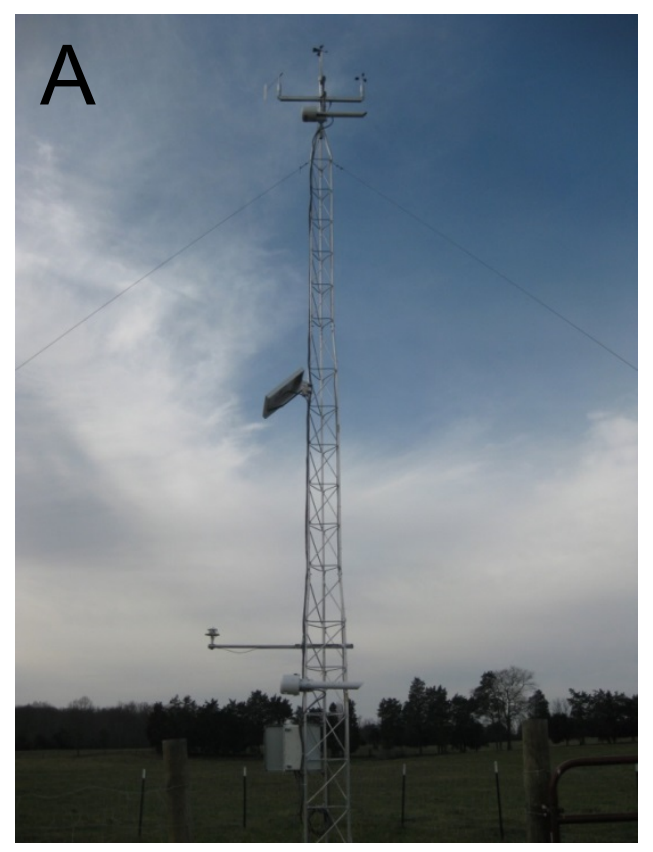

\section{B}
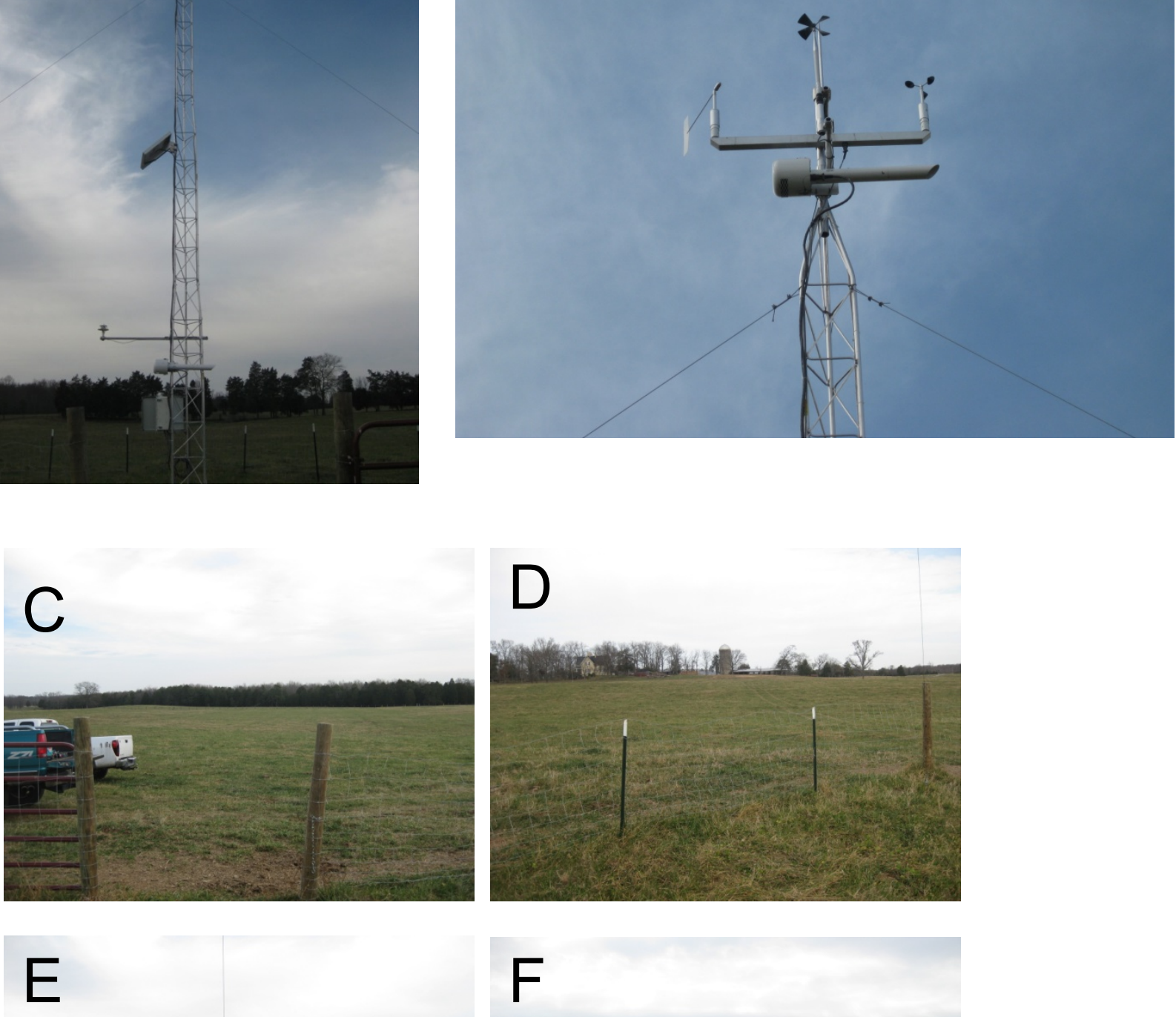

\section{F}
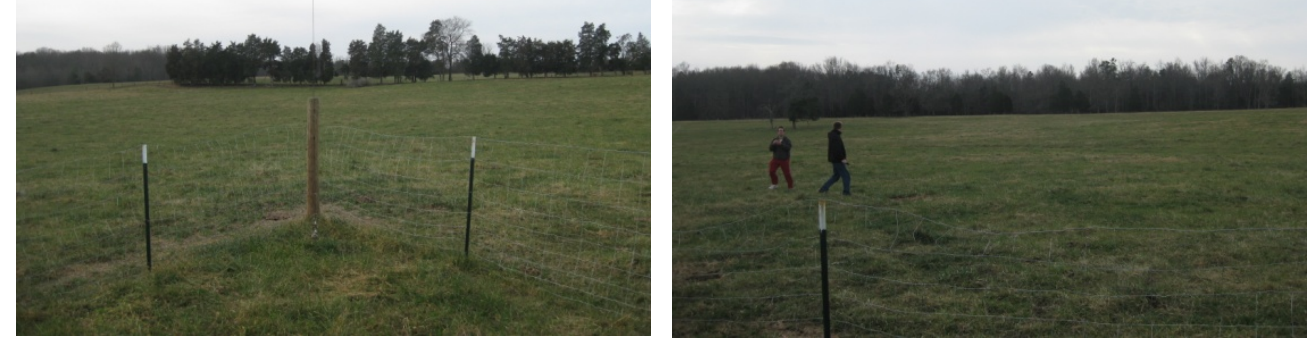

Figure A.2: Photos of the south tower (A), close up of the anemometer at $10 \mathrm{~m}$ (B), and views to the east (C), north (D), west (E), and south (F) facing away from the tower. 

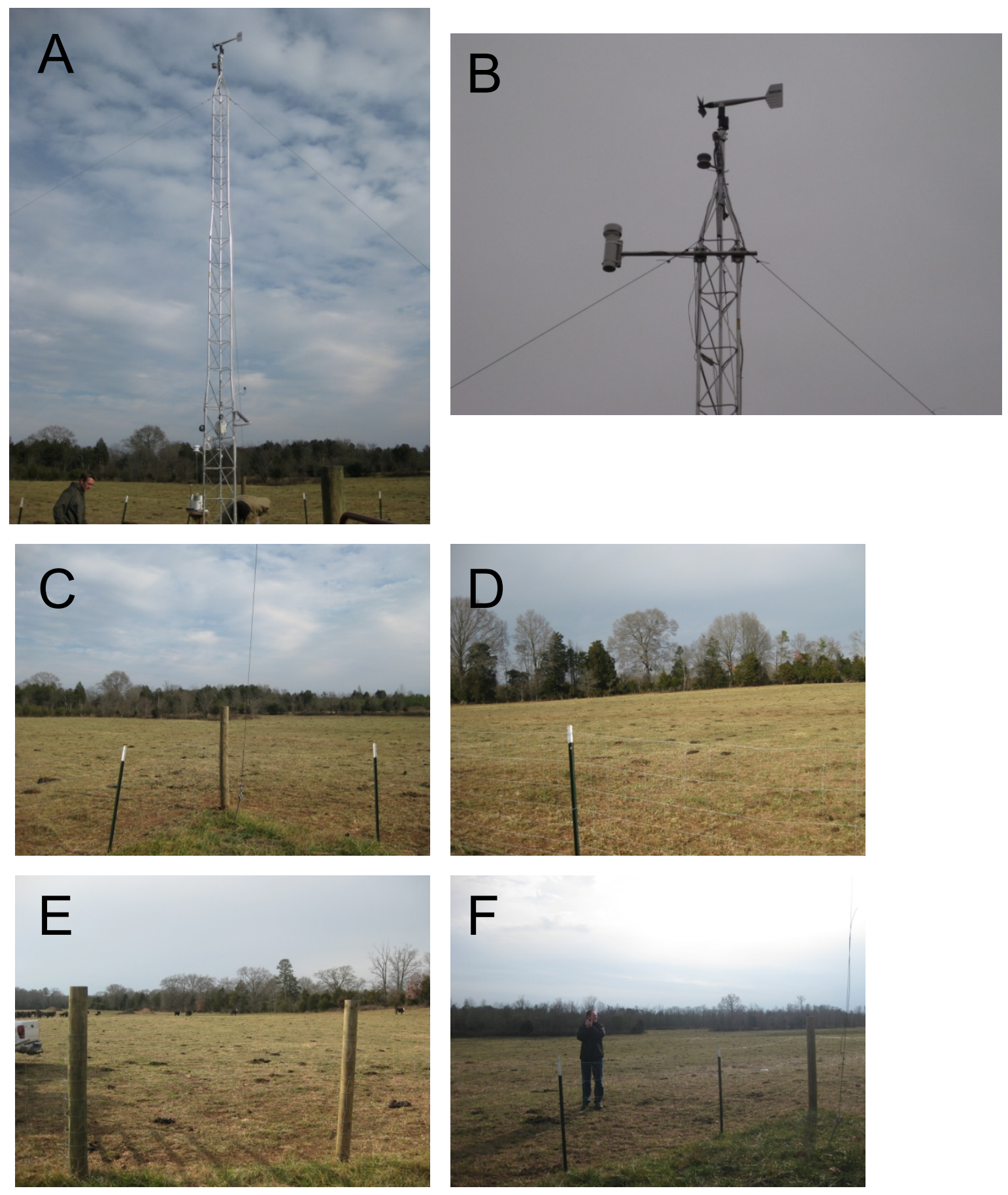

Figure A.3: Photos of the east tower (A), close up of the anemometer at $10 \mathrm{~m}(\mathrm{~B})$, and views to the east (C), north (D), west (E), and south (F) facing away from the tower. 

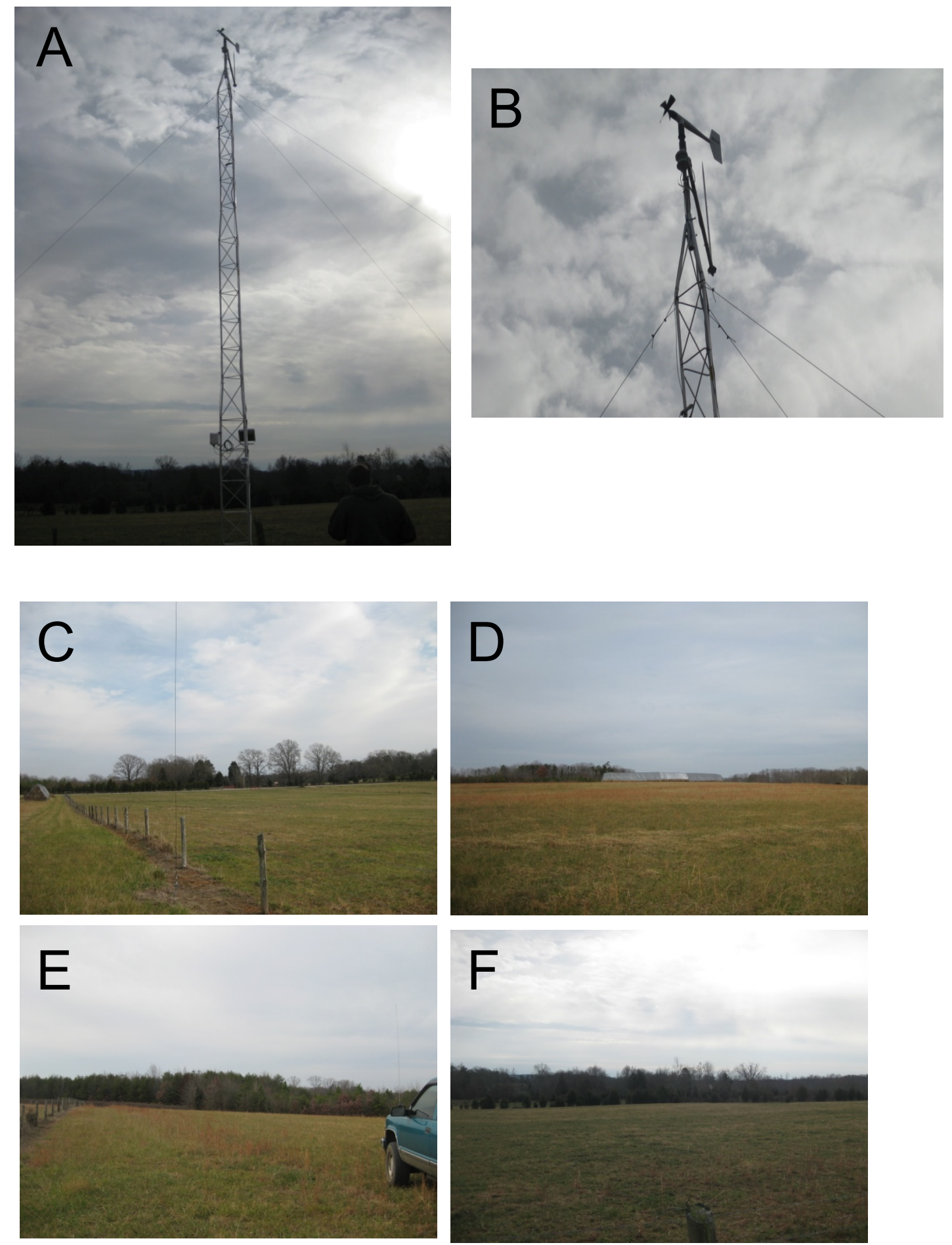

Figure A.4: Photos of the north tower (A), close up of the anemometer at $10 \mathrm{~m}(\mathrm{~B})$, and views to the east $(C)$, north (D), west $(E)$, and south (F) facing away from the tower. 

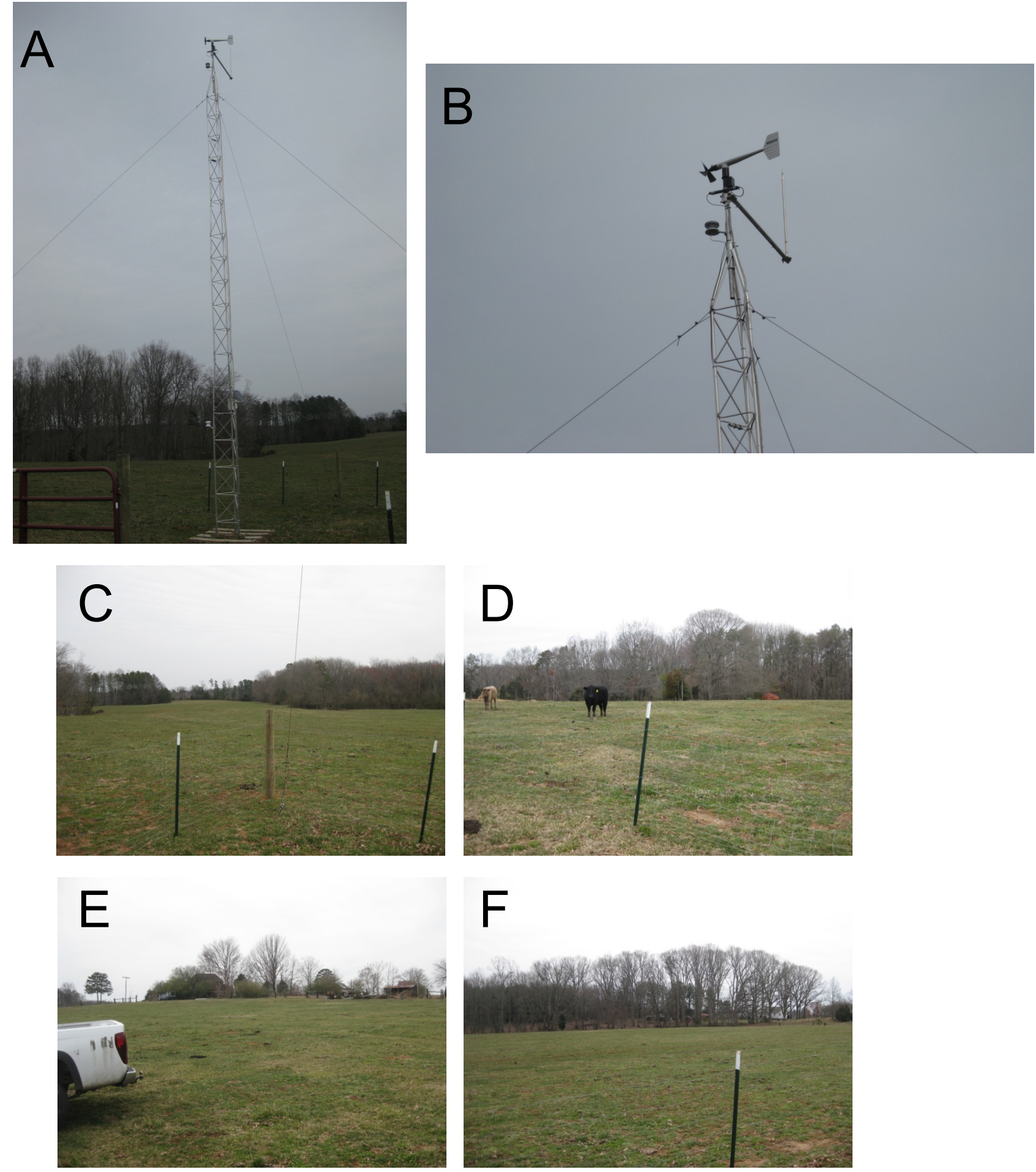

Figure A.5: Photos of the west tower (A), close up of the anemometer at $10 \mathrm{~m}(\mathrm{~B})$, and views to the east (C), north (D), west (E), and south (F) facing away from the tower. 


\section{A.2: Data management and quality control}

Data loggers are installed at each tower and record data from all instruments every minute. The Campbell Scientific dataloggers (baseline and south towers) sample data every second while the HOBO data loggers sample data every second for all variables except wind speed and direction, which samples every 3 seconds. A rigorous quality assurance/quality control (QC/QC) plan is applied to the collected data to ensure that an accurate data set is obtained. A visual flow chart (figure A.6) is provided and is also explained in the following section. Roughly every two weeks the data are downloaded from each tower by a Virginia Uranium representative and sent to UVA electronically or by members of the De Wekker lab group. These data are then compiled into monthly data files. At this time, we perform an initial visual quality check of the data to identify any significant gaps in and/or issues with the data. All minute data files are then converted into hourly data files using a code collaboratively written by Stephan de Wekker and Stephanie Phelps using the IDL programming language. In order for a specific data point to be incorporated into an hourly average, it must fall between predefined thresholds of logical values for each particular variable. This quality control step is referred to as quality control phase 1 . If a data point does not fall between the specified thresholds (Table A.4) then it is replaced with a 'NaN'. Another visual quality check, referred to as quality control phase 2 , is conducted for the hourly averaged data and any obvious outliers are changed to 'NaN'. Hourly averages for all variables are calculated only when at least 30 minutes of quality-controlled data are present for one hour. The format of the hourly averaged files is identical for each tower and the "NaN" identifier is used for missing or invalid data. 


\section{Chatham Data Flow Process}

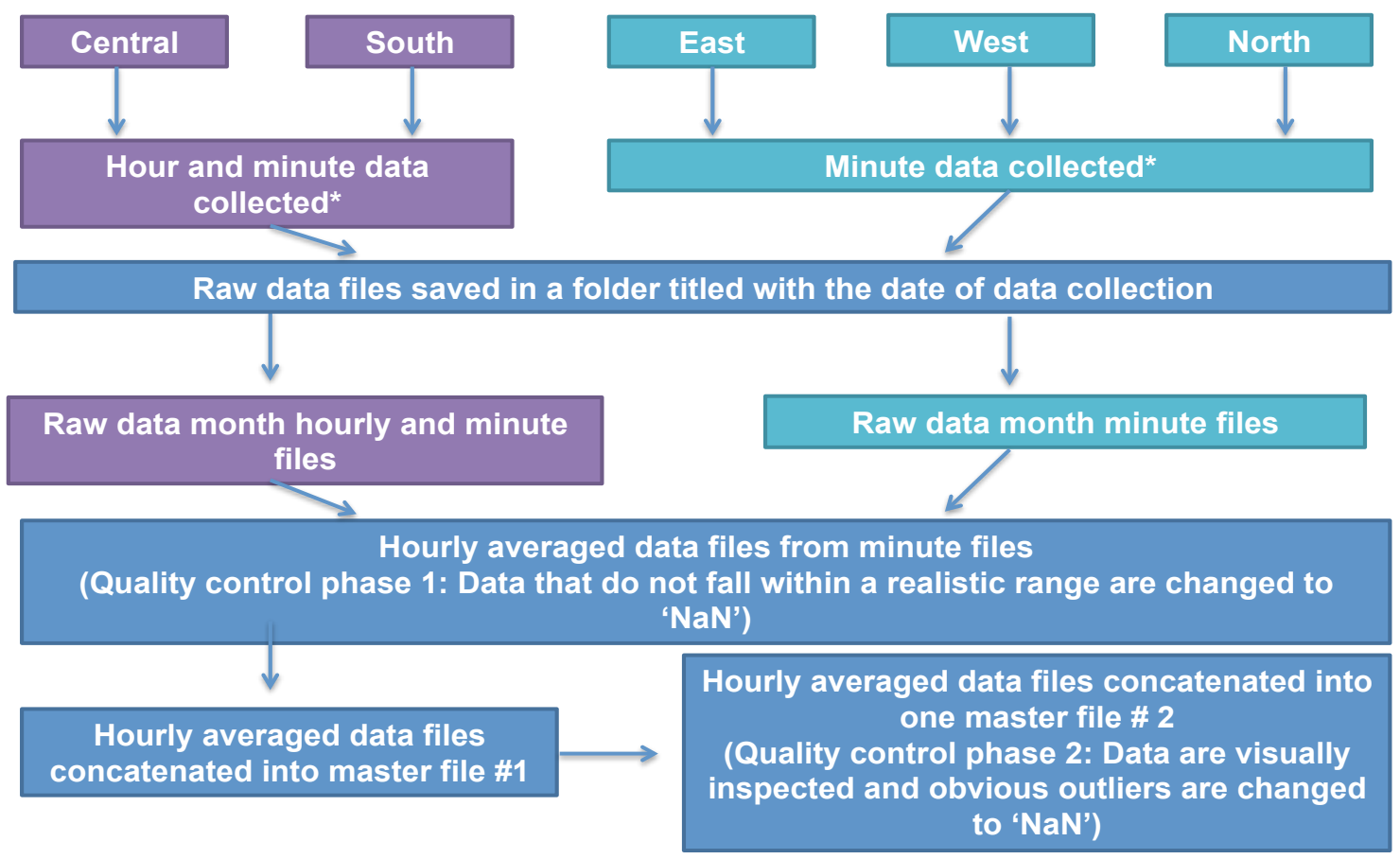

*Data collected by Stewart East (July 2012- Nov. 2013) or De Wekker lab group (Nov. 2013 - Present)

Figure A.6: Data quality control and quality assurance flow chart for the data that comes from the five $10 \mathrm{~m}$ meteorological towers involved in this study.

Table A.4: The thresholds the minute data are passed through to ensure accurate data points are used in the hourly averages. If a data point does not fall within these realistic thresholds, then it will be disregarded and not used in the hourly average.

\begin{tabular}{|l|l|l|}
\hline Variable & $\begin{array}{l}\text { Min } \\
\text { Threshold }\end{array}$ & Max Threshold \\
\hline Wind Speed & $0 \mathrm{~m} / \mathrm{s}$ & $30 \mathrm{~m} / \mathrm{s}$ \\
\hline Wind Direction & $0^{\circ}$ & $360^{\circ}$ \\
\hline $2 \mathrm{~m}$ temp & $-25^{\circ} \mathrm{C}$ & $40^{\circ} \mathrm{C}$ \\
\hline $10-2 \mathrm{~m}$ temp & $-15^{\circ \mathrm{c}}$ & $15^{\circ \mathrm{c}}$ \\
\hline Solar Radiation & $0 \mathrm{~W} / \mathrm{m}^{2}$ & $2000 \mathrm{~W} / \mathrm{m}^{2}$ \\
\hline
\end{tabular}


For some variables such as the wind direction, the averaging procedure follows some specific steps. To average wind direction, the first step is to break down the mean wind speed into the $u$ and $v$ components of the wind. All wind variables are measured in relation to true north. The $u$ wind component represents the zonal component of the wind and a positive $u$ value denotes wind blowing from the west. The $v$ wind component represents the meridional component of the wind and a positive $v$ value denotes winds blowing from the south. The $u$ and $v$ wind components are related to the total wind speed $\mathrm{U}$ and the wind direction $\theta$ (in degrees) by:

$$
\begin{aligned}
& u=-U * \sin (\theta * \pi / 180) \\
& v=-U * \cos (\theta * \pi / 180)
\end{aligned}
$$

For each 1-minute data, $\mathrm{u}$ and $\mathrm{v}$ are determined and then averaged to hourly values, $u \_a v g$, and $v \_a v g$. From these hourly averaged $u$ and $v$ component of the winds, the hourly averaged wind direction $\theta_{-} a v g$ is calculated using the inverse tangent function:

$$
\theta_{-} a v g=\tan ^{-1}\left(-u_{-} a v g / v_{-} a v g\right) * 180 / \pi
$$

\section{Appendix B: Kestrel Testing}

Kestrel 4500 handheld weather meters were used to measure vertical profiles of wind speed, wind direction and temperature using an originally designed attachment apparatus during three different field campaigns. Details about the structure and the use of the tethersonde set up are included in section xx of this thesis. In order to assure the accuracy of the Kestrel 4500 and the entire tethersonde setup, a number of tests were conducted prior to the field experiments. 
The specifications for the wind speed, wind direction and temperature variables for the Kestrel 4500 are found in Table B.1. The wind measurements from the Kestrel 4500 were extensively tested to ensure the instrument is suitable for scientific research. Tests were conducted both on stationary surfaces and attached to the blimp. For testing, the Kestrel 4500 was compared to other Kestrel 4500's and RM Young anemometers. Before this work began, all Kestrel 4500's involved in the study were sent to the manufacturer for routine calibration. All instruments were returned with no known issues prior to and post calibration and the most recent version of the Kestrel 4500 software was loaded to the each instrument.

Table B.1: The accuracy and resolution for the variables used from the Kestrel 4500 handheld weather meter.

\begin{tabular}{|l|l|l|}
\hline Variable & Accuracy & Resolution \\
\hline Wind Speed & $0.1 \mathrm{~m} / \mathrm{s}$ & $0.1 \mathrm{~m} / \mathrm{s}$ \\
\hline $\begin{array}{l}\text { Wind } \\
\text { Direction }\end{array}$ & $\pm 1^{\circ}$ & $5^{\circ}$ \\
\hline Temperature & $\pm 1^{\circ} \mathrm{C}$ & $0.1^{\circ} \mathrm{C}$ \\
\hline
\end{tabular}

To begin the testing, the Kestrel instruments were compared to each other to ensure that the same data, within a realistic range, were collected across multiple Kestrel 4500's and from different Kestrel wind vanes. A total of 26 hours of data were collected where different combinations of four different Kestrel 4500's and wind vanes were compared. The tests occurred during a variety of wind, temperature, time of day, and cloud cover conditions in three different geographical locations. The locations included Eleuthra, Bahamas, Blairsville, Georgia, and two locations in Charlottesville, Virginia (Figure B.1). The durations of these tests were each roughly four hours long. The general results of the tests are included in Table B.2. 


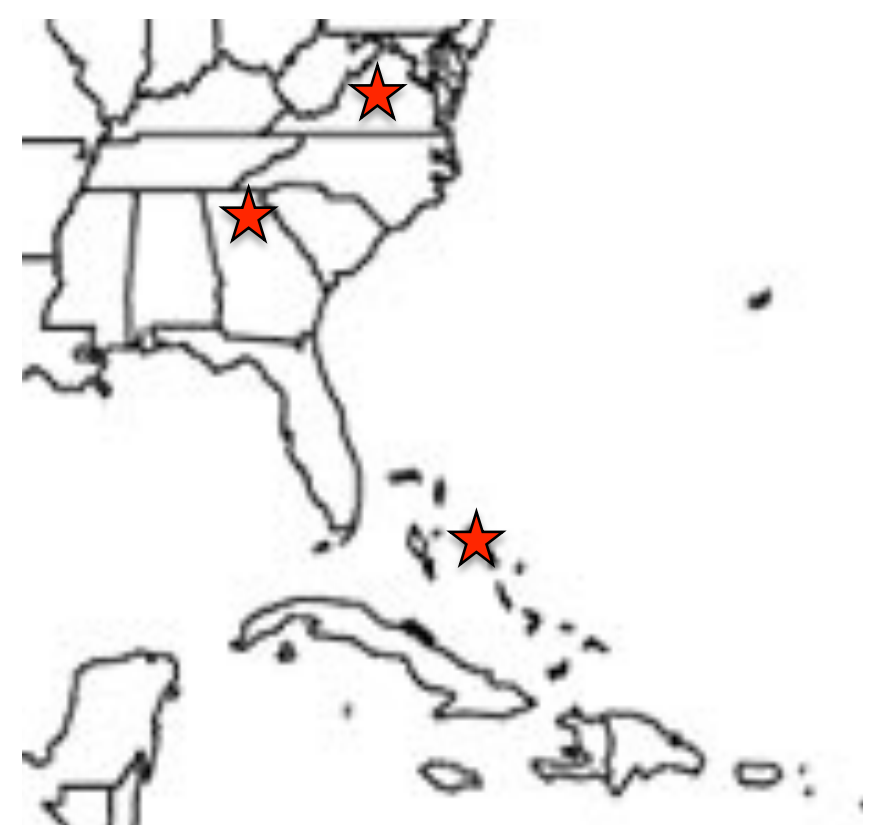

Figure B.1: The locations where the kestrel vs. kestrel tests took place (red stars). These locations included Eleuthra, Bahamas, Blairsville, Georgia, and two locations in Charlottesville, Virginia.

Table B.2: Results from side by side comparisons of Kestrel 4500 weather meters. MAE refers to the mean average error.

\begin{tabular}{|c|c|c|}
\hline Variable & 2 s MAE & 1 min MAE \\
\hline Wind Speed & $0.204 \mathrm{~m} / \mathrm{s}$ & $0.127 \mathrm{~m} / \mathrm{s}$ \\
\hline Wind Direction & $16.5^{\circ}$ & $11^{\circ}$ \\
\hline
\end{tabular}

For each test, the Kestrel's collected data at a 2 second rate. During post processing steps, the 2 second data were averaged into one minute data. It was found that with the increased averaging time the differences between the Kestrels became smaller. In general, the results from the sideby-side Kestrel tests proved that the instruments were consistent enough to move forward with testing. A major source of error from these tests could be nearby obstructions causing differences in wind characteristics between the two side-by-side sensors. The testing sites were confined to locations where the sensors could be left alone for a number of consecutive hours. This requirement reduced the number of choices for possible testing locations and, therefore, the 
selected locations each had minimal, but not absent, nearby obstructions that could alter the wind flow patterns.

The next step in testing the Kestrel 4500's was to test them next to RM Young propeller anemometers on stationary surfaces since RM Young anemometers are considered more accurate. For these tests, a total of 34 hours of data were collected in tests that occurred in $3-10$ hour increments. For these tests, the Kestrel 4500's collected data at a 2 second interval and the RM Young anemometer collected data at a 10 second interval. The differences in sampling interval are due to limitations imposed by the HOBOware data logger. These tests were also conducted during a variety of weather conditions in three different geographical locations that were different from previous tests. The results from these tests are found in Table B.3.

Table B.3: Results from side by side comparisons of Kestrel 4500 weather meters and RM Young Anemometer. MAE refers to mean average error.

\begin{tabular}{|c|c|c|}
\hline Variable & 10 s MAE & 1 min MAE \\
\hline Wind Speed & $0.373 \mathrm{~m} / \mathrm{s}$ & $0.198 \mathrm{~m} / \mathrm{s}$ \\
\hline Wind Direction & $35^{\circ}$ & $28^{\circ}$ \\
\hline
\end{tabular}

For these comparisons, the Kestrel 4500 data were either averaged to 10 second data or 1 minute data and either the raw RM Young data or 1 minute averaged data were used. Similar to the Kestrel 4500 vs. Kestrel 4500 tests, we found that the agreement increased with increasing averaging time. The results from these comparisons showed favorable agreement for wind speed and less favorable agreement for wind direction. Although the wind direction differences were undesirable, subsequent comparisons between the Kestrel 4500 mounted on the tether balloon and the RM young mounted on the tower proved more promising, as shown later in this section. Possible reasons for the undesirable wind direction comparison could be because 1) nonobstructed testing locations were difficult to find and some testing locations were subject to 
wakes from buildings and vegetation and 2) the RM Young anemometer must be oriented with true north and error could arise from the constant need to move and re-orient the instrument between tests.

Finally, tests of the entire tethersonde system (Kestrel 4500 mounted to the tether balloon line) were conducted between the tethersonde and the $10 \mathrm{~m}$ towers. For these tests, the Kestrel 4500's attachment apparatus was connected to the line of the 13-foot blimp and held at the $10 \mathrm{~m}$ height adjacent to the RM Young anemometer, which is mounted at the $10 \mathrm{~m}$ height on the tower. These tests occurred in two ways. First, a 4-hour test was conducted at the north tower where the balloon was left at $10 \mathrm{~m}$ for a continuous 4 hour period. Second, during each field campaign the kestrel apparatus was situated at the $10 \mathrm{~m}$ height adjacent to the $10 \mathrm{~m}$ towers for 10 minutes after each profile. The wind data were then compared to one another. The results from this test are provided in table B.4 and are more promising than the previous Kestrel 4500 vs. RM Young test in terms of wind direction.

Table B.4: Results from side by side comparisons of Kestrel 4500 weather meter (mounted on tether balloon) and RM Young Anemometer (mounted on tower). MAE refers to mean average error

\begin{tabular}{|c|c|c|}
\hline Variable & $\mathbf{1 0} \mathbf{~ s ~ M A E}$ & $\mathbf{1}$ min MAE \\
\hline Wind Speed & $0.44 \mathrm{~m} / \mathrm{s}$ & $0.31 \mathrm{~m} / \mathrm{s}$ \\
\hline Wind Direction & $27^{\circ}$ & $21^{\circ}$ \\
\hline
\end{tabular}

This resulted in roughly 15 hours of Kestrel 4500 vs. RM Young comparison. A source of error from this set of tests could be due to the low wind speed conditions at the $10 \mathrm{~m}$ height during each field experiment. Based on prior knowledge and previous tests, the accuracy of the wind measurements should increase with increasing wind speed when the Kestrel is mounted on a 
stationary object. However, as the wind speed increases the accuracy of wind measurements on the tethersonde decreases because the blimp will move around and causes the Kestrel to tilt..

\section{Appendix: C: WRF evaluation}

Since the nocturnal boundary layer is difficult for numerical weather models to resolve, careful consideration must be given to the choice of parameterization schemes used. This is especially true for the planetary boundary layer parameterization scheme, which highly influences the amount of near surface mixing resulting in drastic changes in the near surface wind characteristics. After some sensitivity testing, a combination of parameterization schemes was determined that best simulates the nocturnal boundary layer in the Chatham region. The same combination of settings was used for each WRF model run for each field campaign. For every run, the microphysics and convective parameters were turned off because only clear conditions are modeled in this study. In addition, the widely used Unified Noah land-surface model land/surface physics scheme (Tewari et al. 2004) is used for all model runs. Since the planetary boundary layer (PBL) scheme has a large impact on near surface model wind output, especially for stable boundary layer conditions, three different PBL schemes were compared to determine which scheme should be used for the model runs. The three different schemes tested include 1) YSU scheme (Hong et al. 2006), 2) MYNN scheme (Nakanishi and Niino 2006), and 3) Mellor-Yamada-Janjic TKE scheme (Janjic 1994). 30-hour model runs were conducted holding all schemes the same except the PBL scheme. One exception to this was when WRF was run using the Mellor-Yamada-Janjic TKE scheme. For this scheme to work correctly, the surface layer scheme must be set to the Monin-Obukhov (Janjic) scheme (Janjic 2002). For the other two runs, the surface layer scheme is set to the MM5 Monin-Obukhov scheme (Zhang and Anthes 1982). 
The three different PBL schemes tested (YSU, MYNN, and MYJ) were used for WRF model runs for August 14 to August 152013 (field campaign \#1) and the output is shown in every other hour increments between 23 LST and 13 LST in figures C.1, C.2 and C.3. 

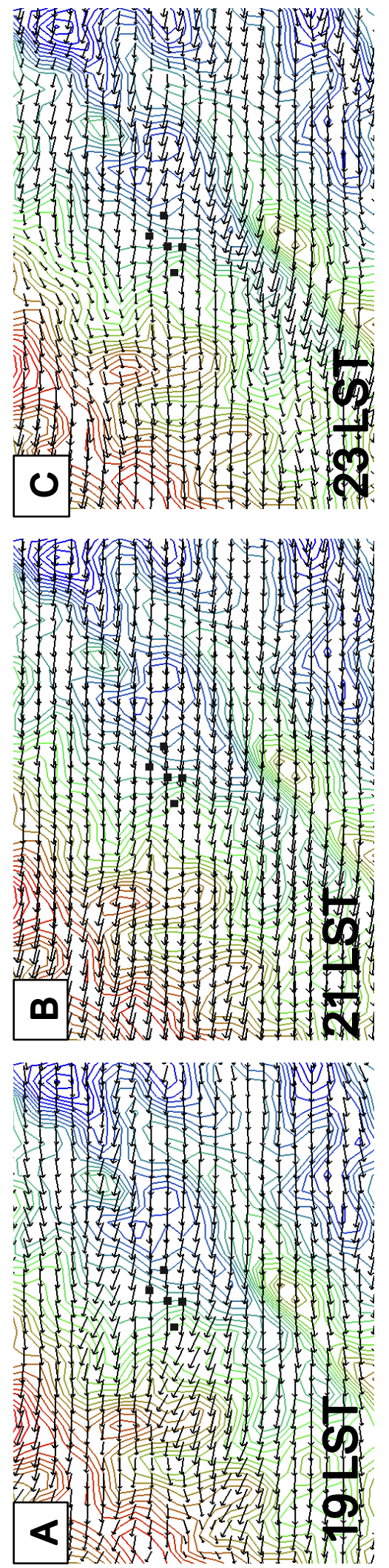
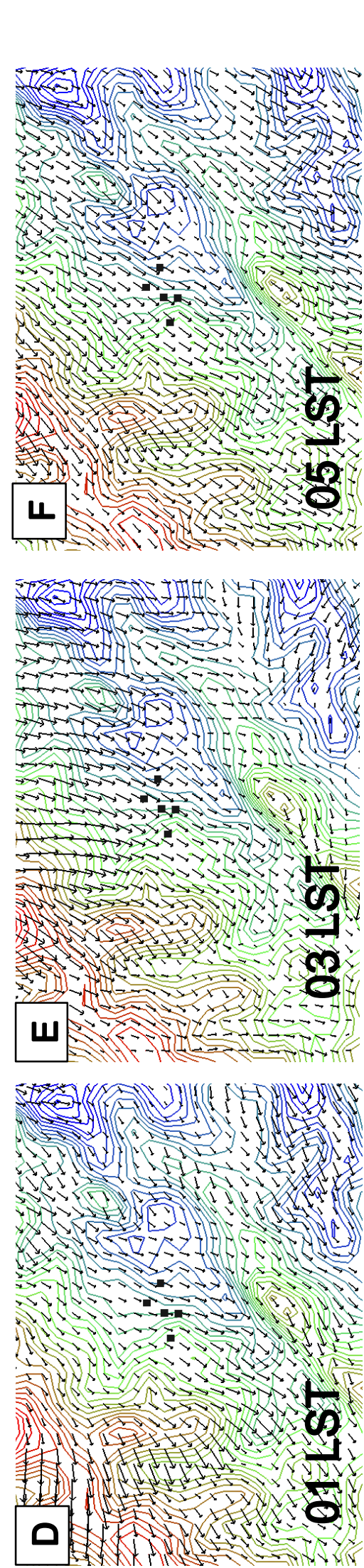

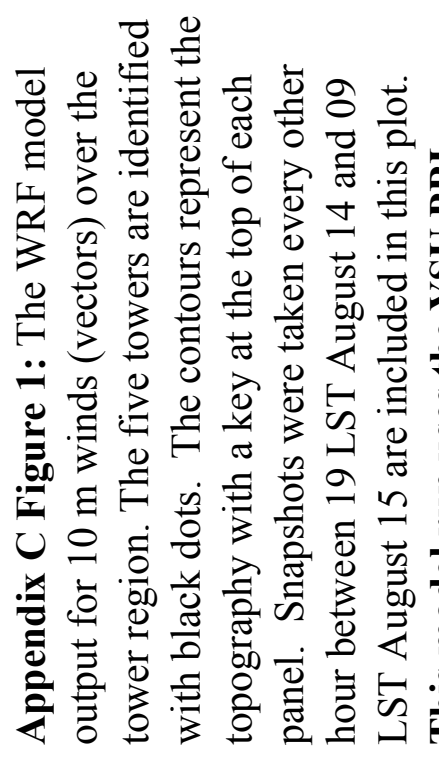

-

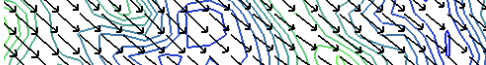

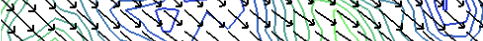

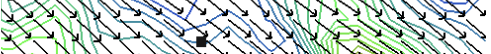

$+1,1,1,1,1,1,1$

11,5 L

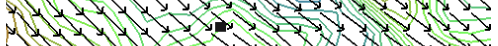

$1,1,1,1,1$
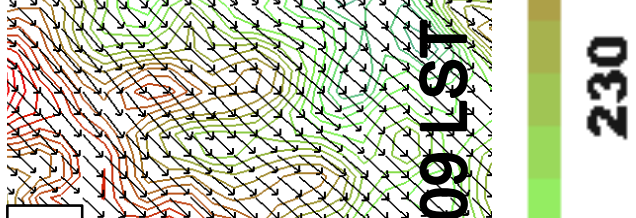

I

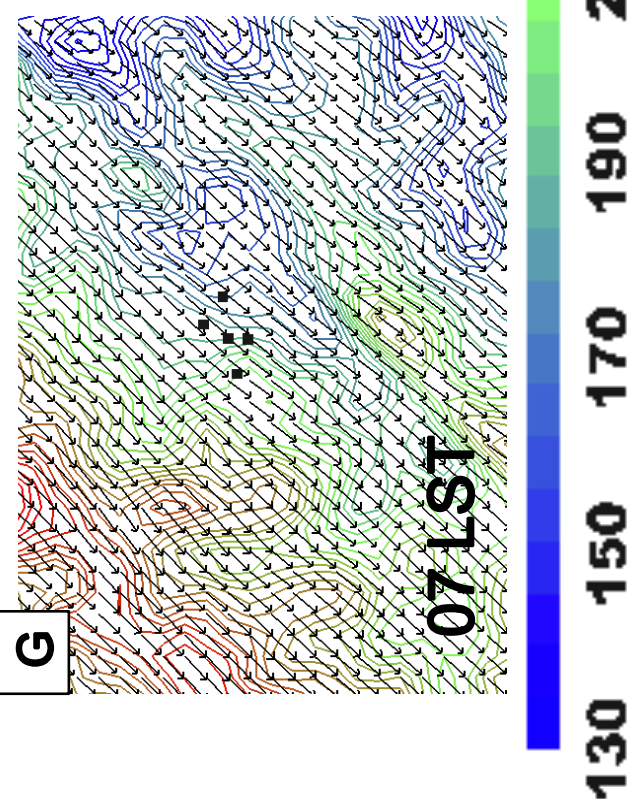



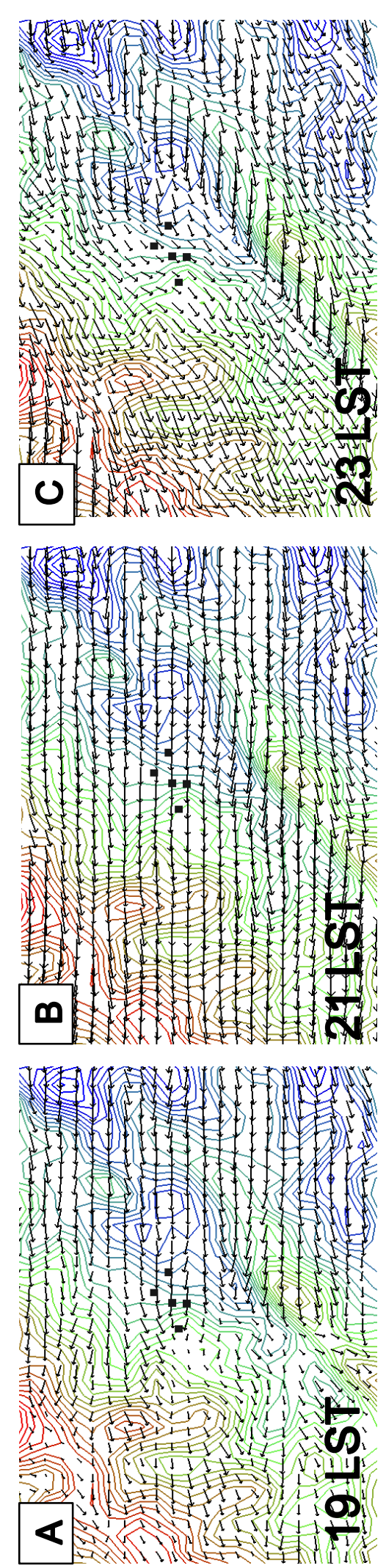
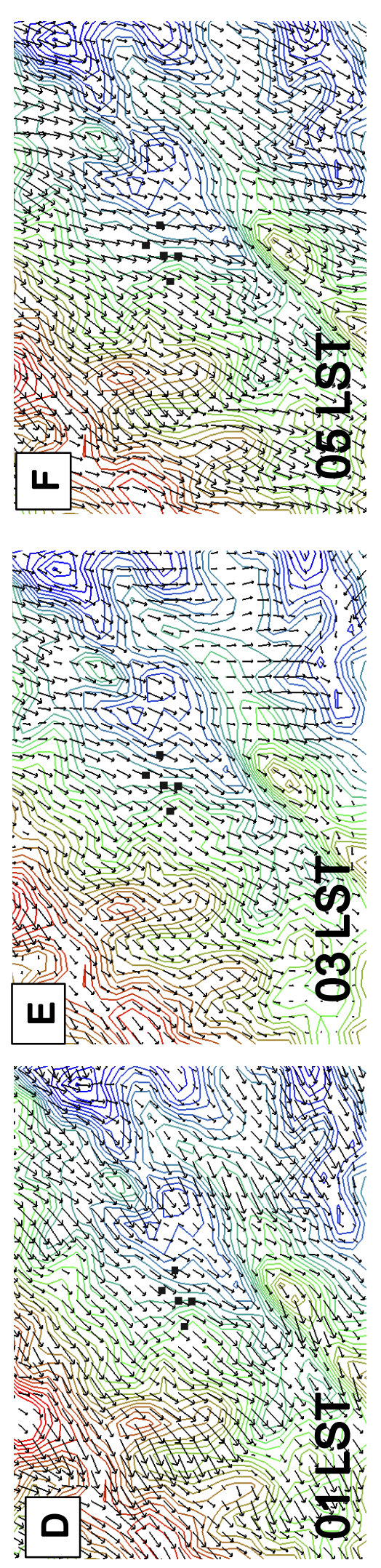

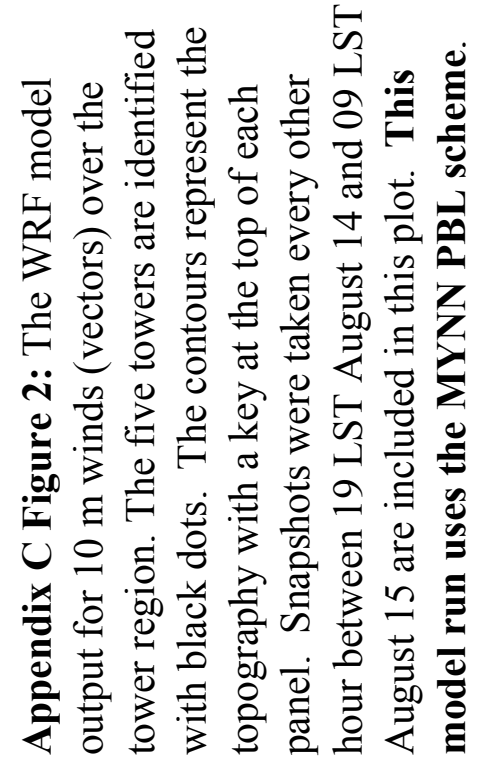

롱

L 1 1111 4 L 11 L - LIIII 1 1 - L I I $1+1,1,1,11$ $1+111111$ $11+1,1$ $11+11 \ldots$ 1 1 - 1 1 1 1 I 1.1.1.1.1. I 1 I I W......

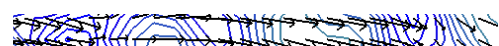

ant
○

N 

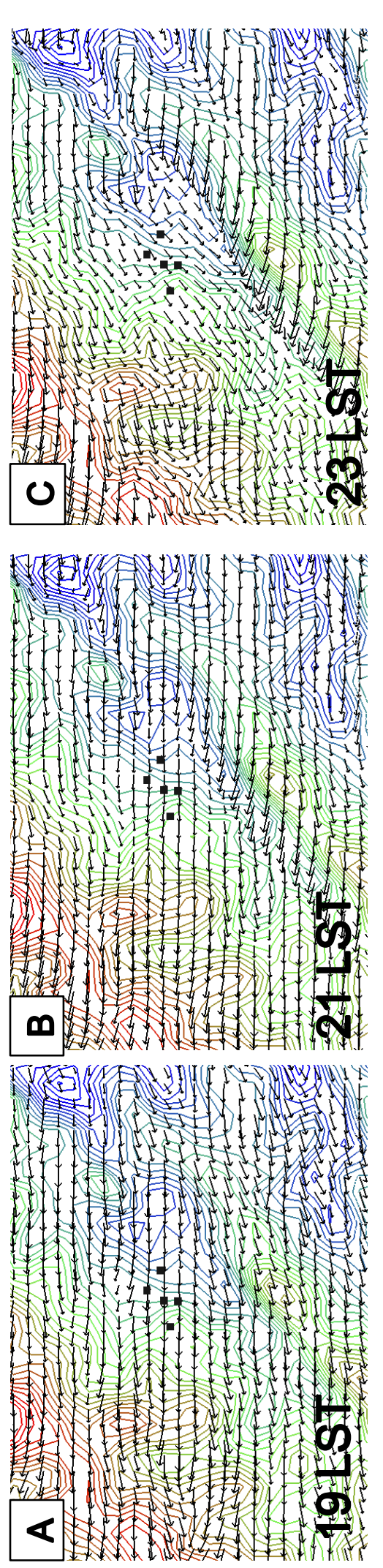
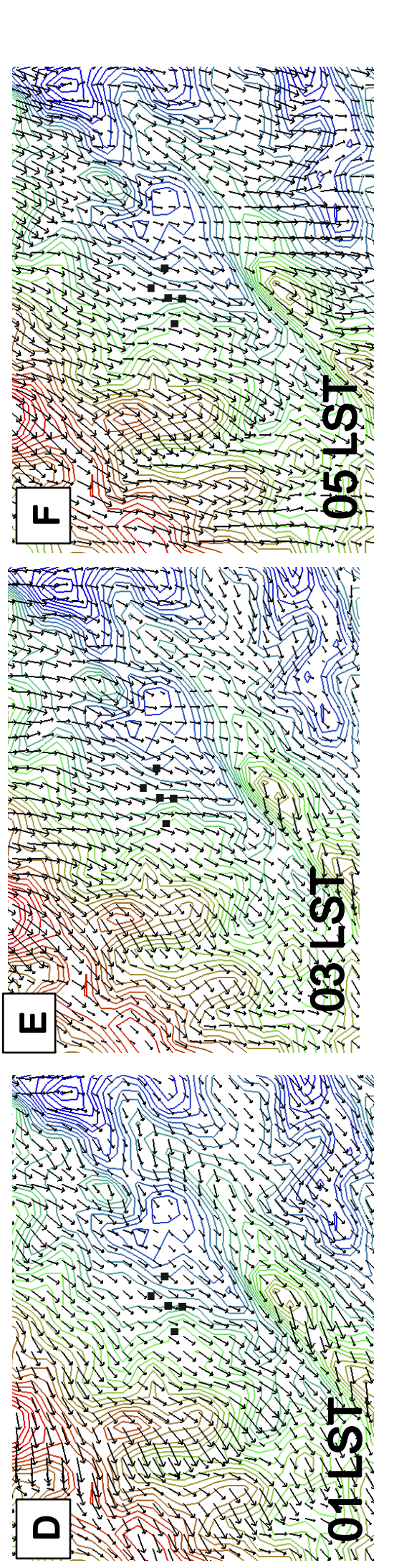

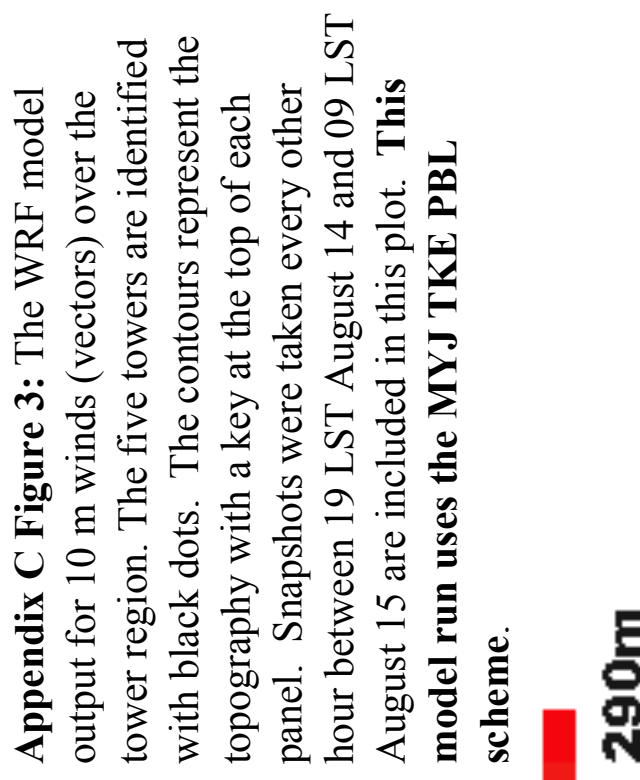

2

1 1 $1,1,1$

- $1,1,1$ 11 L I I 1 1 1 1 1

$1,1,1,1$

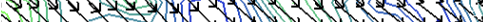

1 $1,1,1,1,1$

1 1,121

- $1,1,1,1$

$11+1,111$

$1+1+1-1,1<1<1$

$1+1+1+1,1+1,1$

- 1 $1,1,1,1,1$

- $1,1,1,2$

- 1 1 1.1.1.

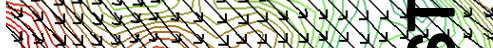

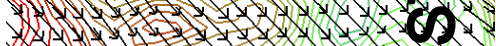
- I l 1.11 - I 1 1 J 1 J J J

I I I

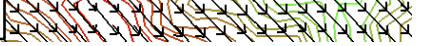

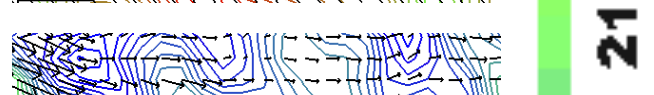

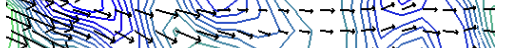

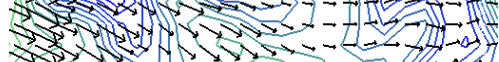

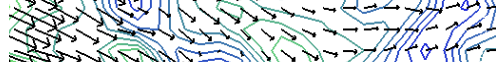

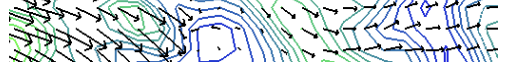

- 1.

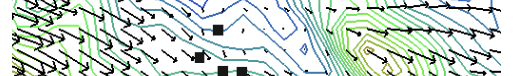

in 1 ,

9

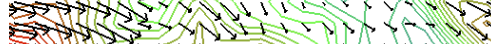

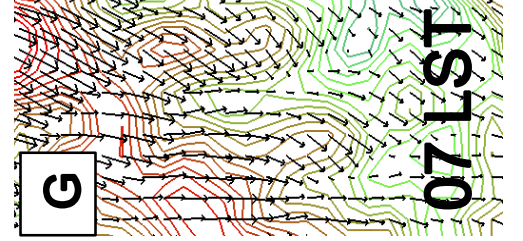

9

$\frac{O}{N}$

ํㅗ
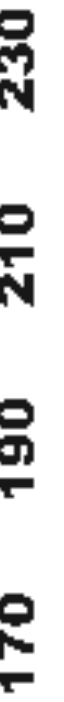

t5

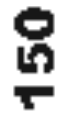


During this night, a regional drainage flow caused the winds to shift from easterly, to northerly, and back to northeasterly between 23 LST and 13 LST. In addition, drainage flows off of the ridge to the south of the towers causes some easterly flows within close proximity of the towers late in the night. It is evident that the YSU PBL scheme leads to too much mixing at the surface leading to too strong of winds at the surface, and, therefore, decreased evidence of the local and regional terrain induced flows that occurred this night (figure C.1). This model run showed a much different overall flow pattern compared to the other two runs and is not a good representation of the regional flow for this night because of the aforementioned reasons. The runs with the MYNN and MYJ PBL schemes were especially similar to one another, but the MYJ run represented the actual $10 \mathrm{~m}$ winds the best and was therefore chosen as the PBL scheme to be used for the model runs (Figure C.2 and C.3). Otherwise, these two runs showed very similar regional flow patterns and are considered to represent the regional flow for this night well.

For each modeled night, or for each field experiment night, the hourly WRF model output and tower $10 \mathrm{~m}$ wind speed and wind direction data are compared. For the first night (August 14 - August 15 2013), the wind speeds predicted by WRF are slightly stronger than the actual winds reported from the tower and the wind direction is agreeable between the actual winds and the WRF output. The winds at the tower become northwesterly between 22 LST and 8 LST at the tower while WRF shows more north/ northeasterly flow during the same time (figure C.4). The northwesterly trend of the actual winds are evidence of the regional drainage flow and it is not surprising that WRF does not fully capture the full wind shift from east/northeast to northwest during this night. As for field experiment two (April 9, 2014 - April 10, 2014), there is good agreement between the WRF model run and the tower $10 \mathrm{~m}$ wind data (figure C.5). The third 
field campaign (May 19, 2014 - May 20, 2014) WRF simulation showed some scatter in wind direction measurements for both the tower and the WRF output between 06 LST May 19, 2014 and 16 LST May 19, 2014 (Figure C.6). This scatter is not of concern because it occurs during the 'spin up' time for the model and does not occur during the night, which this study is most concerned with. After 16 LST May 19, 2014, good agreement is seen for the remaining portion of the run. The wind speed measurements are in good agreement throughout this model run. We acknowledge that there are some discrepancies in the accuracy of the model output, although, for the purposes of this study, the WRF model produces sufficient results to gather the 'overall' picture of how the winds flow in the Chatham region.
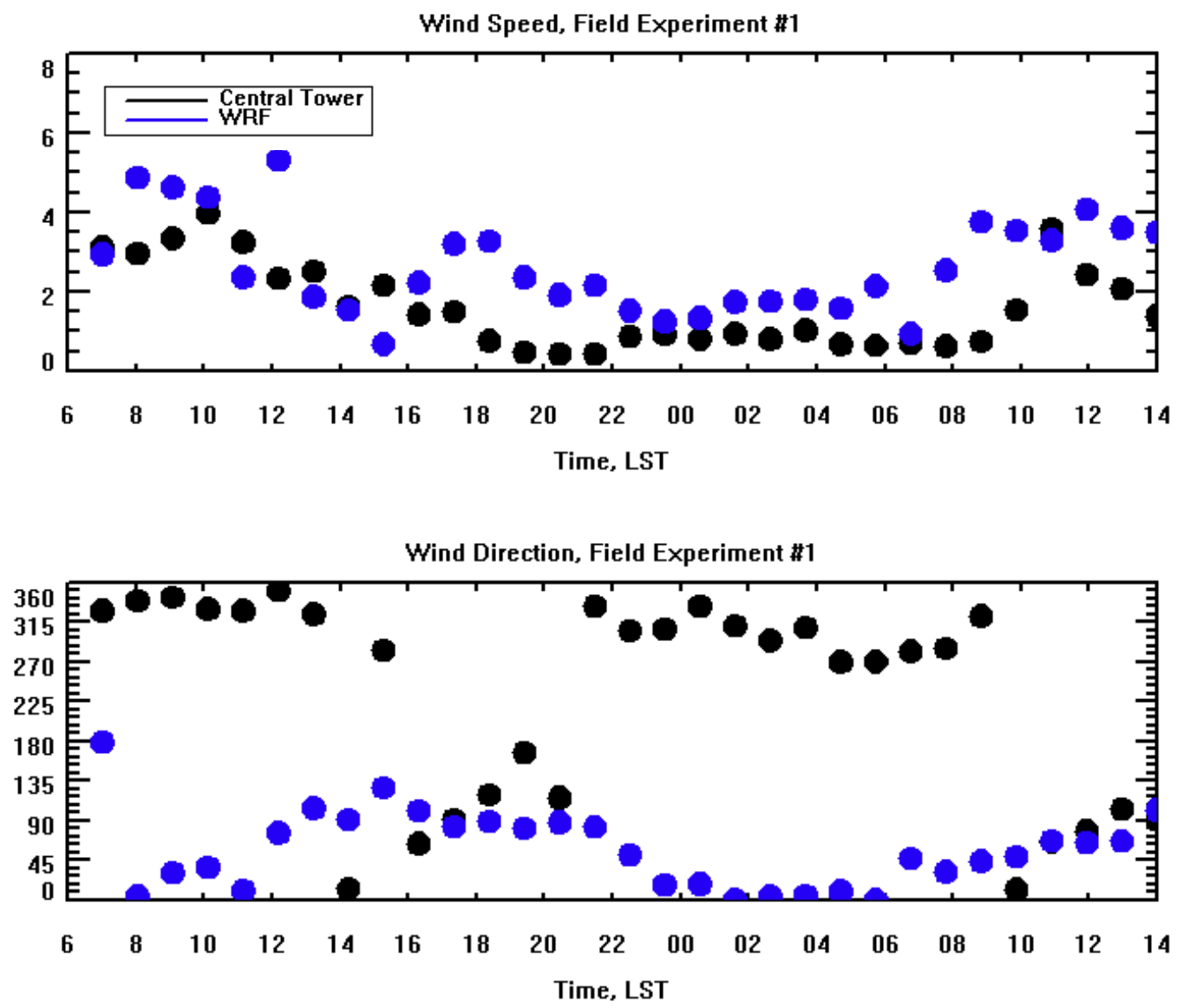

Figure C.4: Time series of $10 \mathrm{~m}$ winds from the baseline tower (black) and WRF $10 \mathrm{~m}$ winds (blue) for the times between 06z August 14, 2013 - 14z August 15, 2013 (field campaign \#1). 

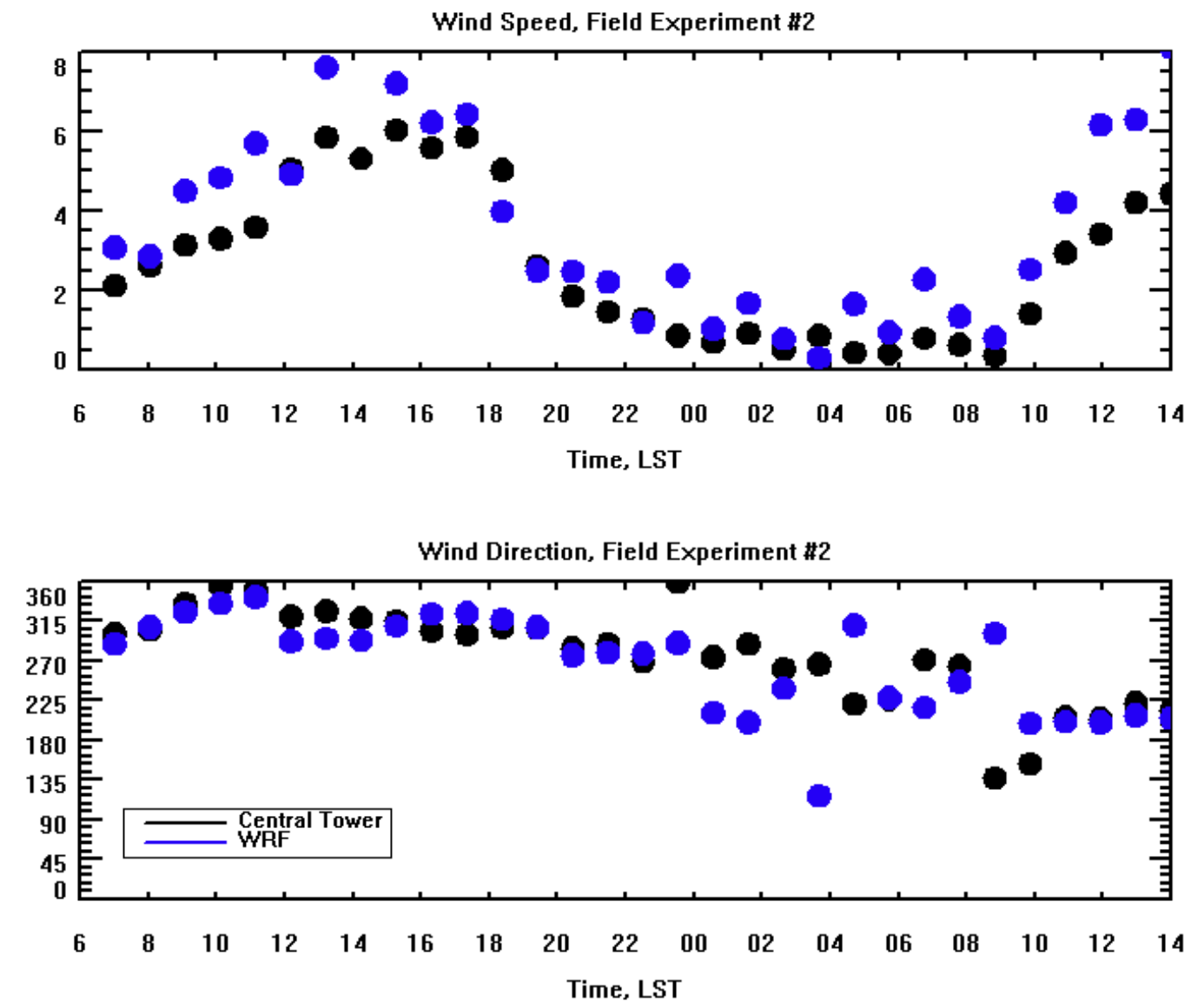

Figure C.5: Time series of $10 \mathrm{~m}$ winds from the baseline tower (black) and WRF $10 \mathrm{~m}$ winds (blue) for the times between 06z April 9, 2014-14z August 10, 2014 (field campaign \#2). 

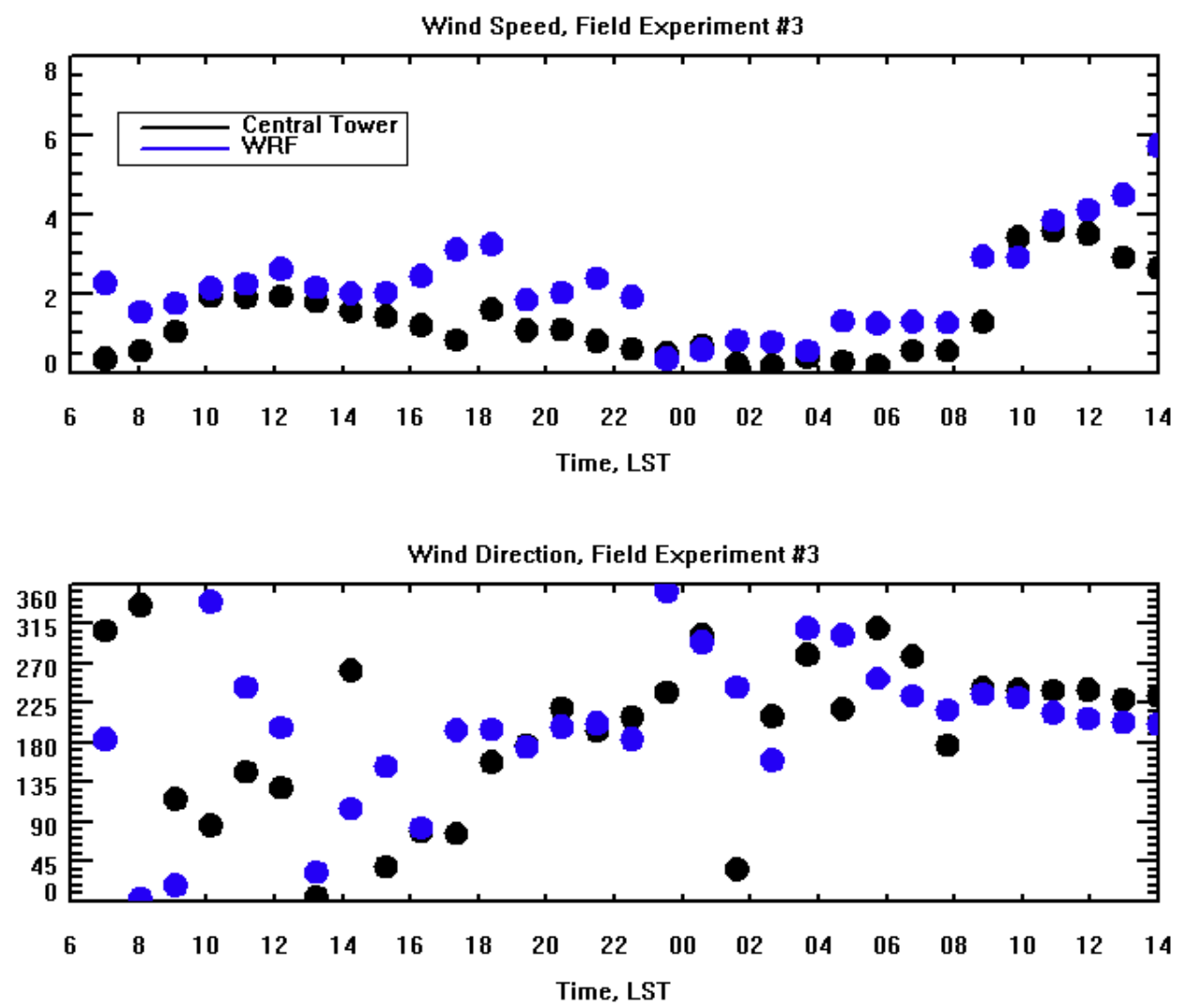

Figure C.6: Time series of $10 \mathrm{~m}$ winds from the baseline tower (black) and WRF $10 \mathrm{~m}$ winds (blue) for the times between 06z May 19, 2014 - 14z May 20, 2014 (field campaign \#3. 